\title{
Patients treated with the long gamma nail : a study of the use of the long gamma nail, the first 5 years after introduction in the Netherlands
}

Citation for published version (APA):

van Doorn, R. (2001). Patients treated with the long gamma nail : a study of the use of the long gamma nail, the first 5 years after introduction in the Netherlands. [Doctoral Thesis, Maastricht University]. Universiteit Maastricht. https://doi.org/10.26481/dis.20011019rd

Document status and date:

Published: 01/01/2001

DOI:

10.26481/dis.20011019rd

Document Version:

Publisher's PDF, also known as Version of record

Please check the document version of this publication:

- A submitted manuscript is the version of the article upon submission and before peer-review. There can be important differences between the submitted version and the official published version of record.

People interested in the research are advised to contact the author for the final version of the publication, or visit the DOI to the publisher's website.

- The final author version and the galley proof are versions of the publication after peer review.

- The final published version features the final layout of the paper including the volume, issue and page numbers.

Link to publication

\footnotetext{
General rights rights.

- You may freely distribute the URL identifying the publication in the public portal. please follow below link for the End User Agreement:

www.umlib.nl/taverne-license

Take down policy

If you believe that this document breaches copyright please contact us at:

repository@maastrichtuniversity.nl

providing details and we will investigate your claim.
}

Copyright and moral rights for the publications made accessible in the public portal are retained by the authors and/or other copyright owners and it is a condition of accessing publications that users recognise and abide by the legal requirements associated with these

- Users may download and print one copy of any publication from the public portal for the purpose of private study or research.

- You may not further distribute the material or use it for any profit-making activity or commercial gain

If the publication is distributed under the terms of Article 25fa of the Dutch Copyright Act, indicated by the "Taverne" license above, 


\section{Patients treated with}

\section{the long Gamma nail}

A study of the use of the long Gamma nail, the first 5 years after introduction in the Netherlands

PROEFSCHRIFT

ter verkrijging van de graad van doctor aan de Universiteit van Maastricht, op gezag van de Rector Magnificus. Prof. Dr. AC Nieuwenhuijzen Kruseman volgens het besluit van het college der decanen. in het openbaar te verdedigen op vrijdag 19 oktober 2001 om 14.00 uur 


\section{Promotor}

Prof. Dr JWJL Stapert

\section{Beoordelingscommissie}

Prof. Dr RGT Geesink (voorzitter)

Prof. Dr PLO Broos (Katholieke Universiteit Leuven)

Prof. Dr JMA van Engelshoven

Prof. Dr J Troost

Prof. Dr AB van Vugt (Erasmus Universiteit Rotterdam) 


\section{Paranymfen}

Dr RRW] van der Hulst

Drs JS Burgers

The patients were gathered from the following surgeons and orthopedic surgeons:

PAM Vierhout. ADP van Walsum. Medical Spectrum Enschede

HJThM Haarman, P Patka, FC Bakker, Free University Hospital Amsterdam

$A B$ van Vugt, University Hospital Leiden

AJH Kerver. St Fransiscus Hospital. Rotterdam

B] Dwars, Slotervaart Hospital, Amsterdam

PB Dunki Jacobs. JH Pot, Medical Center Alkmaar

C van der Werken, LS de Vries, ER Hammacher. University Hospital Utrecht PVM Pahlplatz, Leyenburg Hospital, The Hague

JM Ultee. St Lucas Hospital, Amsterdam

JWJL Stapert, FAJM van den Wildenberg. University Hospital Maastricht JSK Luitse. Onze Lieve Vrouwe Gasthuis. Amsterdam

GJ Clevers. Diakonessenhuis, Utrecht

DJ Swank, Groenehart Hospital, Gouda:

R Leemans, Medical Center Leeuwarden North

VA de Ridder. Westeinde Hospital, The Hague

HW Bolhuis, Apeldoorn Hospital

PCM de Jong. Spaarne Hospital. Heemstede

FG] Laudy, St Maartens Gasthuis. Venlo

G] Heijmans, Midden-Twente Hospital. Hengelo

$\mathrm{H}$ den Hollander. Medical Center Leeuwarden South

JA Charbon. ThJ van Straaten. St Joseph Hospital, Veldhoven

AGA Spelde, Canisius Hospital, Nijmegen

KJ Oosterhuis. Lorentz Hospital Zeist

A Verburg. Maasland Hospital, Sittard. 
This work was done from the University Hospital Maastricht, the Catharina Hospital of Eindhoven, and finished at the TweeSteden hospital of Tilburg. The Netherlands.

The publication of this thesis was supported by:

Stryker Howmedica Osteonics, Eindhoven

Nederlandse Vereniging voor Traumatologie

Two Beats. Heerhugowaard

Mathys Medical, Zeist

Stöpler. Utrecht

Grafische vormgeving en lay-out omslag en binnenwerk:

B. Schaart, OPZET, Santpoort-Zuid

Drukwerk:

Castellum. Alphen a/d Rijn

CIP-GEGEVENS KONINKLIJKE BIBLIOTHEEK, DEN HAAG

Doorn, Ron van

Patients treated with the long Gamma nail. A study of the use of the long Gamma nail, the first 5 years after introduction in the Netherlands. Ron van Doorn. Thesis University of Maastricht. faculty of Medicine. With references, with summary in Dutch.

ISBN 90-9015200-8

Subject headings: femur, fracture, Gamma nail, intramedullary osteosynthesis, metastasis, osteotomy, revision surgery.

\section{O R. van Doorn, Dongen, The Netherlands}

All rights are reserved. No part of this publication may be reproduced or transmitted in any form or by any means, electronic or mechanic. including photocopy, recording or any information storage and retrieval system, without the prior permission in writing from the author. 


\section{Contents}

Chapter I

Introduction

page 7

Chapter 2

Anatomy in daily practice

page II

Vascularisation

Innervation

Bone

Musculature

Chapter 3

Historical overview of femoral fracture treatment page 21

Fracture site

Treatment modalities

Chapter 4

The long Gamma nail

page 45

Development

Technical description

Insertion technique

Chapter 5

The use and the opinion in The Netherlands

page 61

Chapter 6

Primary fractures

page 69

Chapter 7

Pathological fractures

page 81

Chapter 8

To solve problems after failure

of a standard Gamma nail

page 95

Chapter 9

Lengthening and derotational osteotomy

page 105

Chapter 10

Summary

page 115

Chapter II

Samenvatting

page 121

Enquiry form

page 127

Dankwoord

page 131

Curriculum vitea

page 134 

Introduction 


\section{Figure 1.1}

The different indications for treatment with a long Camma nail. $A$ multitrauma young patient with a shattered femur. An old female with a low energy fracture, due to osteoporosis. $A$ fractured metastasis of a bre. ast carcinoma. $A$ fractured femur after insertion of a standard Gamma nail.

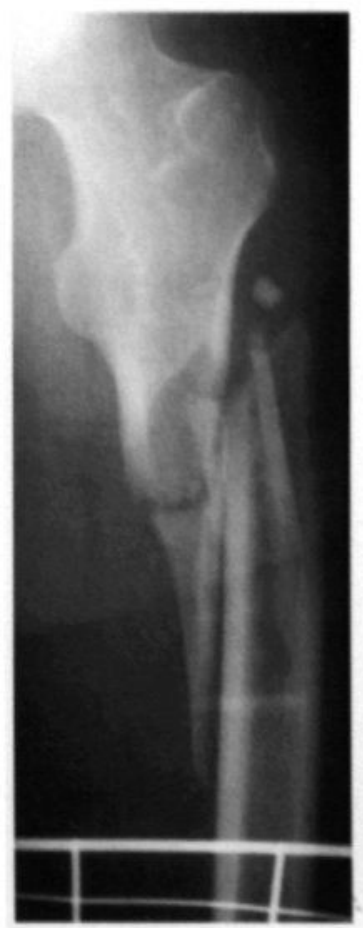

The long Gamma nail was developed for the treatment of fractures of the proximal femur. It offers excellent biomechanical properties for patients with acute proximal femoral fractures and impending or pathological fractures. It can also solve problems after failure of previous attempts at osteosynthesis \{figure 1.1 \}. Because of the stability provided by the implant early mobilisation with full weight bearing is possible in nearly all patients.

The goal of treatment of an injury is to achieve an optimal quality of life in the short and long term, with full recovery of mobility. This goal is best reached by a strong implant that is inserted in a simple procedure, allows full weight bearing. and has few complications. The surgeon has to know about biomechanical problems, and how to use the implant for different indications. He should develop technical skills to enable him to do a perfect operation that leads to an optimal result for the patient. He should be a capable doctor, and able to manage the various medical problems in this diverse and difficult group of patients.

The long Gamma nail is an intramedullary nail, with a diameter of $11 \mathrm{~mm}$. It is bent and curved anteriorly and lateromedially \{figure 1.2\}. The proximal end is anchored by a lag screw into the femoral neck and head, and a set screw is inserted in the proximal part of the nail to prevent rotation and extrusion of the lag screw. The distal end can be anchored with two locking bolts. The lag screw shows an anteversion of $10^{\circ}$ in relation to the distal locking bolt. The implant is introduced through short incisions after closed reduction. Theoretically, the long Gamma nail can stabilise all femoral fractures from those of the femoral neck to
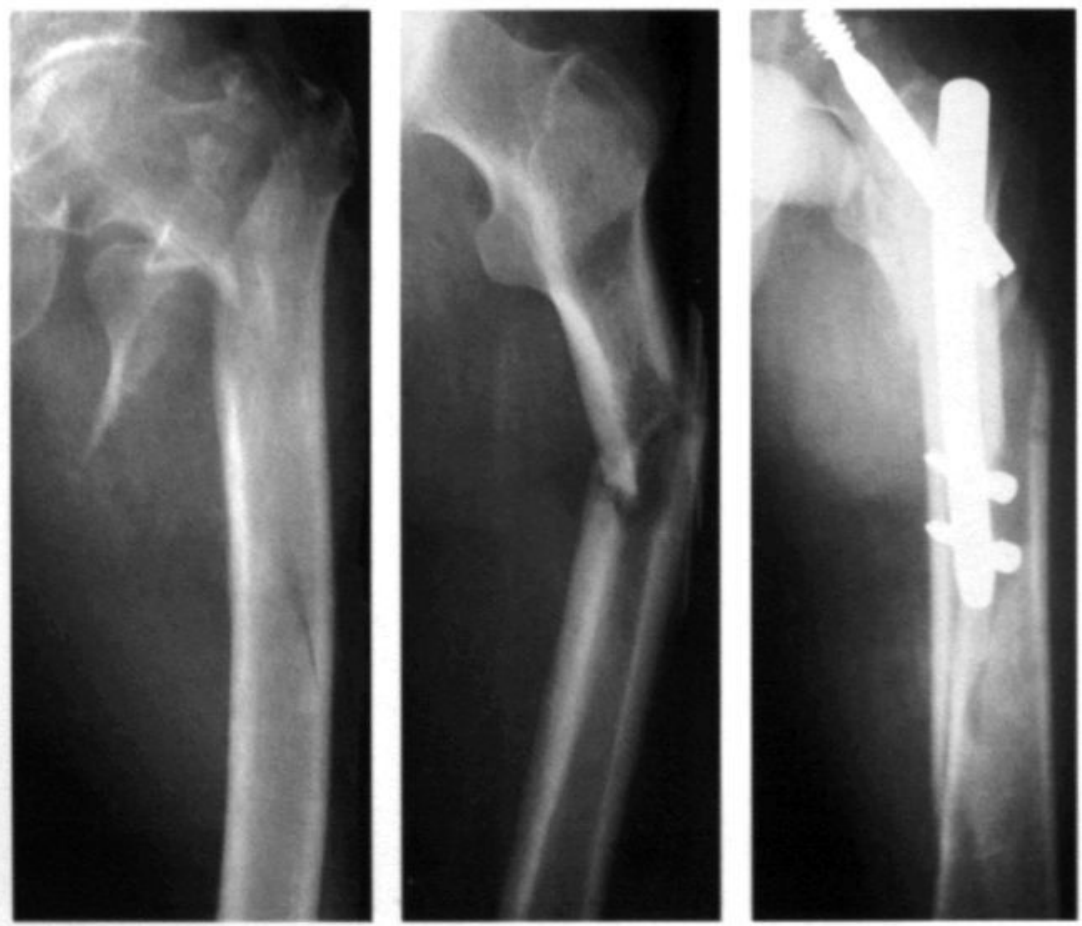
those in the supracondylar region. Fractures of the femoral neck, and supracondylar region, as well as simple trochanteric and femoral shaft fractures are, however, better treated with other devices. The long Gamma nail can be used in adults of all ages if the femoral canal can be reamed to 13 $\mathrm{mm}$. In children and adolescents with open epiphyses, implants that do not penetrate the epiphysis must be used.

We have used the nail in multiply injured patients, old people with low energy fractures, those with pathological fractures, and those in whom previous treatment for a fracture in the proximal femur has failed \{figure 1.I\}.

Multiply injured patients are usually young people who have had motor vehicle accidents or falls from heights. They must be managed according to the Advanced Trauma Life Support (ATLS) principles with damage-control surgery to safe their lives. Fractures of long bones must be stabilised after resuscitation and stabilisation of vital functions and coagulation. The pelvis and femur particularly must be stabilised to stop bleeding and to prevent late complications and multiple organ failure. The main goal of the treatment of femoral fractures is to bring the femoral head into correct alignment with the femoral condyles, with particular attention to rotation and length. The operation should be simple with minimal loss of blood. Early exercise and full weight bearing are necessary to allow full function to be regained as soon as possible. Even in a multiply injured patient who is being ventilated passive movements promotes early function.

Old people often sustain low energy injuries that result in less comminuted fractures with less dislocation. Sometimes long spikes make the reduction difficult. Surgical fixation must allow full weight bearing, because old people cannot mobilise properly with partial or no weight bearing. The quality of the bone apposition in these patients is less critical but internal rotation must be prevented. Other misalignments are relatively easily accepted, so open reduction must be kept to a minimum. These patients often have other diseases that have to be dealt with. Early mobilisation is important to optimise their general conditions and prevents complications such as decubitus ulcers, urinary tract infection, and pulmonary infection.

Patients with pathological fractures must be able to bear weight immediately because their life expectation is limited, and its quality is dependent on preservation of their mobility and relief of pain. Bone consolidation is often very slow or not achieved at all, which means that the implant must be stable to the end of their lives. The whole femur can contain metastases, even when they are not visible on the radiograph. The entire femur, from the head to the condyles, must be stabilised to prevent future fractures from progression of metastatic disease.

Patients whose previous implant has failed are a technical challenge. Repeated anchorage in the femoral head can cause problems and there is a greater chance of infection.

Figure 1.2

The long

Camma nail

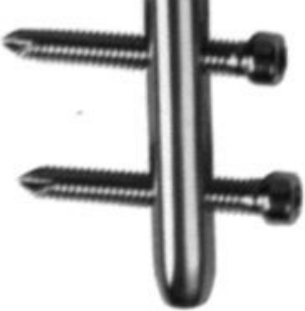


Knowledge of the biomechanical implications and the functional anatomy is necessary for optimal insertion of a long Gamma nail (chapter 2). We give a historical perspective of the treatment of femoral fractures to explain the development and the position of the nail in relation to other treatments (chapter 3). We describe the development of the Gamma nail, give a technical description, and describe the technique of insertion, with tricks and pitfalls, in chapter 4 . The opinion of the Dutch (orthopaedic) trauma surgeons about, and the use of the long Gamma nail in their trauma departments are described in chapter 5 . The results of nearly 500 patients treated with a long Gamma nail, by many different surgeons in 24 hospitals throughout the Netherlands, are given in the remaining chapters. We give details of patients with primary fractures in chapter 6 , of pathological fractures in chapter 7. and of failures of previous implants in chapters 8 and 9. Patients with special problems are discussed in the various chapters as well. At this stage we want to thank all participating hospitals and (orthopaedic) surgeons who included patients, for their co-operation. In range of patients included: PAM Vierhout, ADP van Walsum. Medical Spectrum Twente; HJThM Haarman. P Patka, FC Bakker, Free University Hospital Amsterdam: AB van Vugt. University Hospital Leiden: AJH Kerver, St Fransiscus Hospital, Rotterdam: BJ Dwars. Slotervaart Hospital. Amsterdam: PB Dunki Jacobs. JH Pot. Medical Centre Alkmaar: C van der Werken. LS de Vries, ER Hammacher. University Hospital Utrecht: PVM Pahlplatz, Leyenburg Hospital. The Hague; JM Ultee, St Lucas Hospital. Amsterdam: JWJL Stapert. FAJM van den Wildenberg. University Hospital Maastricht: JSK Luitse, Onze Lieve Vrouwe Gasthuis, Amsterdam; GJ Clevers, Diakonessenhuis, Utrecht: DJ Swank, Groenehart Hospital, Gouda; R Leemans. Medical Center Leeuwarden North; VA de Ridder. Westeinde Hospital. The Hague: HW Bolhuis. Apeldoorn Hospital; PCM de Jong. Spaarne Hospital, Heemstede: FGJ Laudy. St Maartens Gasthuis, Venlo: GJ Heijmans, Midden-Twente Hospital, Hengelo: $\mathrm{H}$ den Hollander. Medical Center Leeuwarden South: JA Charbon. ThJ van Straaten, St Joseph Hospital, Veldhoven: AGA Spelde, Canisius Hospital, Nijmegen: KJ Oosterhuis, Lorentz Hospital Zeist: A Verburg. Maasland Hospital, Sittard.

We performed this study to see if the goals for the various groups of patients can be reached with the long Gamma nail. This thesis gives an overview at this time. whereas treatment of these patients is continuing to develop. In the future new ideas and implants will come and may lead to even better results. 
Anatomy in daily practice 
In this chapter the major anatomical structures and some relevant details are described. For detailed anatomy, textbooks and atlasses must be used. The emphasis in this chapter is on the practical consequences, which are discussed at the end of each section.

\section{Blood vessels}

The deep femoral artery and a few arteries from the pelvis serve the thigh. The superficial femoral artery serves mainly the lower leg. The femoral vein and the long saphenous vein drain the entire limb.

The common femoral artery \{figure 2.1 \} enters the thigh behind the midpoint of the inguinal ligament. It lies between the femoral vein medially and the femoral nerve laterally. The artery gives rise to the deep and superficial femoral arteries. The deep femoral artery runs between the long and short adductor muscles, and soon splits into, usually five, branches. The superficial femoral artery runs in the adductor canal of Hunter, formed by the medial vastus of the quadriceps muscle. the adductor muscles, and the sartorius muscle. The superficial femoral artery

Figure 2.1

Anatomy of the ventral aspect of the right thigh enters the poplitial fossa through an opening in the insertion of the great adductor muscle. Immediately above the knee the descending genicular artery arises mainly to feed the knee, and some branches supply the femur retrogradely.

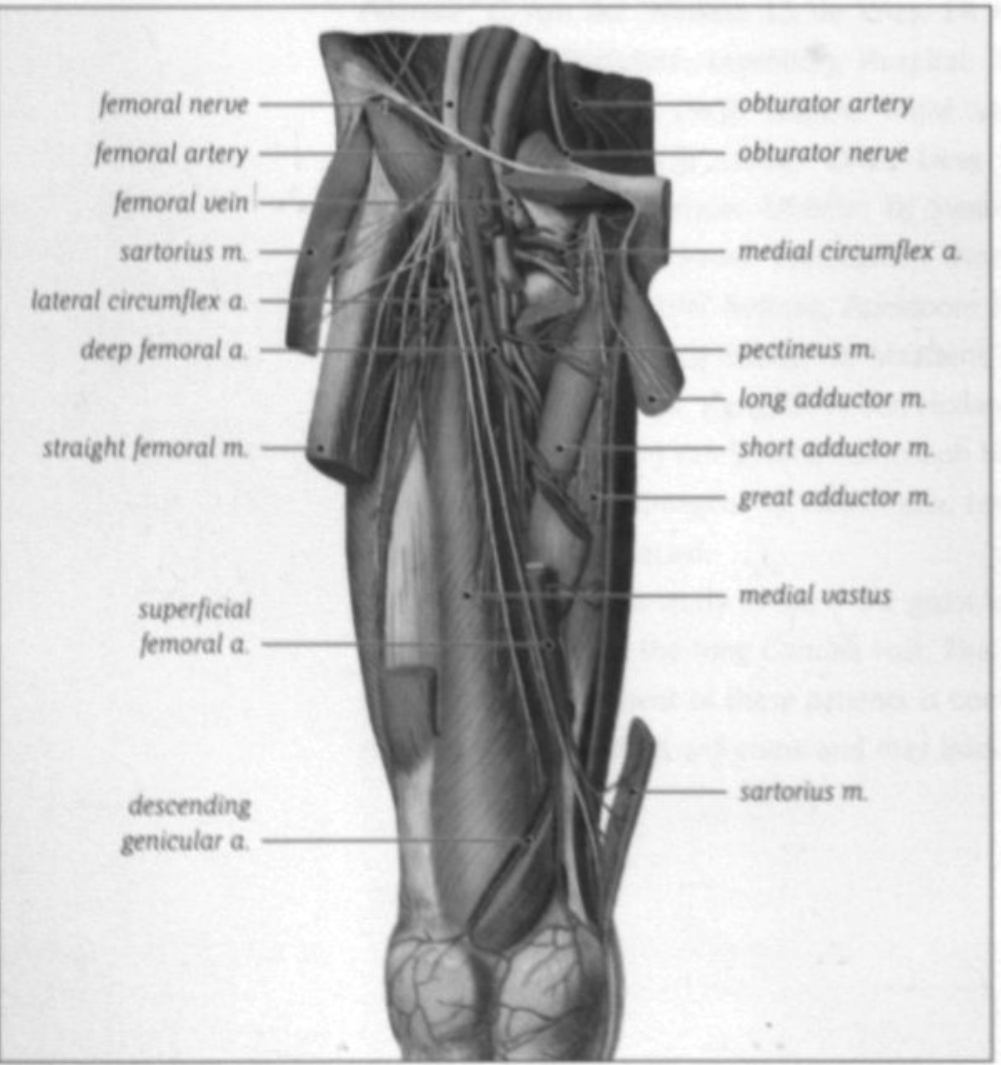

These branches anastomose with the descending branches of the deep femoral artery and obturator artery. A third supply to the proximal part of the femur is through smaller arteries directly from the pelvis (haemorrhoidal, inferior mesenteric. lumbar arteries). These branches leave the pelvis through the obturator foramen. and form rich collaterals if the iliac artery is obstructed.

The obturator artery and the deep femoral artery supply the femoral head and neck \{figure 2.2\}.' A branch of the obturator artery. the foveal artery, enters the femoral head through the capitis femoris ligament. It supplies $20 \%$ to $33 \%$ of the epiphyseal part of 
the head, particularly in younger people. The deep femoral artery gives rise to the medial and lateral femoral circumflex arteries, which form the extracapsular arterial ring. The medial femoral circumflex artery supplies the ring from behind and the lateral femoral circumflex from in front. Ascending cervical arteries run from this ring to the femoral head. Posterosuperiorly they run through the capsule to the

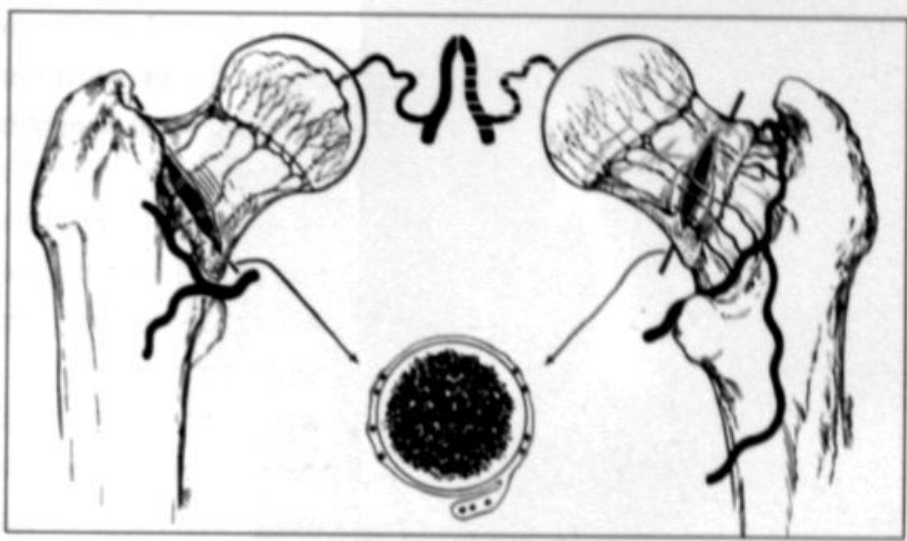
cartilage of the head. Anteriorly they enter the femoral neck at the trochanteric junction. The posterosuperior branches supply $66 \%-80 \%$ of the epiphyseal part. and $33 \%$ of the metaphyseal part of the head. The anterior branches supply two thirds of the metaphyseal part of the head. The ascending cervical arteries form the subsynovial intracapsular ring. which is often incomplete.

The supply to the femoral shaft is similar to that of other long bones \{figure 2.3$\}{ }^{2}$ Nutritional arteries enter the dorsal aspect of the femur by the foramen nutricium, which run a few centimetres from distal to proximal through the cortex. The epiphyseal-metaphyseal blood supply is formed by multiple arteries entering the endosteum of the metaphysis from the periphery. These two systems form the endosteal supply to the inner two thirds of the cortex. Periosteal vessels develop from surrounding tissues, mainly muscle, run in the length of the femur, and pierce the cortex perpendicularly. They serve mainly the outer third of the cortex. The endosteal and periosteal networks anastomose. with a physiological centrifugal blood flow.

The bone marrow contains a dense network of venous sinusoids. These drain through the metaphysis into the deep femoral vein.

\section{Practical consequences}

Vascular trauma causes haemorrhage and ischaemia in the acute phase. Lesions of the obturator, and the femoral circumflex artery may be the cause of femoral head necrosis and non-union in the long run.

Lesions are most common in the superficial femoral artery. because of its superficial position. If the artery is transsected the smooth muscle contracts and stops the bleeding. particularly in a hypotensive patient. When the blood pressure rises after resuscitation secondary bleeding can

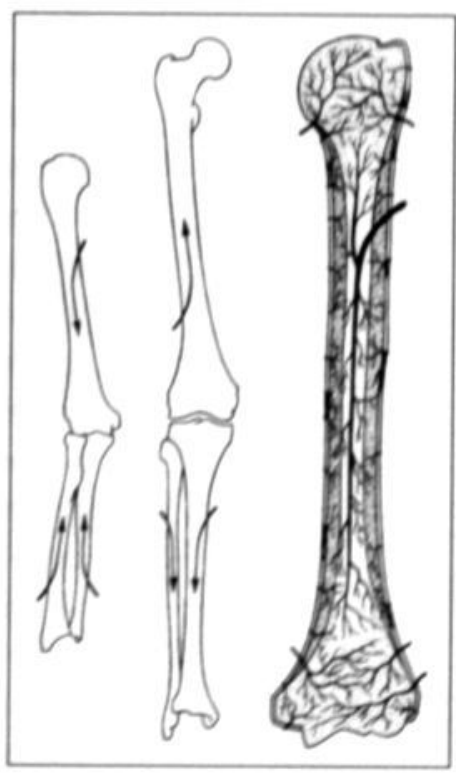
occur. Arteries with longitional lesions do not contract. and massive blood loss ensues. In blunt trauma, the artery can rupture without causing haemorrhage. An expanding haematoma with severe pain on active adduction point to the diagnosis. Blunt trauma can also cause an intimal rupture, resulting in an ischaemic
Figure 2.2

Blood supply to the femoral makes anastomoses with the medial and lateral circumflex arteries through the intra and extra capsular ring.

Figure 2.3

The blood supply to long bones. The femur is similar to the humerus. only the direction of the nutrition artery is different. head. The obturator artery 
limb \{figure 2.4\}. The severity of blood loss or ischaemia establishes the priority of operation. The bone is usually stabilised first to prevent disruption of a fresh vascular reconstruction or anastomosis "s.

latrogenic lesions of the deep femoral artery occur by dissection or incorrect placement of a retractor around the proximal femur. ${ }^{\circ 7}$ Exploration from the anteromedial side is necessary. because the arteries are difficult to approach from a lateral incision. These branches can be ligated without problems because there is a good collateral blood supply. One of our patients who had an osteotomy (chapter 9) had this complication.

Both traumatic and iatrogenic lesions of the long saphenous vein occur. Condylar and proximal tibial Kirschner $(K)$ wires for temporary traction can perforate the vein. The smooth muscle does not contract resulting in bleeding, which is easily stopped by

Figure 2.4

An intimal rupture due to a midshaft femoral fracture. a simple ligature or pressure bandage. Because of the good collateral circulation it is not necessary to repair the vein.

Beside the major vascular lesions, a femoral fracture in itself causes substantial blood loss (a closed fracture about I.S L, an open fracture up to $5 \mathrm{~L}$ ). Particularly in multiply-injured patients this loss of blood can become life-threatening. ${ }^{8}$

Ischaemia causes necrosis of the femoral head and non-union of fractures of the femoral neck. The capsular vessels form the main supply to the femoral head. They are torn in femoral neck fractures, or can be damaged by dissection during intramedullary nailing, particularly by straight nails, which are inserted in the piriform fossa. whereas curved nails are inserted from the tip of the trochanter.

The vascular supply to the shaft is damaged by the fracture and by the fixation of the fracture. The anastomoses between the endosteal and periosteal blood vessels normally allow centrifugal flow. The endosteal supply is interrupted by a fracture, whereas the periosteal supply is mostly intact because the perforating vessels arise from the surrounding muscles. The flow in the anastomoses reverses. and revascularises the whole cortex within 3-6 weeks. Intramedullary nailing. with or without reaming. damages the endosteal blood supply, but again the flow in the anastomoses reverses, and leads to revascularisation. Open reduction and fixation damage the periosteal supply, which can be a disaster because it can mean complete devascularisation of the bone.

The venous sinusoids in the bone marrow are disrupted by reaming. The high pressure during reaming reverses the flow in the veins and allows fat particles and bone marrow to enter the circulation. This mechanical explanation of the fat embolism syndrome is conjectural. The emboli are shown by echocardiography in all patients, but usually do not lead to clinically relevant fat embolism." 


\section{Nerves}

The sciatic nerve enters the gluteal compartment through the infrapiriformis foramen \{figure 2.5\}. It runs dorsal to the short rotator muscle into the space between the major adductor and the biceps muscles. The nerve divides into the common peroneal and the tibial nerves, usually at the level of the distal third of the femur, sometimes this bifurcation is inside the pelvis. The sciatic nerve innervates the muscles of the dorsal thigh, the lower leg. and the foot. Its sensory fibres arise from a quarter of the lower leg and foot. The femoral nerve runs with the superficial femoral artery in the adductor canal of Hunter. It innervates the muscle and skin of the front of the thigh. The sensory end branch, the saphenous nerve, innervates the skin of the medial side of the lower leg and foot. The obturator nerve enters the limb through the obturator foramen and innervates the adductors. It has no sensory branches.

\section{Practical consequences}

The sciatic nerve is prone to iatrogenic injury by open reductions, by osteotomies of the trochanteric area, and by prosthetic hip replacements. The area just beneath the piriform muscle is particularly at risk. If, during operation, the nerve is seen to be thinner than expected, the bifurcation might be in the pelvis. In that case, the common peroneal nerve passes through the piriform muscle and has a more dorsal position in the thigh. Dissection has therefore to be done with continuous contact with the femur. Homann retractors must be placed very carefully. Penetrating injuries may damage all nerves and are often combined with vascular lesions.

Neurapraxia can be caused by too extensive use of the traction table. Considerable force can be applied to the structures in the limb during reduction of the fracture. The sciatic and femoral nerves are both at risk. Sciatic neurapraxia is first observed in the peroneal branch. The lesion has to be recorded, but treatment remains conservative.

An under-reported problem is pudendal neurapraxia. It is caused by excessive pressure of a small counter traction device, mainly with an adducted limb. Loss of sensation is noticed in the perineum and dorsal side of the scrotum or labia. Even male impotence can result. These complaints are often not mentioned if not directly asked about. They disappear in $3-6$ months. 


\section{Bon e}

The femur consists of two articulating parts, joined by the shaft \{figure 2.6\}. The proximal articulator is the femoral head, neck, and trochanter. Distally the medial and lateral condyles are the articulators. The femoral neck points upwards and inwards from the shaft, this is called the CCD angle of about $125^{\circ}$. If the

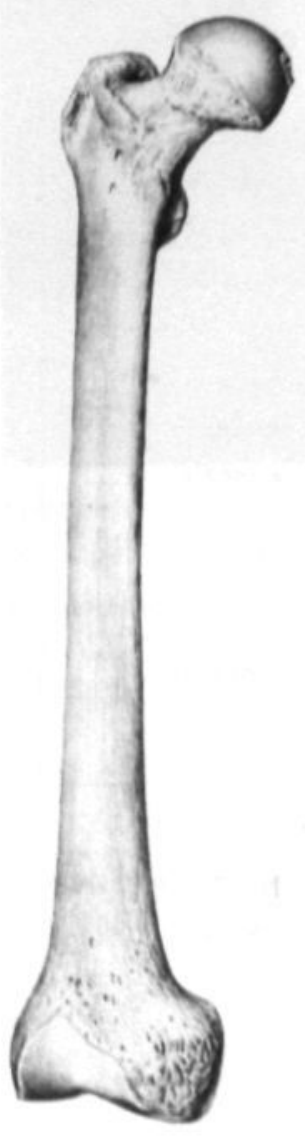

Figure 2.6

The right femur seen from ventral. medial and dorsal. In the right and left picture the $\mathrm{CCD}$ angle between the femoral head. neck and shaft can be seen. In the middle picture the antecurvation of the femoral shaft. and the anteversion of the femoral neck in relation to the condyles can be observed.
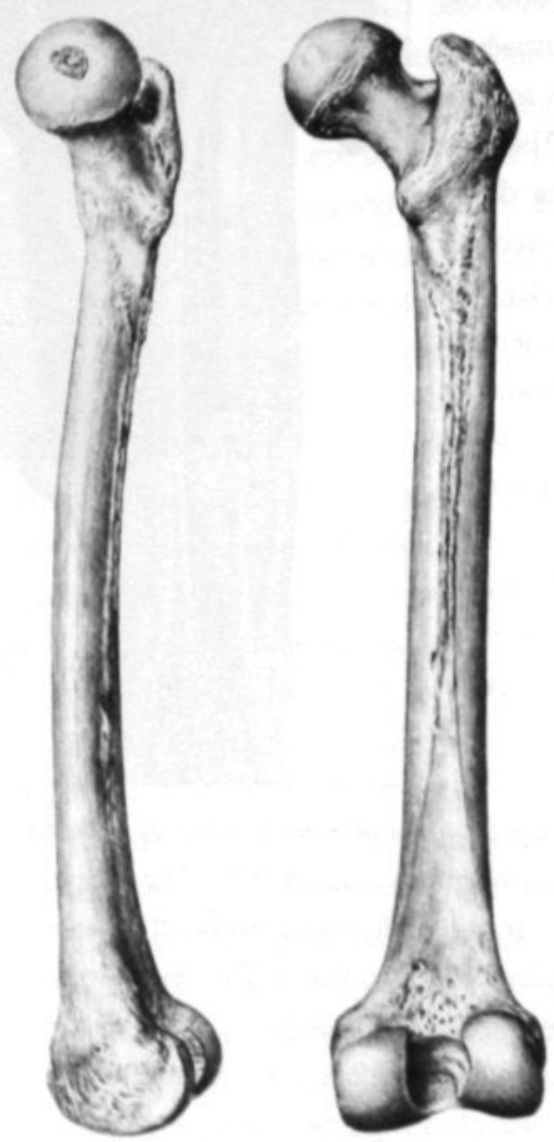

femur is laid on a flat surface, the femoral neck is pointing forwards at an angle of $11^{\circ}$ to $15^{\circ}$, called the anteversion angle. The greater trochanter is lateral and ventral in relation to the shaft. The medial side is almost hollow, the trochanteric fossa. This runs by the piriform fossa towards the femoral neck. The lesser trochanter is situated at the posteromedial part of the femur. Dorsally the trochanters are connected by the prominent intertrochanteric crista, ventrally by the intertrochanteric linea. All those structures are important for muscle insertion.

The shaft has an anterior bow. with a radius of $110 \mathrm{~cm} .{ }^{10}$ In $\mathrm{sec}$ tion. the proximal shaft is nearly round, the distal shaft triangular. The femoral canal has a sandglass appearance. The smallest part, the isthmus, is situated in the proximal third of the shaft. The line of force when standing is from ventral cortex proximally to dorsal cortex distally. ${ }^{2}$ In the sagital plane the line runs from the centre of the femoral head through the lateral condyl to the second toe \{figure 2.7\}. This indicates that compression force is on the medial cortex, as a result of the lever arm forces even precisely at the site of the lesser trochanter. Laterally a tension force acts maximally at the trochanter tip. The tension force results in the direction and thickness of the bone trabecula. It controls the bone growth and breakdown, which is a continuous process during life. During adolescence the isthmus measures about $6 \mathrm{~mm}$, in the elderly patients this can reach $14 \mathrm{~mm}$. The anterior curve is exaggerated during life, and becomes extreme in Paget disease. 


\section{Practical consequences}

The anatomy of the bone is extremely important for the correct insertion of the long Gamma nail and will be discussed in chapter 4 .

\section{Muscles}

The muscles in the thigh comprise hip muscles and femoral muscles. A third group is biarticular, which are important for compound movements \{figure 2.8 \}. The hip muscles are divided into three groups: ventral, deep dorsal and superficial dorsal.

The ventral group contains the psoas muscle and the iliacus muscle. These originate from the iliac fossa of the pelvis and the lumbar spine, pass over the hip joint behind the inguinal ligament, and insert into the lesser trochanter. They adduct and dorsiflex the femur.

The deep dorsal group, the short external rotator muscle. consist of six small muscles: the piriform, the two gemelli, the quadratus, and the two obturator muscles. They run from inside the pelvis to the back of the femur. The muscles abduct, and rotate the thigh externally.

The superficial dorsal group is formed by the gluteal muscles, and the tensor muscle of the fascia lata. The greater gluteal muscle inserts on a dorsal rim under the greater trochanter, the gluteal tuberosity, and on the fascia lata. It dorsiflexes and rotates the femur externally. The lesser and middle gluteal muscles insert on the greater trochanter and abduct the limb. Part of these muscles rotates externally, another part rotate internally. The tensor of fascia lata arises from near the anterior superior iliac spine. The insertion is on the greater trochanter, and into the fascia lata that inserts at the lateral tibial condyl.

The femoral muscles lie in a fascial sheet, the fascia lata. At the lateral side, this fascia is strengthened to form the ileotibial tract. The tensor and the greater gluteal muscle insert on this structure. From the fascia lata septa runs towards the linea aspera femoris, which forms three compartments within the thigh.

The extensor compartment contains the sartorius, the quadriceps, and the articular muscle of the knee. Their main function is to extend the knee. The sartorius muscle and the medial great muscle of the quadriceps are biarticular and also flex the hip. The sartorius also abducts the femur.

The flexor compartment (the hamstring) contains the semitendinous, the semimembranous and the biceps muscles. Apart from the short part of the biceps. they are biarticular. They extend the hip, and flex the knee. Part of them rotate externally. part internally.

The adductor compartment contains the pectineus, the gracilis, and the three adductor muscles. They adduct the limb and flex the hip and the knee, because they are biarticular. They also take part in external and internal rotation.

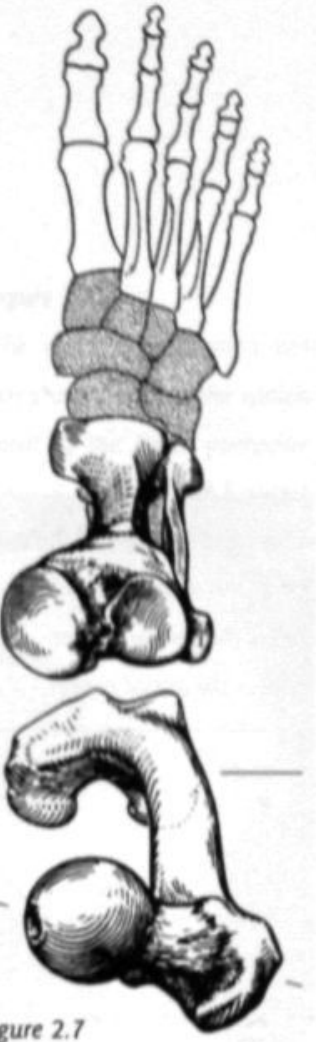

figure 2.7

The line of force when stan: ding. The force runs from the femoral head to the medial condyle and second toe.

The anteversion of the femoral head in regars to the condyles is clearly seen 
Figure $\mathbf{2 . 8}$

Origo and insertion of the mus. cle of the right hip and thigh Left is the ventral aspect. right is the dorsal aspect.

\section{Practical consequences}

The muscle attachments cause typical deformity after each type of fracture. The gluteal muscles act on the greater trochanter and cause abduction. The nearer the fracture line is to the insertion the more prominent the abduction of the proximal fragment will be. Adductor muscles insert on to the linea aspera femoris over a long distance. They adduct the distal fragment and can cause shortening of the limb. particularly in high shaft fractures. In fractures of the lower femoral shaft the adduction and abduction forces compensate for each other. The attachment of the short rotator muscles on the dorsal aspect of the greater trochanter causes strong external rotation and abduction of the proximal fragment. The iliopsoas muscle inserts on the lesser trochanter and causes flexion and external rotation. This is the most difficult force to overcome and therefore the crucial point for proper reduction. It therefore seems logical to distinguish fractures based on the involve-

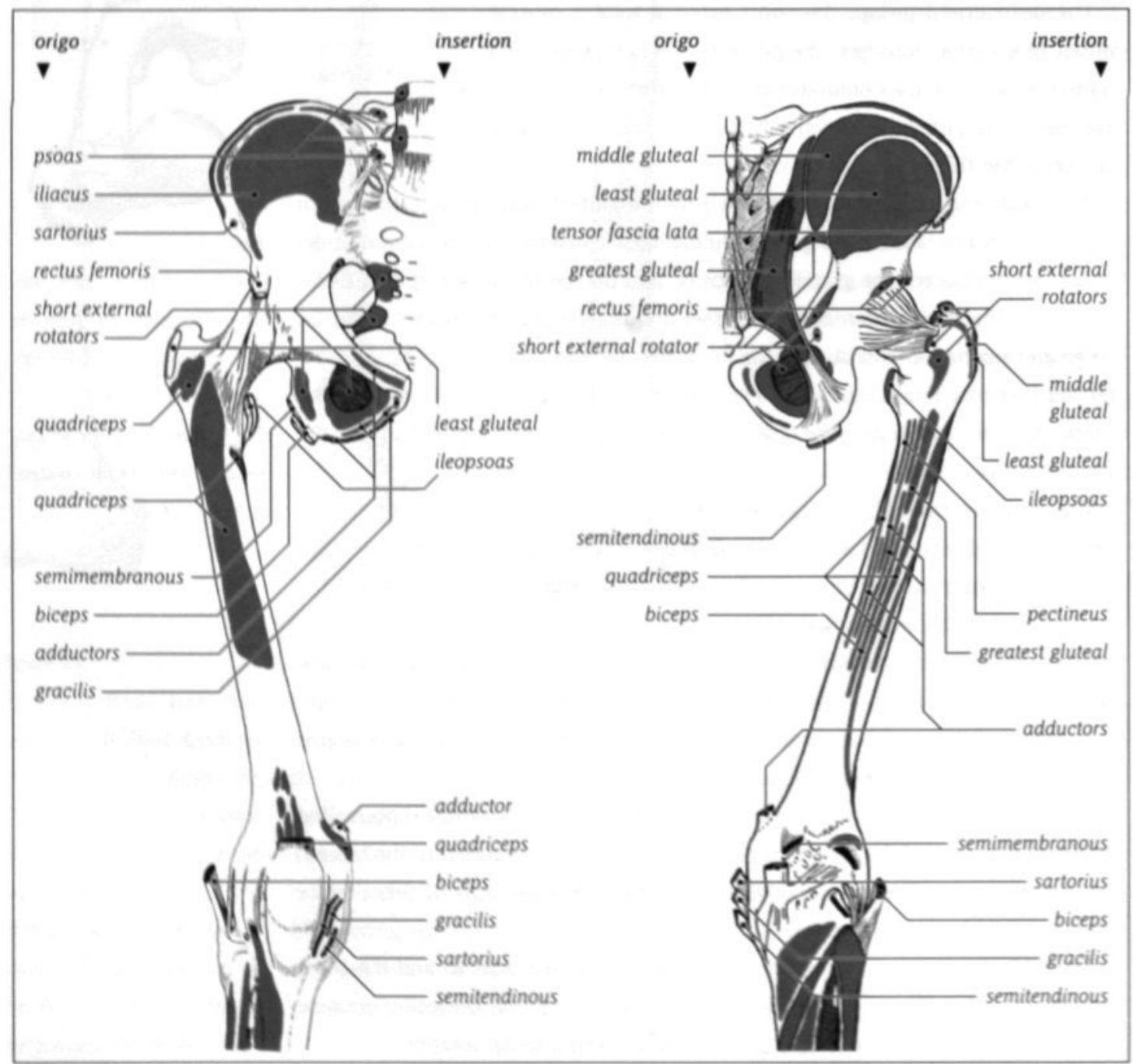


ment of the lesser trochanter \{figure 2.9\}. In a type I fracture, the lesser trochanter is separated from both proximal and distal fragments. The lesser trochanter can be part of a wedge fracture, imbedded in a gross comminution zone, or the middle part in a two-stage fracture. Forces resulting from muscle attachments are relatively easy to overcome by traction \{figure 2.9 a.b \}. In a type II fracture, the lesser trochanter remains part of the head fragment. which will be flexed and externally rotated \{figure $2.9 \mathrm{c}$ \}. Reduction is achieved by traction and external rotation of the limb. If closed reduction is not successful the proximal part can be

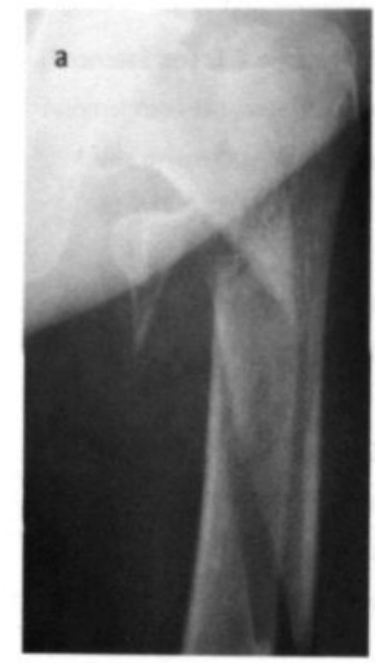

manipulated with a partly inserted nail or Steinmann pin into the femoral neck. In type III fractures, the lesser trochanter is attached to the distal fragment. This is the least

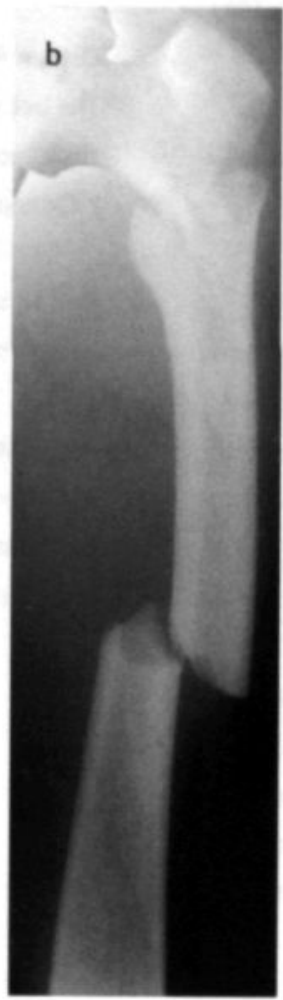
common type. The distal fragment is externally rotated. shortened, and falls away under the influence of gravity \{figure $2.9 \mathrm{~d}$ \}. Reduction is achieved by traction and internal rotation, but this is often hard to achieve. In our series of primary fractures described in chapter 6 open reduction was required twice as often in the 24 type III fractures (21\%), as in the 233 type I (9\%) and 42 type II fractures (12\%).
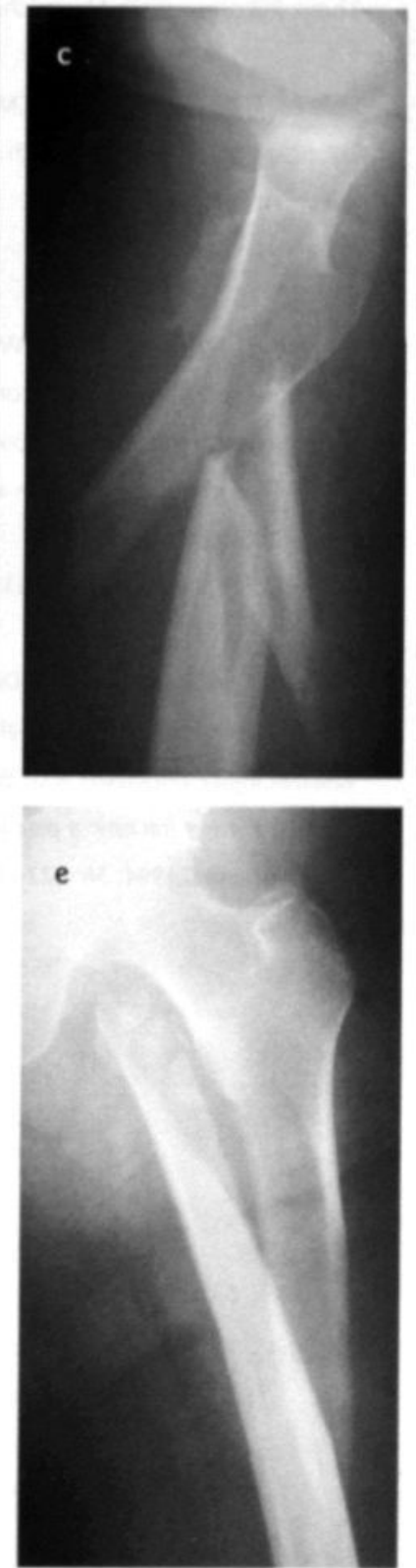

Figure 2.9.

The different dislocation pat. terns according to the attach. ment of the lesser trochanter

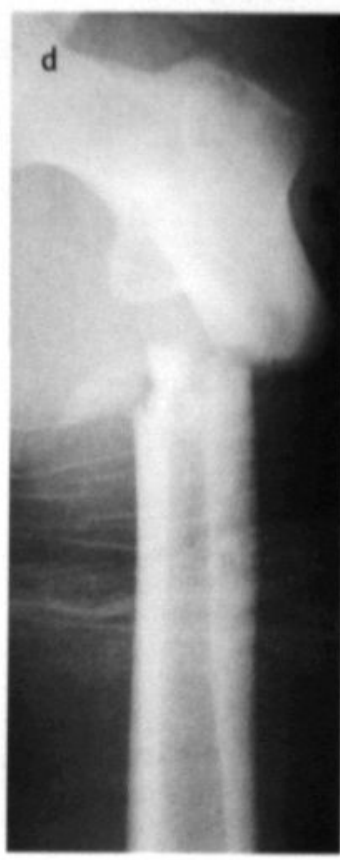

Type I: lesser trochanter separa. ted from the proximal and dis. tal fragment. Only the special type in $c$ gives problems with reposition. Type II: the lesser trochanter remains to the proxi. mal fragment, reposition is achieved by external rotation. Type III: the lesser trochanter attached to the distal fragment. Reposition is performed by internal rotation, but is mostly difficult achieve, because the distal fragment will fall away due to gravity. 


\section{References}

1. Vugt $A B$ van. The unsolved fracture. a prospective study of 224 consecutive cases with an intracapsular hip fracture. Thesis Catholic University of Nijmegen, I99I.

2. Stapert JWJL. Intramedullaire osteosynthese van het femur.

Thesis Rijksuniversiteit Maastricht, 1983.

3. Starr AJ. Hunt JL, and Reinert CM.

Treatment of femur fracture with associated vascular injury.

J. Trauma. 1996; 40: 17-21.

4. Connolly JF, Whittaker D. and Williams E. Femoral and tibial fractures combined with injuries to the femoral or popliteal artery. $A$ review of the literature and analysis of fourteen cases.

J. Bone Joint Surg. Am. 1971: 53: 56-68.

5. Kluger $Y$, Gonze MD, Paul DB. DiChristina DG. Townsend RN, Raves $\|$ et al. Blunt vascular injury associated with closed mid-shaft femur fracture: a plea for concern. J. Trauma. 1994: 36: 222-225.
6. Ryan JR, Rowe DE, and Salciccioli GG. Prophylactic internal fixation of the femur for neoplastic lesions. J. Bone Joint Surg. Am. 1976; 58: 1071-1073.

7. Waddell JP. Preventing vascular injuries in revision total hip replacement.

Can. J. Surg. 1992: 35: 223.

8. Ostrum RF, Verghese GB, and Santner TJ. The lack of association between femoral shaft fractures and hypotensive shock.

J. Orthop. Trauma. 1993: 7: 338-342.

9. Duis $\mathrm{HJ}$ ten. The fat embolism syndrome. Injury. 1997: 28: 77-85.

10. Harper MC, and Carson WL. Curvature of the femur and the proximal entry point for an intramedullary rod.

Clin. Orthop. 1987: 220: 155-161. 
Historical review of treatment of femoral fractures 
The long Gamma nail is used for subtrochanteric fractures with extension in the femoral shaft, and combined fractures of the shaft and femoral neck. Knowledge of the options for the treatment of femoral neck fractures, trochanteric fractures, and femoral shaft fractures is therefore essential. The historical review in this chapter is according the fracture site (femoral neck, trochanteric region, and femoral shaft), and the methods of treatment (plates and nails). Extensive reviews are to be found in textbooks and other theses. ${ }^{1-5}$

\section{Historical review according to fracture site}

\section{Femoral neck}

The main problems in the treatment of patients with fractures of the femoral neck has been necrosis of the femoral head and non-union. Incomplete reduction causes malunion with varus deformity and shortening. ${ }^{5-7}$ These complications are related to biomechanical problems and loss of blood supply to the head. ${ }^{8-10}$ The vascularisation of the head depends mainly on the capsular vessels. which can be ruptured in displaced fractures. ${ }^{11-13}$ Even in young healthy patients with optimal blood supply whose fractures have been properly reduced these problems may occur. ${ }^{6.7 .14}$

In 1867 Phillips introduced a technique for longitudinal and lateral traction to eliminate "shortening or other deformity". is Asepsis, anaesthesia, and reliable material for osteosynthesis are necessary for a good operation. In the beginning ivory, wood, fibular autographs, and the first iron quadriflange nails (1916) gave severe technical complications. ${ }^{\text {P }}$ Since the introduction of the Smith-Peterson triflange nail (1931) made of Vitallium. operative techniques have become more successful. ${ }^{16}$ The introduction of cannulated screws and fluoroscopy added the dimension of minimally invasive surgery. ${ }^{17}$ Telescoping nails and screws that allow gradual impaction of the fracture site resulted in further improvements and reduced the risk of penetrating the femoral head. ${ }^{18-21}$ In addition to these fixation techniques, bone grafts are sometimes used. ${ }^{n 2.3}$ Nowadays cannulated screws and sliding hip screws are most widely used. ${ }^{5.24 .28}$

In 1940 Moore and Bohlman introduced primary prosthetic replacements. which have become popular for the treatment of fractures of the femoral neck fractures. ${ }^{27.39}$ The lifetime of prostheses varies from 10 to 15 years, so replacements may be necessary, particularly in younger people. ${ }^{33.44}$ These reoperations are technically demanding. Deep infections are rare but have major consequences. because they often lead to Girdlestone procedures or arthrodesis." 3

\section{Trochanteric region}

Nowadays conservative treatment of unstable trochanteric and subtrochanteric fractures has been almost completely abandoned. Historically conservative treat- 
ment can be divided into functional and anatomical approaches. ${ }^{36-39}$ The functional approach emphasised early mobilisation with adequate analgesics. The fracture was ignored. which led to varus deformity, external rotation, and shortening. ${ }^{37}$ In the anatomical approach, alignment of the fracture was maintained by a plaster spica cast, ${ }^{38.40}$ or traction:39.40 both result in considerable morbidity and mortality.

Operative treatment is now standard because the results are better. ${ }^{3.41-44}$ Stable pertrochanteric fractures are not difficult to treat, and can be managed successfully with all kinds of implants. ${ }^{45.46}$ Treatment of unstable pertrochanteric fractures and subtrochanteric fractures remains challenging:-47.51 these fractures are highly unstable because of comminution and lack of a posteromedial buttress. In consequence all forces have to be carried by the implant. with its weakest point in the proximal anchorage. Varus angulation and implant failure must be prevented. The challenge is to obtain an adequate anchorage in the proximal fragment of a strong implant, which is connected to the femoral shaft by a solid mechanical system. 2.53

Three different groups of implants are available: plating devices, intramedullary devices, and replacement prostheses. Prosthetic replacements for trochanteric fractures have not gained widespread support. ${ }^{54.56} \mathrm{~A}$ prosthesis allows early mobilisation and full weight bearing. Insertion of a prosthesis is a more serious surgical procedure than plate or nail osteosynthesis. Estimation of the head-neck length during operation is difficult because the landmark of the lesser trochanter is fractured and displaced. The solid head of the implant may also accelerate wear on the acetabular cartilage, and cause early pain. In selected patients with severe osteoporosis, or when stabilisation of a comminuted fracture with any type of device is questionable. prosthetic replacement of the Leinbach or bipolar type may be considered. Plates and nails are described in a separate section.

\section{Femoral shaft}

Before the turn of the 19th century, femoral fractures were splinted with wood. leather, or plaster of Paris. However, splinting is insufficient to maintain fracture alignment. Skin traction has the risk of skin necrosis due to the shearing forces. ${ }^{57}$ Steinmann (1907). and Kirschner (1909) designed transosseous pins that allowed efficient traction. sometimes in combination with splint systems (Thomas splint). ${ }^{5800}$ Traction is a good method of initial stabilisation, and can be used when resources are scarce or the infection rate is high. as in developing countries and in war surgery. ${ }^{61.62}$ Perkins traction is preferred. It is traction with a thick nail through the proximal tibia, with free movement of the knee joint. The disadvantage of supracondylar traction is scarring and reduced movement of the ileotibial tract with limited movement of the knee.

External fixation gained popular in the seventies.". It provides bony fixation. wound access, and permits early ambulation. The main disadvantages are high 
rates of non-union as a result of the limited stability, pin-tract infections, and fixation of the quadriceps muscle to the bone, resulting in loss of knee movements. ${ }^{63-66}$ Laterally-placed frames are stiff in the frontal plane, whereas anterior placed frames are stiff in the sagittal plane. Two frames at right angles work well together. ${ }^{67}$ External fixation is a good temporary measure in high-energy injuries when rapid fracture stabilisation is required. At present external fixation is used mostly for periarticular injuries or when there are multiple associated injuries, in grade III open fractures, when there are associated vascular injuries, ${ }^{68-73}$ and in some forms of corrective osteotomies. ${ }^{14 n}$

Plates and nails are technically less demanding to use for shaft fractures than for trochanteric fractures because good anchorage can be found proximal and distal to the fracture site.

Figure 3.I.

Developement of the AO pla. tes. The initially round hole pla. tes are changed to oval holes. The third. Dynamic Compres. sion Plates (DCP) can be placed under compression due to the design of the screus and sferical made holes. the screws can be placed under different angles. The last schow are the Limited Contact DCP with the advantage of preserving the vascularity better.
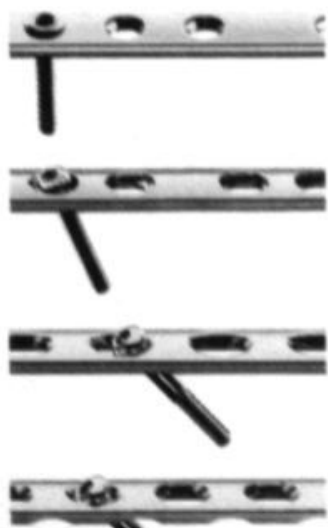

\section{of treatment}

\section{Plating} lisation.
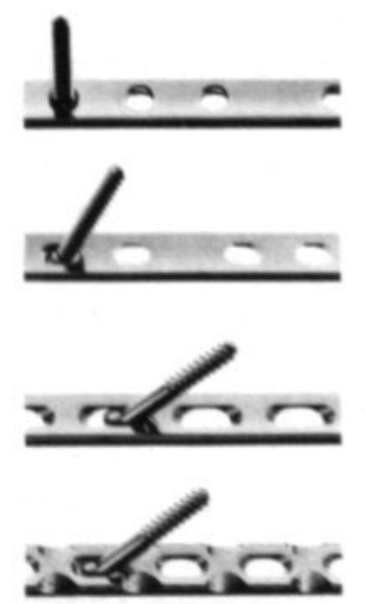

\section{Historical review of methods}

The Arbeitsgemeinschaft für Osteosynthesefragen ( $A O)$, in English called the Association for the Study of Internal Fixation (ASIF) has played a major part in the design and implementation of plate osteosynthesis in Europe. ${ }^{78}$ Since their introduction in 1958, four basic principles have been used: anatomical reduction, stable internal fixation, preservation of blood supply, and early active pain-free mobi-

Treatment is by open reduction and internal fixation (ORIF), with emphasis on the first two principles. An anatomically aligned and stabilised fracture reduces the forces on the plate. and thereby prevents implant fatigue: "the bone must protect the plate". The side opposite to the plate -for the femur this means the medial cortex- is most crucial. When good contact between the fracture elements is not achieved by reduction of the bony fragments, a bone grafts is added..$^{19}$ In excep-

tional cases cement or additional medial plates can be used. ${ }^{79}$ An absolutely stable fixation is aimed for. which means that the fracture gap is reduced to less than $0.1 \mathrm{~mm}$. and movement between the fracture fragments is impossible. The bone heals without callus formation, which is regarded as a sign of instability. Plates have evolved from simple plates with round holes to the Dynamic Compression Plate (DCP), and Limited Contact Dynamic Compression Plate (LCDCP) \{figure 3.1\}. The DCP is still the one most commonly used. An eccentrically placed screw with a spherical undercut and an inclined plate hole are the essential design properties of the DCP. 
Together with prebending and lag screws, an absolutely stable anatomical alignment under compression can be achieved.

Anatomically reduced fractures look good on radiographs. but problems of union remain common. Every movement causes strain on a fracture site. which is absorbed by the tissue in between the fracture elements. In an anatomically reduced fracture, with a very small fracture gap $(10 \mu \mathrm{m})$, single cell layers are easily disrupted in absorbing the strain. When the fracture gap is wider it will take longer for tissue to grow in, but that tissue shares the strain and 'quietly' remodels to bone \{figure 3.2\}." Secondly. the extensive dissections that are

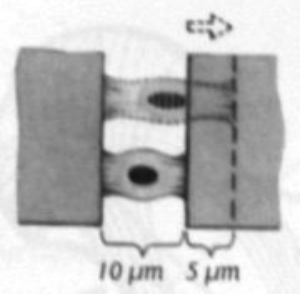
necessary to achieve anatomical reduction further damage the already torn vasculature. Thirdly, bone growth stimulating factors in the fracture haematoma are evacuated.

These problems added the concept of biological plating to the four principles. ${ }^{80}$ This aims to minimise surgical damage to the blood supply. and to create optimal tissue tolerance by using titanium as the implant material. The Limited Contact Dynamic Compression Plate (LCDCP) was developed, which is a titanium plate with lateral undercuts that preserves the periosteal blood supply and allows bone formation in between. The good results of this plate give rise to the even more extreme Point Contact Fixator (PC-Fix). ${ }^{81}$ The LISS plate

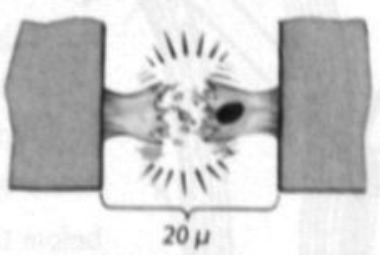

is developed with an unicortical stable screw fixation. Conventional operation techniques need extensive dissection. Reduction of this dissection and therefore reduction of vascular damage is achieved by the wave plates and the bridge plates. ${ }^{82-84}$ These plates are anchored only in the proximal and distal fragment to leave the fracture zone relatively intact. Percutaneous insertion of plates preserves the blood supply even better. ${ }^{85.86}$

Anchorage of plates for proximal femoral fractures is found in the subchondral bone of the femoral head. The fixed angle nail plate devices of Jewett. Holt, and McLaughlin were the first generation. ${ }^{8 / 92}$ The main technical problems were implant failures at the junction of the proximal anchorage device and distal plate. and protrusion of the hardware through the head as a result of collapse at the fracture side. The U-shaped blade plates are stronger, and give excellent purchase in the femoral head and neck, even in patients with osteoporosis \{figure 3.3\}..pss These single part devices are technically difficult to insert. and impaction at the fracture side can still cause penetration of the femoral head. The third generation devices are the sliding screw systems. ${ }^{43 \%}$ These systems have two components. which makes insertion less complicated. A lag screw slides through the part of the implant fixed to the femoral shaft. Sliding of the lag screw diminishes acetabular 


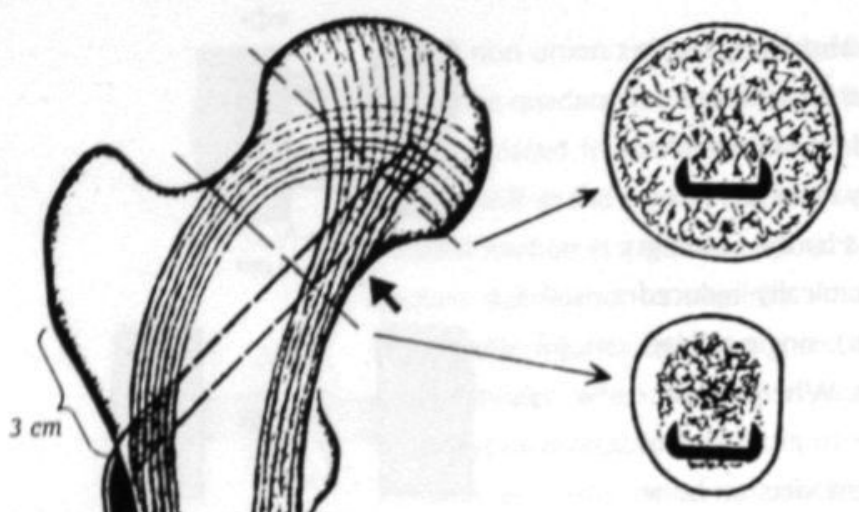

perforation: implant fatigue fractures: and pullout of the side plate on the diaphysis. ${ }^{45.9798}$ When telescoping of the screw is obstructed, the implant behaves as a rigid nail plate. Jamming of the gliding mechanism is prevented when the fracture is adequately reduced. ${ }^{51.99}$ when the steepest possible angle is used. ${ }^{43}$ when enough of the shank is inside the barrel, ${ }^{100}$ and when the implant has enough room to collapse before the screw thread impinges on the barrel. ${ }^{101}$ The Medoff plate adds a dynamic fixation on the femoral shaft by using two plates gliding in each other. ${ }^{102.103}$ These sliding mechanisms work only when they cross the fracture line.

Open reduction and internal fixation techniques need major dissection. which damages the vasculature. particularly if the medial side of the femur has to be explored. Nerves can be injured, particularly in the proximal femur where the scia-

Figure 3.3

The $130^{\circ}$ angle blade plate. The ideal position of the blade.

tic nerve is close to the dorsal aspect of the femur. Adhesion of the vastus lateralis to the bone can cause stiffness of the knee. ${ }^{104}$ Active range of movement exercises for the knee are therefore encouraged soon after operation. The bone implant construction is not stable enough to allow early weight bearing: depending on the degree of consolidation weight bearing is allowed or postponed. ${ }^{105}$

\section{Nailing}

After a fracture. which imply damage to the endosteal blood supply, the centrifugal blood flow reverses to a centripetal mode. which make the preservation of the periosteal blood supply important in trauma surgery (chapter 2). Nailing does not compromise the periosteal vessels and with closed nailing the fracture haematoma is not evacuated. so the early local cellular and humoral response. which is critical for normal fracture healing, is not disturbed. During reaming bone marrow elements and cortical fragments are pushed into the fracture haematoma and act to some extent as cancellous bone grafts. ${ }^{106.10 \%}$ Those bone marrow fragments may enter the circulation. ${ }^{108} 109$ The discussion about the relevance of this embolisation is going on. "10.118 Nailing is minimally invasive with a lower infection rate and less adhesion of the quadriceps to the femur." ${ }^{.9}$

The almost straight tubular anatomy of the femoral shaft is ideal for intramedullary fixation. Nails are solid or tubular and tubular nails are slotted or non-slotted. The first nails were V-shaped and were hammered into the fernur. They gave good results in simple fractures, but their use was problematical in more complex injuries. ${ }^{120.121}$ To strengthen tubular nails the diameter is enlarged. which makes reaming necessary. The guide wire that can be used with cannulated nails makes insertion easier. Slotted nails have a low torsion stiffness, but their elastic recoil 
makes them sufficiently rotationally stable in a fractured femur. ${ }^{121-123}$ The open portion of the tubular nails contains debris that results theoretically and in animal models in more infections, but this has not been confirmed clinically. ${ }^{126}$ The discussion about the embolisation of reamer products during reaming encouraged the development of solid nails that do not need reaming. ${ }^{11 z i z m z s}$ To make the nails inert and strong. titanium is used. 129.130

The average anterior curve of the femoral shaft in an adult has a radius of about $110 \mathrm{~cm}$. ${ }^{11} \mathrm{~A}$ mismatch in the curve of the femur and the nail introduces stresses during insertion. particularly in rigid nails. These stresses can result in fractures of the femur. ${ }^{124}$ iz Prebending the nail, seeking a slightly more anterior entrance, and over-reaming the canal diminish the risk of these fractures. ${ }^{125}$

Nails can be straight or bowed laterally (Latero-Medial curve, or LM angle). Straight nails are preferably introduced in the piriform fossa, which can give rise to a fracture of the femoral neck, and damage the medial femoral circumflex artery \{figure 3.4\}. resulting in necrosis of the femoral head. ${ }^{132-13}$ Introduction of a straight nail needs the limb be adducted. The entry point of these straight nails is in line with the femoral canal. Lateral bowed nails are inserted at the tip of the trochanter. They conserve the blood supply to the head fragment, and have less chance of fracturing the femoral neck. Adduction can be less, but the entrance is not completely in line with the medullary canal with more chance of jamming the medial cortex.

In the nail-bone composite the bone is sharing the load. compared with the load-shielding construction in plating techniques. ${ }^{50.139}$ Because a nail is strong and offers load sharing properties, it prevents rotation and axial instability. ${ }^{125.143}$ Early weight bearing is allowed. $140-142$ The nail can be locked in a dynamic mode in some nails to accelerate fracture healing. 14

Fatigue failure through the middle portion of a nail is rare.

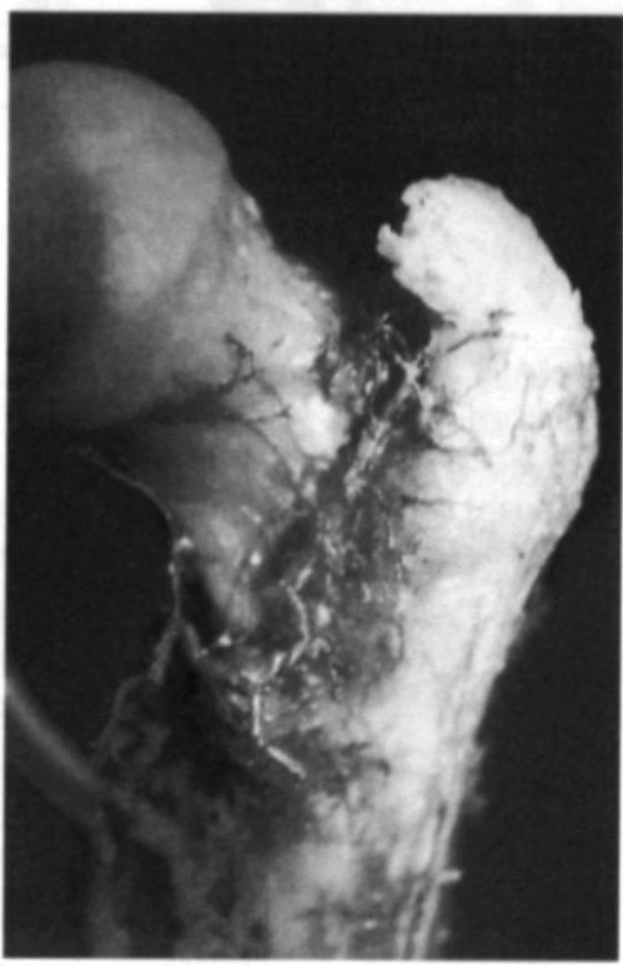
Deformation and breakage occur mainly at the proximal or distal ends through the screw holes, or at the junction of two parts of a nail. ${ }^{145-152}$ Over-reaming of the medullary canal and using undersized nails diminishes the contact area in the femoral canal, which results in a concentration of the load at the locking screw sites. The holes in the nails reduce the amount of metal at these sides. Most manufacturers now thicken the nail wall, widen the proximal nail diameter, or cold work the holes to improve the life of the nail at these sites.

Intramedullary nails are divided into centromedullary, condylocephalic, and cephalomedullary.

Figure 3.4

The vascular distrbution to the femoral head, seen from dorsal. Notice the close relation to the greater trochanter, especially in the piriform fossa. 


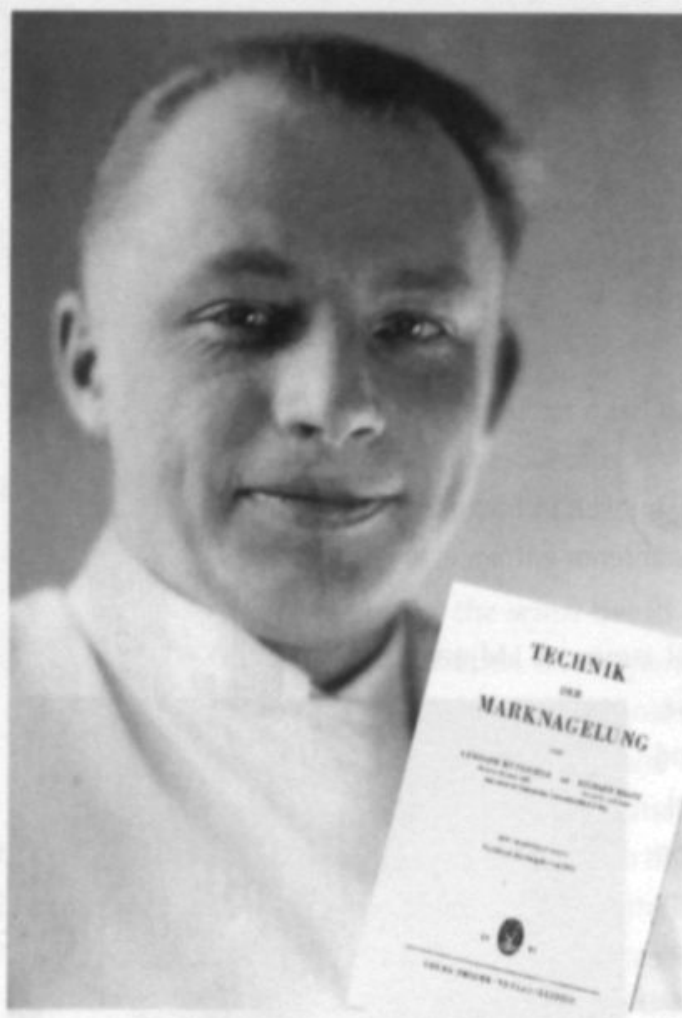

CENTROMEDULLARY NAILS are contained within the medullary canal. Proximal locking is in an intact trochanteric area, which limits their use in proximal fractures. Küntscher ushered in the modern era of nailing in 1939 \{figure 3.5\}. ${ }^{120.153}$ The initial response to his first design, the V-shaped nail, was unfavourable. Many of his colleagues condemned the concept as "non-physiological" and predicted a disastrously high rate of nonunion. Later he produced the slotted. cloverleaf 'Küntscher' nail \{figure 3.6\}. ${ }^{153}$ The slot made the nail elastic. with the idea that the nail would generate stability by impinging proximal and distal to the fracture. The good clinical results have resulted in a global acceptance of the intramedullary nailing technique. ${ }^{154-156}$ Through the years nearly all aspects of the nail have changed, but the basic concept and system have remained unchanged.

CONDYLOCEPHALIC NAILS were introduced in 1970. The technique of Ender and Simon-Weidner was

Figure 3.5

Küntscher and his book about the technique of intramedullary nailing (1945) based on the rods of Lezius-Herzer and Küntscher, which never gained much acceptance. ${ }^{13 z}$ is The $4.5 \mathrm{~mm}$ Ender rods are elastic and prebent. They have a three-point fixation: the introduction point at the medial supracondylar fossa, the intact lateral femoral cortex at the isthmus, and the femoral head. This produces a force to the head-neck fragment resulting in valgus. ${ }^{159}$ Although the lever arm forces are reduced as a result of the intramedullary position, the nails need medial support to allow weight bearing. Penetration of the femoral head. distal migration (which results in knee pain), shortening, rotational instability, varus deformity. and additional supracondylar fractures are known problems. ${ }^{157-162}$

CEPHALOMEDULLARY NAILS are intramedullary nails that get proximal anchorage in the femoral neck and head. The long Gamma nail belongs in this group.

The first Küntscher $Y$ nail (1940) was an intramedullary device through which another device was placed at $145^{\circ}$ into the fernoral head \{figure 3.6\}..$^{120}$ This model is similar to the standard Gamma nail. He developed his $\mathrm{Y}$ nail to a model in which a semicircular nail is first introduced into the femoral neck and head. Through this part a straight intramedullary rod is placed \{figure 3.6\}. It forms a rigid stabilisation of the proximal fragment. ${ }^{16-16}$ The Zickel nail (1967) is an intramedullary rod, which is anchored in the femoral head with a modified SmithPetersen nail \{figure 3.6\}. A set screw at the top of the rod fixes both parts to a rigid construction. ${ }^{106}$ In those three nails distal locking is not possible, which 
results in rotational instability and loss of length. ${ }^{103169}$ Reports claim a non-union rate of less than $2 \%$. $14010-12$ Mechanical failure. protrusion, and the need for accessory fixings because of comminution have been described. ${ }^{16}$ insin fractures as a result of removing the nail are an obvious disadvantage of the strongly bent Zickel nail.5.mss In 1984 Russell and Taylor introduced their straight Reconstruction Nail \{figure 3.7\}. 12 .140:m By eliminating the longitudinal slot in the nail and varying the thickness of the wall they improved the fatigue performance and reduced the shear at the fracture site. Proximal anchorage is in the femoral head with two screws. Distal anchorage can be achieved with two screws. The nail is rigid with high torsion stability. The results are good and the nail is the most commonly used one in the USA. ${ }^{\text {in-18: }}$

The long Gamma nail is somewhat more flexible, and
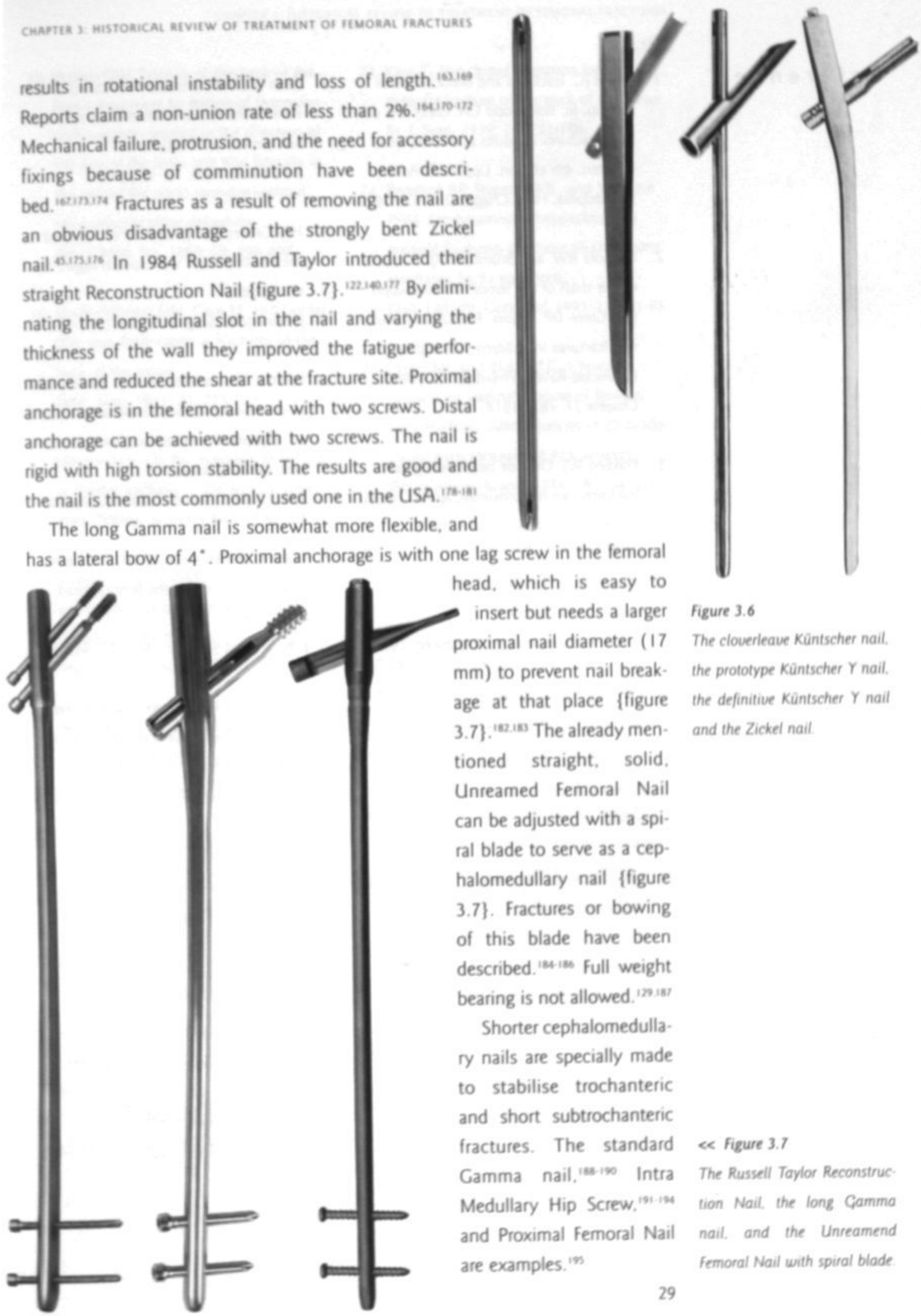
head, which is easy to insert but needs a larger proximal nail diameter ( 17 $\mathrm{mm}$ ) to prevent nail breakage at that place \{figure 3.7\}. ${ }^{102.18}$ The already mentioned straight, solid. Unreamed Femoral Nail can be adjusted with a spiral blade to serve as a cephalomedullary nail ffigure 3.7\}. Fractures or bowing of this blade have been described. bearing is not allowed. ${ }^{128}$

Shorter cephalomedullary nails are specially made to stabilise trochanteric and short subtrochanteric fractures. The standard Gamma nail. ${ }^{183} 190$ Intra Medullary Hip Screw. ${ }^{19-194}$ and Proximal Femoral Nail are examples. ${ }^{19}$

« Figure 3.7

The Russell Taylor Reconstruction Nail, the long Camma nail. and the Unreamend femoral Nail with spiral blade. 
I. Delee JC. Fractures and dislocations of the hip. In: Rockwood CA. Green DP, editors. Fractures in adults and fractures in children. 4th edition. Lippincott-Raven. Philadelphia, 1996. Chapter 26: 1659-1825.

2. Bucholz RW, and Brumback RJ. Fractures of the shaft of the femur. In: Rockwood CA, Green DP, editors. Fractures in adults and fractures in children. 4th edition. Lippincott-Raven. Philadelphia. 1996. Chapter 27: 1827-1918.

3. Prakken $W$ J. Over de behandeling van fracturen van het proximale femur. Thesis University Hospital Utrecht, 1983.

4. Stapert JWJL. Intramedullaire osteosynthese van het femur.

Thesis Rijksuniversiteit Maastricht. 1983.

5. Vugt $A B$ van. The unsolved fracture. a prospective study of 224 consecutive cases with an intracapsular hip fracture. Thesis Catholic University of Nijmegen. 1991.

6. Jakob M. Rosso R. Weller K, Babst R. and Regazzoni P. Avascular necrosis of the femoral head after open reduction and internal fixation of femoral neck fractures: an inevitable complication? Swiss. Surg. 1999: 5: 257-264.

7. Kregor P]. The effect of femoral neck fractures on femoral head blood flow. Orthopedics. 1996: 19: 1031-1038.
8. Senn N. The treatment of fractures of the neck of the femur by immediate reduction and permanent fixation.

J. A. M. A. 1889: 13: 150-159.

9. Hey-Groves EW. Treatment of fractured neck of the femur with special regard to the results.

J. Bone Joint Surg. Br. 1930: 12: 1-14.

10. Lausten CS, and Arnoldi CC. Blood perfusion uneven in femoral head osteonecrosis. Doppler flowmetry and intraosseous pressure in 12 cases.

Acta Orthop. Scand. 1993: 64: 533-536.

II. Trueta J, and Harrison MHM. The normal vascular anatomy of the femoral head in adult man.

J. Bone Joint Surg. Br. 1953: 35: 442-461.

12. Judet J. Judet R, Lagrange J, and Dunoyer J. A study of the arterial vascularisation of the femoral neck in the adult.

J. Bone Joint Surg. Am. 1955: 37: 663-680.

13. Gill T]. Sledge JB, Ekkernkamp A, and Ganz R. Intraoperative assessment of femoral head vascularity after femoral neck fracture.

J. Orthop. Trauma. 1998: 12: 474-478.

14. Alho A, Benterud JG. and Solovieva S. Internally fixed femoral neck fractures. Early prediction of failure in 203 elderly patients with displaced fractures. Acta Orthop. Scand. 1999: 70: 141-144. 
15. Phillips GW. Fracture of the neck of the femur: treatment by means of extension with weights, applied in the direction of the axis of the limb, and also laterally in the axis of the neck: recovery without shortening or other deformity.

Am. J. Med. Sci. 1869: 58: 398-400.

16. Smith-Petersen MN, Cave EF, and Gorder GW van. Intra-capsular fractures of the neck of the femur.

Arch. Surg. 1931: 23: 715-759.

17. Johansson S. On the operative treatment of medial fractures of the fermoral neck. Acta Orthop. Scand. 1932: 3: 362-385.

18. Virgin $\mathrm{H}$, and MacAusland WR. A continuous traction screw for fixation of fractures of the hip.

Ann. Surg. 1945: 122: 59-67.

19. Pugh WL. A self-adjusting nail-plate for fractures about the hip joint. J. Bone Joint Surg. Am. 1955: 37: 1085-1093.

20. Massie WK. Functional fixation of femoral neck fractures: Telescoping Nail Technique. Clin. Orthop. 1958: 12: 230-255.

21. Clawson DK. Intracapsular fractures of the femur treated by the Sliding Screw Plate Fixation Method.

J. Trauma. 1964: 4: 753-756.

22. Judet $R$. Treatment of fractures of the femoral neck by pedicled grafts.

Acta Orthop. Scand. 1962: 32: 421-427.
23. King T. The closed operation for intracapsular fracture of the neck of the femur. Br. J. Surg. 1939: 26: $721-748$.

24. Bertelink BP, Stapert JWJL, and Vierhout PAM. De dynamische heupschroef bij mediale fracturen van het collum femoris: resultaten bij SI patiênten.

Ned. Tijdschr. Geneeskd. 1993; 137: 81-85.

25. Parker MJ. and Blundell C. Choice of implant for internal fixation of femoral neck fractures. Meta-analysis of 25 randomised trials including 4.925 patients. Acta Orthop. Scand. 1998: 69: 138-143.

26. Bray TJ. Femoral neck fracture fixation. Clinical decision making. Clin. Orthop. 1997: 339: 20-31.

27. Laursen JO. Treatment of intracapsular fractures of the femoral neck in Denmark: trends in indications over the past decade. Acta Orthop. Belg. 1999: 65: 478-484.

28. Lagerby M, Asplund S, and Ringquist I. Cannulated screws for fixation of femoral neck fractures. No difference between Uppsala screws and Richards screws in a randomized prospective study of 268 cases.

Acta Orthop. Scand. 1998: 69: 387-391.

29. Moore AT, and Bohlman HR. Metal hip joint: a case report.

J. Bone Joint Surg. Br. 1943; 25: 688-692.

30. Judet J. and Judet $R$. The use of artificial fernoral head for arthoplasty of the hip joint.

J. Bone Joint Surg. Br. 1950: 32: 166-173. 
31. Thompson FR. Two and a half years' experience with a vitallium intramedullary hip prosthesis.

J. Bone Joint Surg. Am. 1954: 36: 489-500.

32. Huusko T, Karppi P. Avikainen V. Kautiainen $\mathrm{H}$, and Sulkava R. Significant changes in the surgical methods and length of hospital stay of hip fracture patients occurring over 10 years in Central Finland.

Ann. Chir. Gynaecol. 1999: 88: 55-60.

33. Clayer M. and Bruckner J. The outcome of Austin-Moore hemiarthroplasty for fracture of the femoral neck.

Am. J. Orthop. 1997; 26: 681-684.

34. Chua D. Jaglal SB, and Schatzker J. An orthopedic surgeon survey on the treatment of displaced femoral neck fracture: opposing views.

Can. J. Surg. 1997: 40: 271-277.

35. Lee BP. Berry DJ. Harmsen WS, and Sim FH. Total hip arthroplasty for the treatment of an acute fracture of the femoral neck: long-term results. J. Bone Joint Surg. Am. 1998: 80: 70-75.

36. Murray RC, and Frew JFM. Trochanteric fractures of the femur. A plea for conservative treatment.

J. Bone Joint Surg. Br. 1949: 31: 204-219

37. Shaftan GW. Herbsman $\mathrm{H}$. and Pavlides $\mathrm{C}$. Selective conservatism in hip fractures. Surgery. 1967:61: 524-527.

38. Clawson DK. Intertrochanteric fractures of the hip. Am. J. Surg. 1957: 93: 580-587.
39. Anderson R, and McKibbin WB. Intertrochanteric fractures. J. Bone Joint Surg, Br. 1943: 25: 153-168.

40. Cleveland M, Bosworth DM, and Thompson FR. Management of the trochanteric fracture of the femur. J. A. M. A. 1948: 137: $1186-1190$.

41. Evans EM. The treatment of trochanteric fractures of the femur.

J. Bone Joint Surg. Br. 1949: 31: 190-203.

42. Boyd HB, and Griffin LL. Classification and treatment of trochanteric fractures. Arch. Surg. 1949: 58: 853-866.

43. Kyle Rf, Gustilo RB, and Premer RF. Analysis of six hundred and twenty-two intertrochanteric hip fractures. A retrospective and prospective study. J. Bone Joint Surg. Am. 1979; 61: 216-221.

44. Larsson S. Friberg S, and Hansson LI. Trochanteric fractures. Mobility, complications, and mortality in 607 cases treated with the sliding-screw technique. Clin. Orthop. 1990: 260: 232-241.

45. Jensen JS. Tondevold E, and Sonne Holm S. Stable trochanteric fractures. A comparative analysis of four methods of internal fixation.

Acta Orthop. Scand. 1980; 51: 811-816.

46. Heyse-Moore GH, MacEachern AG. and Jameson Evans DC. Treatment of intertrochanteric fractures of the femur.

J. Bone Joint Surg. Br. 1983: 65: 262-267. 
47. Seinsheimer F. Subtrochanteric fractures of the femur.

J. Bone Joint Surg. Am. 1978: 60:300-306

48. Waddell JP. Subtrochanteric fractures of the femur: a review of 130 patients.

J. Trauma. 1979: 19: 582-592.

49. Jensen JS. Sonne Holm S, and Tondevold

E. Unstable trochanteric fractures. A comparative analysis of four methods of internal fixation.

Acta Orthop. Scand. 1980; 51: 949-962.

50. Tencer Af. Johnson KD. Johnston DW. and Gill K. A biomechanical comparison of various methods of stabilization of subtrochanteric fractures of the femur. J. Orthop. Res. 1984: 2: 297-305.

SI. Regazzoni P. Method of treatment of proximal femoral fractures: choice of the implant. In: Marti RK, Dunki Jacobs PB. editors. Proximal femoral fractures.

Operative techniques and complications. Medical Press, London. 1993.

Chapter 17: 389-408.

52. Trafton PG. Subtrochanteric-intertrochanteric femoral fractures.

Orthop. Clin. North Am. 1987: 18: 59-71.

53. Wiss DA. Matta JM. Sima W. and Reber L. Subtrochanteric fractures of the femur. Orthopedics. 1985: 8: 797-800.
54. Stappaerts KH. Deldycke J. Broos PL. Staes FF, Rommens PM, and Claes P. Treatment of unstable peritrochanteric fractures in elderly patients with a compression hip screw or with the Vandeputte (VDP) endoprosthesis: a prospective randomized study.

J. Orthop. Trauma. 1995: 9: 292-297.

55. Rosenfeld RT, Schwartz DR, and Alter AH. Prosthetic replacement for trochanteric fractures of the femur. J. Bone Joint Surg. Am. 1973; 55:420-421.

56. Green S, Moore T, and Proano F. Bipolar prosthetic replacement for the management of unstable intertrochanteric hip fractures in the elderly. Clin. Orthop. 1987; 224: 169-177.

57. Peltier LF. A brief history of traction. J. Bone Joint Surg. Am. 1968: 50: 1603-1617

58. Mathews S. A simple wire pin skeletal traction apparatus.

J. Bone Joint Surg. Am. 1958; 40: 323-325.

59. Mays J. and Neufeld AJ. Skeletal traction methods. Clin. Orthop. 1974: 102: 144-151.

60. Peltier LF. The role of Alessandro Codivilla in the development of skeletal traction. J. Bone Joint Surg. Am. 1969: 51: 1433.

61. Bassey LO. Open fractures of the fernur treated by the pin-in-plaster technique. Contribution to the art and practice of trauma surgery in the Third World. Arch. Orthop. Trauma Surg. 1990; 109: 139-143. 
62. Oberli $H$, and Frick T. Die offene

Femurfraktur im Krieg-173 Fixateur-

externe-Applikationen am Femur

(Afghanistankrieg).

Helv. Chir. Acta. 1992; 58: 687-692.

63. Broekhuizen AH. Femoral fracyures.

indications and biomechanics of external fixation.

Thesis University Hospital Rotterdam, 1988.

64. Jackson RP, Jacobs RR, and Neff JR. External skeletal fixation in severe limb trauma. J. Trauma. 1978: 18: 201-205.

65. Green SA, and Ripley MJ. Chronic osteomyelitis in pin tracks.

J. Bone Joint Surg. Am. 1984: 66: $1092-1098$

66. Alonso JE, Geissler WB, and Hughes JL External fixation of femoral fractures. Indications and limitations. Clin. Orthop. 1989: 241: 83-88.

67. Goodship AE. Watkins PE, Rigby HS, and Kenwright ]. The role of fixator frame stiffness in the control of fracture healing. An experimental study.

J. Biomech. 1993: 26: 1027-1035.

68. Habboushe MP. External fixation system for compound missile wounds of the bone. Injury. 1984: 15: 388-389.

69. Weise K, Weller S, and Ochs U. Verfahrenswechsel nach primarer Fixateur externe-Osteosynthese beim polytraumatisierten Patienten.

Aktuelle. Traumatol. 1993: 23: 149-168.
70. lannacone WM, Taffet R, Delong WG. Jr., Born CT. Dalsey RM, and Deutsch LS. Early exchange intramedullary nailing of distal femoral fractures with vascular injury initially stabilized with external fixation. J. Trauma. 1994: 37: 446-451.

71. Bossche MR van den, Broos PL, and Rommens PM. Open fractures of the femoral shaft. treated with osteosynthesis or temporary external fixation.

Injury. 1995: 26: 323-325.

72. Mohr VD, Eickhoff U. Haaker R, and Klammer HL. External fixation of open femoral shaft fractures.

J. Trauma. 1995: 38: 648-652.

73. Nowotarski PJ. Turen CH, Brumback RJ. and Scarboro JM. Conversion of external fixation to intramedullary nailing for fractures of the shaft of the femur in multiply injured patients.

J. Bone Joint Surg. Am. 2000: 82: 781-788

74. Cech O. Prof. llizarov and his contribution to the challenge of limb lengthening. Injury. 1993: 24 Suppl 2: 2-8.

75. Price CT. and Mann JW. Experience with the Orthofix device for limb lengthening. Orthop. Clin. North Am. 1991; 22 : 651.661

76. Raschike M. Oedekoven G. Ficke J, and Claudi BF. The monorail method for segment bone transport. Injury. 1993: 24 Suppl 2: 54-61. 
77. Johnson EE. Acute lengthening of shortened lower extremities after malunion or non-union of a fracture.

J. Bone Joint Surg. Am. 1994: 76:379-389.

78. Müller ME. Allgồwer M. Schneider R. and Willenegger $\mathrm{H}$. Manual of internal fixation, techniques recommended by the AO-ASIF groep. 3rd edition. Springer-Verslag, Berlin, Heidelberg. New York, 1991.

79. Velasco RU, and Comfort TH. Analysis of treatment problems in subtrochanteric fractures of the femur.

J. Trauma. 1978: 18: 513-523.

80. Weller S. "Die biologische Osteosynthese". Ein unfallchirurgischer Modetrend oder wichtiger operationstechnischer Aspekt? Chirurg. 1995: 66: 53-56.

81. Baumgaertel F. Buhl M, and Rahn BA. Fracture healing in biological plate osteosynthesis. Injury. 1998: 29 Suppl 3: 3-6.

82. Blatter G, and Weber BG. Wave plate osteosynthesis as a salvage procedure. Arch. Orthop. Trauma Surg. 1990: 109: 330-333.

83. Heitemeyer U. and Hierholzer G. Indikation zur überbruckenden Plattenosteosynthese komplexer femurschaftfrakturen. Aktuelle. Traumatol. 1991: 21: 173-181.

84. Karnezis IA. Biomechanical considerations in 'biological' femoral osteosynthesis: an experimental study of the 'bridging' and 'wave' plating techniques. Arch. Orthop. Trauma. Surg. 2000: 120 : 272-275.
85. Wenda K, Runkel M, and Rudig L. Die "durchgeschobene" Kondylenplatte. Unfallchirurgie. 1995: 21: 77-82.

86. Farouk O, Krettek C, Miclau T. Schandelmaier P, Guy P, and Tscherne H. Minimally invasive plate osteosynthesis: does percutaneous plating disrupt femoral blood supply less than the traditional technique? J. Orthop. Trauma. 1999; 13: 401-406.

87. Jewett $\mathrm{EL}$. One-piece angle nail for trochanteric fractures.

J. Bone Joint Surg. Am. 1941:23: 803-810.

88. Wilson HJ, Rubin BD. Helbig FEJ. Fielding $\mathrm{JW}$, and Unis GL. Treatment of intertrochanteric fractures with the Jewett nail: Experience with 1015 cases. Clin. Orthop. 1980: 148: 186-191.

89. Holt EP. Hip fractures in the trochanteric area: treatment with a strong nail and early weight-bearing.

J. Bone Joint Surg. Am. 1963:45: 687-705.

90. Slungaard $U$. Holter $O$, and Haaland $M$. Plate nailing of medial fractures of the femoral neck according to Mclaughlin. Acta Chir. Scand. 1968: 134: 115-118.

91. Jensen JS, and Michaelsen M. Trochanteric femoral fractures treated with McLaughlin osteosynthesis.

Acta Orthop. Scand. 1975: 46: 795-803.

92. Tronzo RG. Hip nails for all occasions. Orthop. Clin. North Am. 1974: 5: 479-491. 
93. Kinast C, Bolhofner BR, Mast JW, and Ganz R. Subtrochanteric fractures of the fernur: results of treatment with the $95^{\circ}$ condylar blade plate.

Clin. Orthop. 1989: 238: 122-130.

94. Ganz R. and Trousdale R. Fixation of per- and subtrochanteric fractures with the $95^{\circ}$ condylar blade plate.

In: Marti RK, Dunki Jacobs PB, editors. Proximal femoral fractures. Operative techniques and complications. Medical Press, London, 1993. Chapter 12: 285-298.

95. Friedl W. and Stallforth $\mathrm{H}$. Wirksamkeit der Abstutzschraube bei Kondylenplattenosteosynthese am proximalen femur. Unfallchirurgie. 1994: 20: 49-52.

96. Jensen JS. Mechanical strength of sliding screw-plate hip implants. A biomechanical study of unstable trochanteric fractures. VL. Acta Orthop. Scand. 1980: 51:625-632.

97. Spivak JM, Zuckerman JD, Kummer F]. and Frankel VH. Fatigue failure of sliding screw in hip fracture fixation: report of three cases.

J. Orthop. Trauma. 1991: 3: 325-331.

98. Paaschburg Nielsen B. Jelnes $\boldsymbol{R}$, Rasmussen LB, and Ebling A. Trochanteric fractures treated by the Mclaughlin nail and plate. Injury. 1985: 16: 333-336.

99. Yoshimini F. Latta L. and Milne EL. Sliding characteristics of compression hip screws in the intertrochanteric fracture: a clinical study.

J. Orthop. Trauma. 1993: 7: 348-353.
100. Kyle RF, Wright TM, and Burstein AH. Biomechanical analysis of the sliding characteristics of compression hip screws. J. Bone Joint Surg. Am. 1980: 62: 1308-1314.

101. Mulholland RC. and Gunn DR. Sliding screw plate fixation of intertrochanteric femoral fractures.

J. Trauma. 1972: 12: 581-591.

102.Lunsjo K, Ceder L. Stigsson L, and Hauggaard A. One-way compression along the femoral shaft with the Medoff sliding plate. The first European experience of 104 intertrochanteric fractures with a I-year follow-up.

Acta Orthop. Scand. 1995: 66: 343-346.

103. Medoff RJ. and Maes K. A new device for the fixation of unstable pertrochanteric fractures of the hip.

J. Bone joint Surg. Am. 1991: 73-A: $1192-1199$.

104.O'Beirne J. O'Connell RJ. White JM, and Flynn M. Fractures of the femur treated with femoral plating using the anterolateral approach. Injury. 1986: 17: 387-390.

105. Riemer BL. Foglesong ME, and Miranda MA. femoral plating.

Orthop. Clin. North Am. 1994: 25: 625-633.

106. Hughes SP. Reichert IL. and McCarthy ID. Biological effects of intramedullary reaming.

J. Bone Joint Surg. Br. 1993: 75: 845-847. 
107. Kessler SB, Hallfeldt KK, Perren SM, and Schweiberer $L$. The effects of reaming and intramedullary nailing on fracture healing. Clin. Orthop. 1986; 212: 18-25.

108. Pell AC, Christie J. Keating JF, and Sutherland GR. The detection of fat embolism by transoesophageal echocardiography during reamed intramedullary nailing. A study of 24 patients with femoral and tibial fractures. J. Bone Joint Surg. Br. 1993: 75: 921-925

109. Kerr PS, Jackson M, and Atkins RM. Cardiac arrest during intramedullary nailing for femoral metastases.

J. Bone Joint Surg. Br. 1993: 75: 972-973.

110. Gurd AR. Fat embolism: an aid to diagnosis.

J. Bone Joint Surg. Br. 1970; 52: 732-737.

111. Sauter AJM. Vetemboli door botbreuk onder statische en dynamische belasting. een experimenteel onderzoek.

Thesis University of Amsterdam, 1980.

112. Alho A. Fat embolism syndrome: etiology. pathogenesis and treatment. Acta Chir. Scand. Suppl. 1980: 499: 75-85.

113. Duis HJ ten. The fat embolism syndrome. Injury. 1997: 28: 77-85
114. Bosse MJ. MacKenzie E]. Riemer BL. Brumback RJ. McCarthy ML. Burgess AR et al. Adult Respiratory Distress Syndrome. pneumonia and mortality following thoracic injury and a femoral fracture treated either with intramedullary nailing with reaming or with a plate.

J. Bone Joint Surg. Am. 1997; 79: 799-809.

115. Heim D, Regazzoni P. Tsakiris DA. Aebi T, Schlegel U, Marbet GA et al. Intramedullary nailing and pulmonary embolism: does unreamed nailing prevent embolization? An in vivo study in rabbits. J. Trauma. 1995: 38: 899-906.

1 16. Martin R. Leighton RK. Petrie D, Ikejiani C. and Smyth B. Effect of proximal and distal venting during intramedullary nailing. Clin. Orthop. 1996: 332: 80-89.

117. Bulger EM, Smith DG, Maier RV, and Jurkovich GJ. Fat embolism Syndrome. A 10-year review.

Arch. Surg. 1997: 132: 435-439.

1 18. Peter RE. Schopfer A, Le Coultre B, and Hoffmeyer P. Fat embolism and death during prophylactic osteosynthesis of a metastatic femur using an unreamed femoral nail.

J. Orthop. Trauma. 1997; 11: 233-234.

119. Bodoky A, Neff U, Heberer M, and Harder F. Antibiotic prophylaxis with two doses of cephalosporin in patients managed with internal foxation for a fracture of the hip. J. Bone Joint Surg. Am. 1993: 75:61-65. 
120. Küntscher G. and Maatz R. Technik der Marknagelung. Georg Thieme, Verlag. Leipzig. 1945.

121. Alho A, Moen O. Husby T, Ronningen $\mathrm{H}$, and Skjeldal S. Slotted versus non-slotted locked intramedullary nailing for femoral shaft fractures.

Arch. Orthop. Trauma Surg. 1992; III: 91-95.

122. Russell TA. Taylor JC, LaVelle DG. Beals NB. Brumfield DL. and Durham AG. Mechanical characterization of femoral interlocking intramedullary nailing systems. J. Orthop. Trauma. 1991: 5: 332-340.

123. Kyle RF, Schaffhausen JM. and Bechtold JE. Biomechanical characteristics of interlocking femoral nails in the treatment of complex femoral fractures.

Clin. Orthop. 1991: 267: 169-173.

124. Tencer Af, Sherman MC, and Johnson $K D$. Biomechanical factors affecting fracture stability and femoral bursting in closed intramedullary rod fixation of femur fractures.

J. Biomech. Eng. 1985; 107: 104-111.

125. Johnson KD, and Tencer AF. Mechanics of intramedullary nails for femoral fractures. Unfallchirurg. 1990; 93: 506-5II.

126. Melcher GA. Metzdorf A. Schlegel U. Ziegler W]. Perren SM, and Printzen G. Influence of reaming versus nonreaming in intramedullary nailing on local infection rate: Experimental investigation in rabbits. 1. Trauma. 1995: 39: 1123-1128.
127. Blitzer CM, and Hamilton L. Oxygen saturation during reaming and intramedullary nailing of the femur.

Orthopedics. 1992: 15: 1403-1405.

128. Pape HC. Dwenger A, Regel G.

Schweitzer G. Jonas M. Remmers D et al. Pulmonary damage after intramedullary femoral nailing in traumatized sheep. Is there an effect from different nailing methods? J. Trauma. 1992: 33: 574-581.

129. Krettek C, and Tscherne H. Osteosynthese von Femurschaftfrakturen mit dem Unaufgebohrten AO-femurnagel (UFN). Unfallchirurg. 1994: 97: 549-567.

130. Kropfl A, Naglik H. Primavesi C, and Hertz $\mathrm{H}$. Unreamed intramedullary nailing of femoral fractures.

J. Trauma. 1995: 38: 717-726.

131. Harper MC, and Carson WL. Curvature of the femur and the proximal entry point for an intramedullary rod.

Clin. Orthop. 1987: 220: 155-161.

132. Simonian PT. Chapman JR, Selznick HS. Benirschike SK. Claudi BF, and Swiontkowski MF. latrogenic fractures of the femoral neck during closed nailing of the femoral shaft.

J. Bone Joint Surg. Br. 1994: 76: 293-296.

133. Christie J, and Court Brown CM. Femoral neck fracture during closed medullary nailing: a brief report.

1. Bone Joint Surg. Br. 1988: 70: 670 
134. Miller SD, Burkart B, Damson E, Shrive N. and Bray RC. The effect of the entry hole for an intramedullary nail on the strength of the proximal femur.

J. Bone Joint Surg. Br. 1993: 75: 202-206.

135. Harper MC, and Henstorf J. Fractures of the femoral neck associated with technical errors in closed intramedullary nailing of the femur. Report of two cases.

J. Bone Joint Surg. Am. 1986; 68: 624-626.

136. Deep K. Sharp I, and Hay SM. Femoral neck fracture complicating intramedullary nailing of femoral shaft.

Injury. 1999: 30: 445-447.

137. O'Malley DE, Mazur JM, and Cummings RJ. Femoral head avascular necrosis associated with intramedullary nailing in an adolescent.

J. Pediatr. Orthop. 1995: 15: 21-23.

138. Thometz JG. and Lamdan R.

Osteonecrosis of the femoral head after intramedullary nailing of a fracture of the femoral shaft in an adolescent. A case report.

J. Bone Joint Surg. Am. 1995: 77:

1423-1426.

139. Curtis MJ. Jinnah RH. Wilson V. and Cunningham BW. Proximal femoral fractures: a biomechanical study to compare intramedullary and extramedullary fixation. Injury. 1994: 25: 99-104.
140. Taylor JC. Russell TA, and LaVelle DG. The Russell-Taylor Reconstruction Nail. Biomechanics / technique / clinical results. 56th Annual Meeting of the American Academy of Orthopaedic Surgeons, Las Vegas, Nevada, 1989.

141. Flahiff CM, Nelson CL, Gruenwald JM. and Hollis JM. A biomechanical evaluation of an intramedullary fixation device for intertrochanteric fractures. J. Trauma. 1993; 35: 23-27.

142. Shaw JA, and Wilson S. Internal fixation of proximal femur fractures: a biomechanical comparison of the Gamma Locking Nail and the Omega Compression Hip Screw. Orthop. Rev. 1993; 22:61-68.

143. Kinast C, Frigg R, and Perren SM. Biomechanics of the interlocking nail. $A$ study of the proximal interlock. Arch. Orthop. Trauma Surg. 1990; 109: 197-204.

144. Goessens ML. Wildenberg FAJM van den. Eggink GJ, and Stapert JWJL. Treatment of fractures of femur and tibia with the telescopic locking nail: design of a new implant and the first clinical results.

J. Trauma. 1999: 46: 853-862.

145. Zimmerman KW, and Klasen HJ. Mechanical failure of intramedullary nails after fracture union.

J. Bone Joint Surg. Br. 1983: 65: 274-275.

146. Stothard J. Sinha BM. and Maughan PA Double fractures of $A O$ intramedullary femoral nails. Injury. 1989: 20: 119.121. 
147. Perren SM, and Beaupre G. Breakage of AOIASIF medullary nails. Material related or design tradeoff?

Arch. Orthop. Trauma Surg. 1984: 102: 191-197.

148. Franklin JL. Winquist RA, Benirschke SK. and Hansen ST. Broken intramedullary nails.

J. Bone Joint Surg. Am. 1988; 70:

1463-1471.

149. Surdo V. and Dalla Pria P. Breakage of the Kuntscher nail in fractures of the femur after healing has occurred.

Ital. J. Orthop. Traumatol. 1991; 17: 125-130.

150. Wu CC, and Shih CH. Biomechanical analysis of the mechanism of interlocking nail failure.

Arch. Orthop. Trauma Surg. 1992: 111 : 268-272

I5I. Brink WA, van den, and Janssen IMC. Failure of the Gamma nail in a highly unstable proximal femur fracture: Report of four cases encountered in the Netherlands. J. Orthop. Trauma. 1995: 9: 53-56.

152.Zafiropoulos G, and Pratt D]. Fractured Gamma nail. Injury. 1994: 25: 331-336.

153. Küntscher G.

The intramedullary nailing of fractures. Clin. Orthop. 1968: 60: 5-12.
155. Weller S. Internal fixation of fractures by intramedullary nailing. Introduction. historical review and present status. Injury. 1993: 24 Suppl 3: 1-6.

156. Rothwell AG. and Fitzpatrick CB. Closed Küntscher nailing of femoral shaft fractures. A series of 100 consecutive patients. J. Bone Joint Surg. Br. 1978: 60: 504-509.

157. Pankovich AM. Flexible intramedullary nailing of long bone fractures: a review. J. Orthop. Trauma. 1987: 1: 78-95.

158. Vécsei V. Ender nailing of trochanteric fractures. In: Marti RK. Dunki Jacobs PB. editors. Proximal femoral fractures. Operative techniques and complications. Medical Press, London, 1993. Chapter 14:311-365

159. Kempf I. Use and limitations of the Ender method with modification by sliding locking. In: Marti RK, Dunki Jacobs PB. editors. Proximal femoral fractures. Operative techniques and complications. Medical Press, London, 1993.

Chapter 15: 367-380.

160. Ender J. and Simon-Weidner R. Die fixierung der trochanteren Brüche mit runden elastischen Condylennàgeln Acta Chir. Austrica. 1970: 1: 40-42.

161. Jensen JS, and Sonne Holm S. Critical analysis of Ender nailing in the treatment of trochanteric fractures.

Acta Orthop. Scand. 1980: 51: 817-825

154. Lentz W. Die Geschichte der Mark-

nagelung. Ein kurzer Ruckblick.

Chirurg. 1990: 61: 474-480: 
162. Perry CR. Brueckmann FR, Pankovich

AM. Sanders RW, and Waddell JP

Flexible intramedullary nailing of long

bone fractures.

Instr. Course. Lect. 1993; 42: 57-66.

163. Seiffert K, and Hesse U. Die operative Behandlung trochanterer Femurfrakturen mit der $\mathrm{Y}$-Nagelung nach $\mathrm{G}$. Küntscher. Zentralbl. Chir. 1993; 118: 658-664.

164. Davis TR. Sher JL. Horsman A, Simpson M. Porter BB, and Checketts RG. Intertrochanteric femoral fractures. Mechanical failure after internal fixation. J. Bone Joint Surg. Br. 1990; 72: 26-31.

165. Cuthbert H, and Howat TW. The use of the Küntscher $\mathrm{y}$ nail in the treatment of intertrochanteric and subtrochanteric fractures of the femur. Injury. 1976: 8: 135-142.

166. Davis AD. Meyer RD, Miller ME, and Killian JT. Closed Zickel nailing. Clin. Orthop. 1985: 201: 138-146.

167. Thomas WG. and Villar RN.

Subtrochanteric fractures: Zickel nail or nail-plate?

J. Bone Joint Surg. Br. 1986: 68: 255-259.

168. Zickel RE. A new fixation device for subtrochanteric fractures of the femur: a preliminary report.

Clin. Orthop. 1967: 54: 115-123.

169. Schatzker J. and Waddell JP. Subtrochanteric fractures of the fernur. Orthop. Clin. North Am. 1980: 11 : $539-554$.
170. Templeton TS, and Saunders EA. A review of fractures in the proximal femur treated with the Zickel nail. Clin. Orthop. 1979; 213-216.

171. Zickel RE. An intramedullary fixation device for the proximal part of the femur: J. Bone Joint Surg. Am. 1976; 58: 866-872.

172. Bergman GD, Winquist RA, Mayo KA. and Hansen ST. Subtrochanteric fracture of the fernur. Fixation using the Zickel nail (published erratum appears in J. Bone Joint Surg. Am. 1988; 70: 152). J. Bone Joint Surg Am. 1987; 69: 1032-1040

173. Brien WW. Wiss DA. Becker V, and Lehman T. Subtrochanteric femur fractu. res: a comparison of the Zickel nail, 95 degrees blade plate, and interlocking nail. J. Orthop. Trauma. 1991: 5: 458-464.

174. Reynders PA. Stuyck J. Rogers RK, and Broos PL. Subtrochanteric fractures of the femur treated with the Zickel nail. Injury. 1993: 24: 93-96.

175. Yelton C. and Low W. latrogenic subtrochanteric fracture: a complication of Zickel nails. J. Bone Joint Surg. Am. 1986: 68: $1237-1240$.

176. Ovadia DN. and Chess JL. Intraoperative and postoperative subtrochanteric fracture of the femur associated with removal of the Zickel nail. J. Bone Joint Surg Am. 1988: 70: 239-243. 
177. Taylor JC, LaVelle DG, and Walker BJ.

Long bone fracture management at the

Cambell Clinic: Experience gained from 1700 fractures treated with the R-T

Interlocking Nail System.

Cambell Clinic. 1991: 1-17.

178. Ostermann PA, and Henry SL. Die

Behandlung ipsilateraler Femurshaft- und

Schenkelhalsfracturen mit dem Russell-

Taylor Rekonstructionnagel.

Chirurg. 1994: 65: 1042-1045.

179. Gibbons CL. Gregg Smith SJ. Carrell TW. Murray DW, and Simpson AH.

Use of the Russell-Taylor reconstruction nail in femoral shaft fractures.

Injury. 1995: 26: 389-392.

180. Townsend PW, Smalley SR, Cozad SC.

Rosenthal HG, and Hassanein RE. Role of postoperative radiation therapy after stabilization of fractures caused by metastatic disease. Int. J. Radiation Oncology Biol. Phys. 1995: 31: 43-49.

181. Randelli P. Landi S. Fanton F, Hoover GK. and Morandi M. Treatment of ipsilateral femoral neck and shaft fractures with the Russell-Taylor reconstructive nail.

Orthopedics. 1999: 22: 673-676.

182. Wit RJ de. Stapert JWJL, and Vierhout PAM. De verlengde Gamma-'nail: onderzoek naar het behandelingsresultaat. Ned. Tijdschr. Geneeskd. 1991: 135: 2386
183. Stapert JWJL. Geesing CLM. Jacobs PB. Wit RJ de, and Vierhout PAM.

First experience and complications with the long Gamma nail.

J. Trauma. 1993: 34: 394-400.

184. Broos PL. Reynders P, and Vanderspeeten K. Mechanical complications associated with the use of the unreamed $A O$ femoral intramedullary nail with spiral blade: first experiences with thirty-five consecutive cases.

J. Orthop. Trauma. 1998: 12: 186-189.

185. Sochart DH. Bamford DJ, and Paul AS. Failure of the spiral blade module of the AO unreamed femoral nail.

Arch. Orthop. Trauma. Surg. 1998: 117 : 415-417.

186. Syed AA, Kennedy JG. Mullet $H$. O'Flanagan J. and Taylor D. Fatigue failure of an $\mathrm{AO}$ spiral blade. Arch. Orthop. Trauma Surg. 2000; 120 : 366-368.

187. Hoffmann R. Sudkamp NP. Muller CA. Schutz M, and Haas NP. Osteosynthesis of proximal femoral fractures with the modular interlocking system of unreamed AO femoral intramedullary nail. Initial clinical results Unfallchirurg. 1994: 97: 568-574.

188. Boriani S, Bettelli G. Zmerly H. Specchia L. Bungaro P. Montanari G et al. Results of the multicentric Italian experience on the Gamma nail: a report on 648 cases. (published erratum appears in Orthopedics 1992: 15: 545)

Orthopedics. 1991: 14: 1307-1314. 
189. Halder SC. The Gamma nail for peritrochanteric fractures.

1. Bone Joint Surg. Br. 1992: $74: 340-344$.

190. Guyer P, Landolt M, Keller H, and Eberle C Der Gamma-Nagel bei per- und intertrochantaren Femurfrakturen-Alternative oder Erganzung zur DHS? Eine prospektive randomisierte Studie anhand von 100 Patienten mit per- und intertrochantaren Femurfrakturen an der Chirurgischen Klinik des Stadtspitals Triemli. Zurich. September 1989-Juni 1990.

Aktuelle. Traumatol. 1991: 21: 242-249.

191. King DH. and Seligson D.

The intramedullary hip screw.

Contemp. Orthop. 1993: 26: 265-269.

192. Rantanen J, and Aro H. Mechanical failure of the intramedullary hip screw in a subtrochanteric femoral fracture. J. Orthop. Trauma. 1996; 10: 348-350.

193. Hardy DC. Descamps Py, Krallis P, Fabeck L. Smets P. Bertens CL et al. Use of an intra. medullary hip-screw compared with a compression hip-screw with a plate for intertrochanteric femoral fractures. A prospective, randomized study of one hundred patients.

J. Bone Joint Surg. Am. 1998: 80: 618-630
194. Ridder VA de, and Lange S, de. Use of an intramedullary hip-screw compared with a compression hip-screw with a plate for intertrochanteric femoral fractures.

A prospective, randomized study of one hundred patients.

J. Bone Joint Surg. Am. 1999; 81:

$1502-1503$.

195. Simmermacher RK, Bosch AM, and Werken $C$ van der. The AOIASIf-proximal femoral nail (PFN): a new device for the treatment of unstable proximal femoral fractures.

Injury. 1999: 30: 327-332. 
The long Gamma nail 


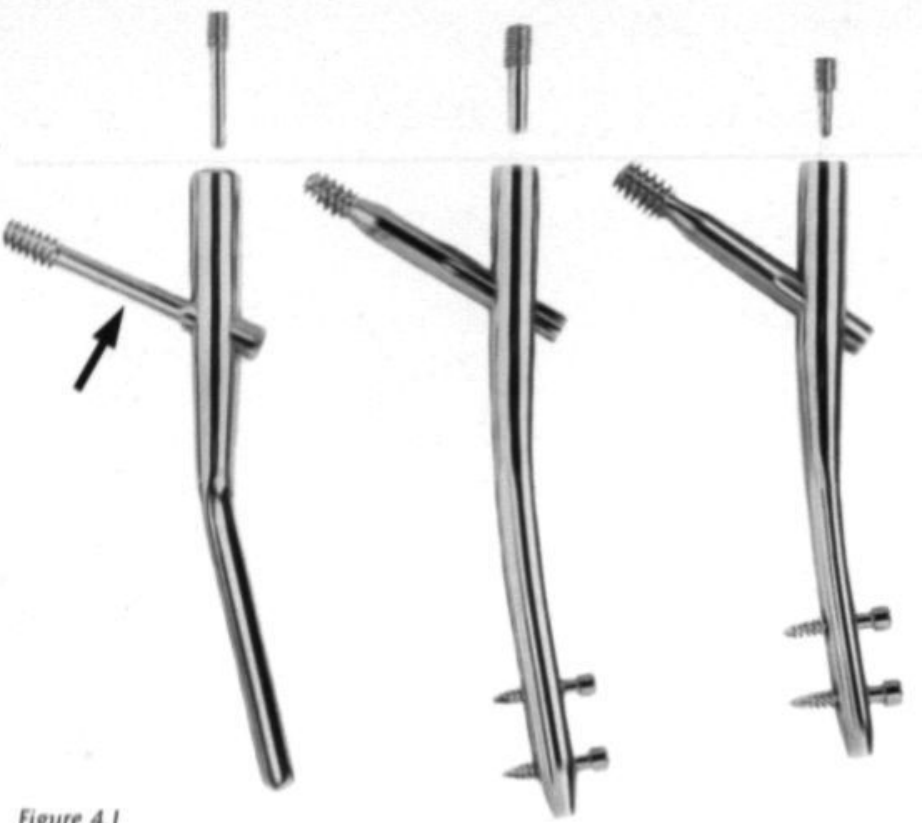

The purpose of this chapter is to familiarise the reader with the long Gamma nail. First. we describe the development of the nail. Then, we give a technical description of the present version. Lastly. we describe the insertion technique, with all kinds of tricks and pitfalls.

\section{Development}

The standard Gamma nail has been available commercially since 1988 . It is a further development of the Küntscher-y nail, and the Zickel nail \{figure 3.6\} (page 29). The first model

The prototype of the Camma nail from Halifax infirmary. called the Mark 1.2.3 version. The difference between the nails are the diameter and length of the shrank (arrow). the Latero-Medial angle, and the possibility of distal locking.

Figure 4.2

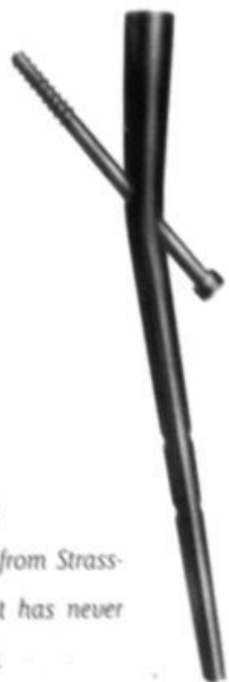

of the Küntscher-y nail resemble the Gamma nail most.

The Gamma nail was developed in two clinics. Halder and Gill in Halifax, UK. started their development after they encountered problems with the Zickel nail. They made their prototype after wax studies of eight cadaveric femora \{figure 4.I\}. Hundreds of this 'Mark-I' version of the Halifax nail were tested. The "Mark-I' has an abrupt LM angle, it cannot be locked distally. and the shank of the lag screw is small \{see arrow in figure 4.I\}. Problems with fractures of the greater trochanter. rotational instability, and disengagement of the shoulder of the lag screw led to the Mark-2 version. This nail is $22 \mathrm{~cm}$ long with a reduced LM curve, the shank is extended towards the thread, and two distal locking bolts can be inserted (table 4.1). This second version was used in 19 pilot studies in hospitals throughout Europe.

During the same period. Grosse and Taglang assisted by Kempf in Strassbourg. France, developed a similar concept based on the Küntscher-y nail. A prototype. which was never used, was made in 1980 \{figure 4.2\}. It is a conical shaped nail with a sharp LM angle. A cervical lag screw is placed in the LM angle with a CCD angle of $135^{\circ}$. In 1983 the dimensions were developed after studies of 80 European femora (table 4.1).' In 1986 the first nails were inserted in 40 patients.

Howmedica brought both concepts after these studies together, and changed the name in 'Gamma nail'. It became a nail of $20 \mathrm{~cm}$ with three distal diameters (12. 14. and $16 \mathrm{~mm}$ ) (table 4.1). The first Gamma nails were commercial available in October 1988 \{figure 4.3\}. In The Netherlands the implant rapidly became popular and surgeons in Germany. France, and Belgium followed. The introduction in the Anglo-Saxon countries was far more difficult and they had bad results because of a lack of training in the technique of insertion. ${ }^{2}$

The technical staff of the AIOD (Association Internationale pour 
IOstéosynthèse Dynamique) in Strassbourg developed the Gamma nail system further, using feedback from regular users. To enable the proximal diameter to be reduced the nails were made of Orthinox ${ }^{\circ}$, because this alloy is $15 \%$ stronger than stainless steel. In October 1993 a new target device made of radiolucent carbon fibre was introduced. The instruments were made more ergonomic: the $140^{\circ}$ nails and the $16 \mathrm{~mm}$ nails were abandoned: the LM angle was more gradually shaped. the tip of the nail was more rounded; and a nail of $11 \mathrm{~mm}$ and lag screws of 85,95 , and 105 $\mathrm{mm}$ were added (table 4.1) \{figure 4.3\}.

In 1997 a trochanteric Gamma nail was introdu-
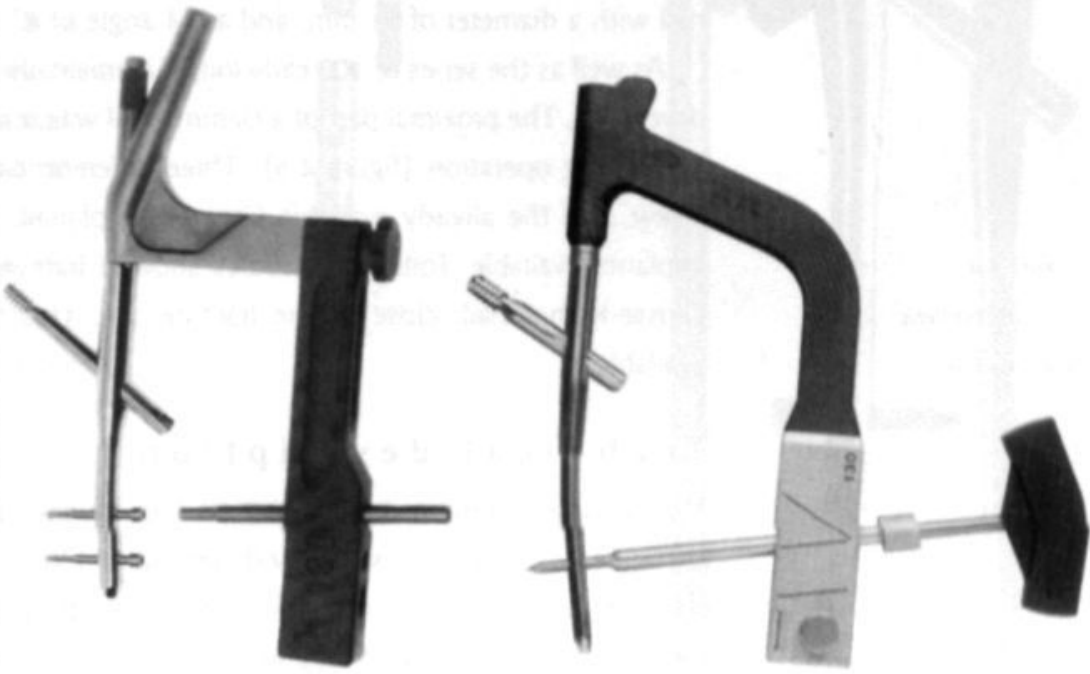
ced \{figure 4.4\}. This was a round Gamma nail $18 \mathrm{~cm}$ long. with a diameter of $11 \mathrm{~mm}$, an LM angle of $4^{\circ}$, and one distal bolt (table 4.1). This nail was specially designed for trochanteric fractures with minimal comminution.

The stimulus for the development of the long Gamma nail in 1989 in The Netherlands was for the treatment of a patient with a pathological fracture of the femur. The fracture was initially stabilised with a standard Gamma nail, but the

\begin{tabular}{|c|c|c|c|c|c|c|}
\hline & Strasbourg & Halifax & $\begin{array}{l}\text { First } \\
\text { Camma nail }\end{array}$ & $\begin{array}{l}\text { Today } \\
\text { Camma nail }\end{array}$ & $\begin{array}{l}\text { Long } \\
\text { Camma nail }\end{array}$ & $\begin{array}{l}\text { Trochanteric } \\
\text { Camma nail }\end{array}$ \\
\hline Material & Stainless steel & Stainless steel & Stainless steel & Orthinox & Orthinox & Orthinox \\
\hline Length & 180 & 220 & 200 & 200 & $\begin{array}{l}320.340,360 . \\
380.400 .420 .440\end{array}$ & 180 \\
\hline ø Proximal & 19 & 17.5 & 17 & 17 & 17 & 17 \\
\hline$\emptyset$ Distal & 12.14 .16 & 12.13 .14 .15 .16 & $12,14.16$ & 11.12 .14 & 11 & 11 \\
\hline Shape & Round & Cloverleaf & Cloverleaf & Cloverleaf & Cloverleaf & Round \\
\hline$C C D$ angle & $125,130,135.140$ & & $125.130,135.140$ & 125.130 .135 & $125,130,135$ & $125,130,135$ \\
\hline LM angle & 3.5 & 10.5 & 10 & 10 & 4 & 4 \\
\hline Antecurvation & No & No & No & No & Yes & No \\
\hline 6 Lag screw & 12.0 & 12.0 & 12.0 & 12.0 & 120 & 120 \\
\hline Length lag screw & $\begin{array}{l}80,90,100 . \\
110,120,130\end{array}$ & & $\begin{array}{l}80,90,100 . \\
110,120,130\end{array}$ & $\begin{array}{l}85.90,95,100 . \\
105.110,120\end{array}$ & $\begin{array}{l}85.90,95,100 . \\
105.110,120\end{array}$ & $\begin{array}{l}85,90,95,100 \\
105,110,120\end{array}$ \\
\hline 0 Distal bolt & 6.0 (CK nail) & 6.0 (full thread) & 6.0 (full thread) & 6.28 (full thread) & 6.28 (full thread) & 6.28 (full thread) \\
\hline $\begin{array}{l}\text { Distance bolt-tip } \\
\text { of nail }\end{array}$ & $19.7 / 44.7$ & & $20 / 40$ & $20 / 40$ & $20 / 40$ & 20 \\
\hline
\end{tabular}


bone fractured distally. The proximal part of a stainless steel 'Mark II' Gamma nail was welded on to a Grosse-Kempf nail. One hundred custom-made long Gamma nails. 32 and $36 \mathrm{~cm}$ long and $12 \mathrm{~mm}$ in diameter with an LM angle of $11^{\circ}$ were used in The Netherlands. ${ }^{3}$ Results with this version resulted in the definitive long Gamma nail with a diameter of $11 \mathrm{~mm}$, and a $\mathrm{LM}$ angle of $4^{\circ}$ (table 4.I) \{figure 4.5\}.

As well as the series of 100 early long Gamma nails a reconstruction model was developed. The proximal part of a Gamma nail was screwed on to a Grosse-Kempf nail during operation \{figure 4.5\}. Three different 'Gamma nail' head parts, the screw, and the already available Grosse-Kempf nail, made a complete range of

\section{Figure 4.4}

The Trochanteric Gamma nail. implants available. Follow up studies showed fractures through the hole of the Grosse-Kempf nail, close to the fracture site. This device is not commercially available.

\section{Technical description}

The long Gamma nail is an unslotted, cannulated nail with a clover leaf profile \{figure 4.5 \}. The nail is $340,360,380,400,420$, or $440 \mathrm{~mm}$ long. The diameter of the nail is $17 \mathrm{~mm}$ proximally, and $11 \mathrm{~mm}$ distally. The anterior curvature has a diameter of $300 \mathrm{~cm}$, and an anteversion of the lag screw seen from the locking bolt of $10^{\circ}$. This means that there are different nails for the left and right femur. The $\mathrm{LM}$ angle is $4^{\circ}$. The CCD angle is $125^{\circ}, 130^{\circ}$, or $135^{\circ}$. The most distal hole is $20 \mathrm{~mm}$ from the rounded tip of the nail. The lag screw has a diameter of $12 \mathrm{~mm}$ and is available in lengths of $85,90,95,100,105,110$, and $120 \mathrm{~mm}$. The thread is $20 \mathrm{~mm}$ long. The outer diameter of the thread is the same as the shank of the screw. The lag screw has grooves in which the set screw grips to prevent rotation. Above this set screw a proximal tissue cap is available. For extraction of the nail only the proximal tissue cap has to be removed, the set screw needs only to be loosened. Distal locking is done freehand. The distal locking bolts are fully thread and have a core diameter of $5.5 \mathrm{~mm}$ and an outer diameter of $6.28 \mathrm{~mm}$.

\section{Insertion technique}

First of all it is necessary to ensure that the correct indications for using a long Gamma nail are present. These are an extensive fracture in the proximal femur, a combined femoral neck and shaft fracture, an (impending) pathological fracture. or a salvation technique for failed previous treatment. The long Gamma nail fits nearly all femora, but congenital malformations or a grossly deformed femur resulting from an old fracture make insertion of the nail impossible. Custom made nails can be ordered to overcome these problems. The template for the measurement of the CCD angle is not necessary, and does not work well because the radiographs are not taken in a precise anteroposterior direction, and differ in rotation. Because of this rotation, the measured angle differs from the actual angle. Most of the time a $125^{\circ}$ angle nail can be used. In a varus hip the lag screw will fit, and in a val- 
gus hip the nail need not be driven far inside the femur to allow the lag screw to take its proper position in the head. A disadvantage of the $125^{\circ}$ device is a reduction in gliding capacity of the lag screw in the Gamma nail. The $135^{\circ}$ angle device is somewhat more difficult because it has tendency to end high in the femoral head with more chance of cut out, particularly in a varus hip. The lever arm forces result in a better impaction of the proximal site. The use of only one type of CCD angle in a clinic has the advantage that if a long Gamma nail is used for complications of a standard Gamma nail the lag screw can follow the same channel with less excavation of the femoral head, and stock-management is easier.

Antibiotics are given preoperatively to reduce the chance of infection. ${ }^{47}$

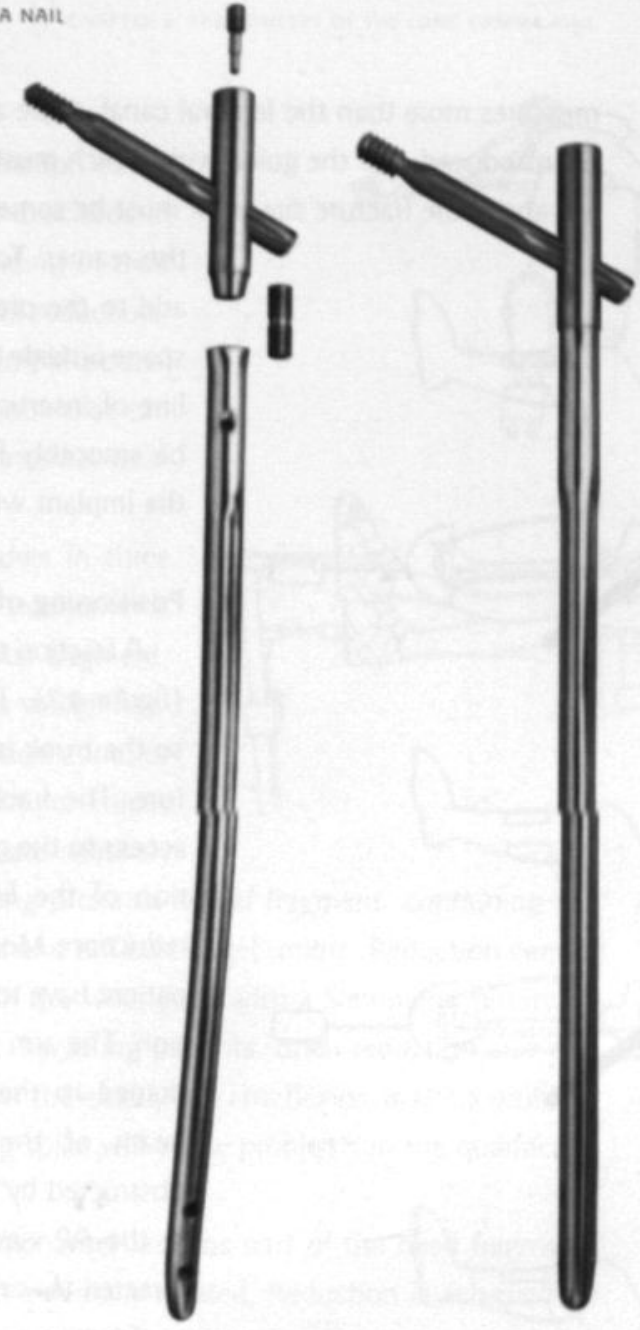

Checks are made that the material needed is available, including the correct nails, three complete introduction sets, and an adequate reamer set.

The aim of the operation is to bring the femoral head to a correct anatomical relation with the femoral condyles, with particular attention to rotation and length. The operation has a non-sterile and a sterile part. In the non-sterile part. the patient is positioned on the table and the fracture reduced under radiographic control. After disinfection and draping, the sterile part begins. The bone is exposed, the guide wire inserted, the femoral canal reamed, the nail inserted, the lag screw and set screw placed, and distal bolts inserted.

To understand the steps in the insertion of all kinds of intramedullary implants. the term 'line of insertion' is introduced \{figure 4.6\}. The line of insertion is the imaginary line from the expected tip of the nail in the femoral canal, through the intramedullary part, the insertion into the bone, the skin incision, and the guide wire, with extension to at least twice the longest part that has to be inserted. To explain this length: the longest part inserted is the reamer with the drill itself. This

Figure 4.5

The reconstruction model is shown on the left. To show the proximal hole in the Grosse. Kemph nail. this part of the most left picture is rotated. The right side schous the definitive version of the long Camma nail. 
measures more than the femoral canal, to be able to reach the condyles. It has to be introduced over the guide wire, which must be controlled to prevent it slipping out above the fracture site, so it must be somewhat longer outside the femur than
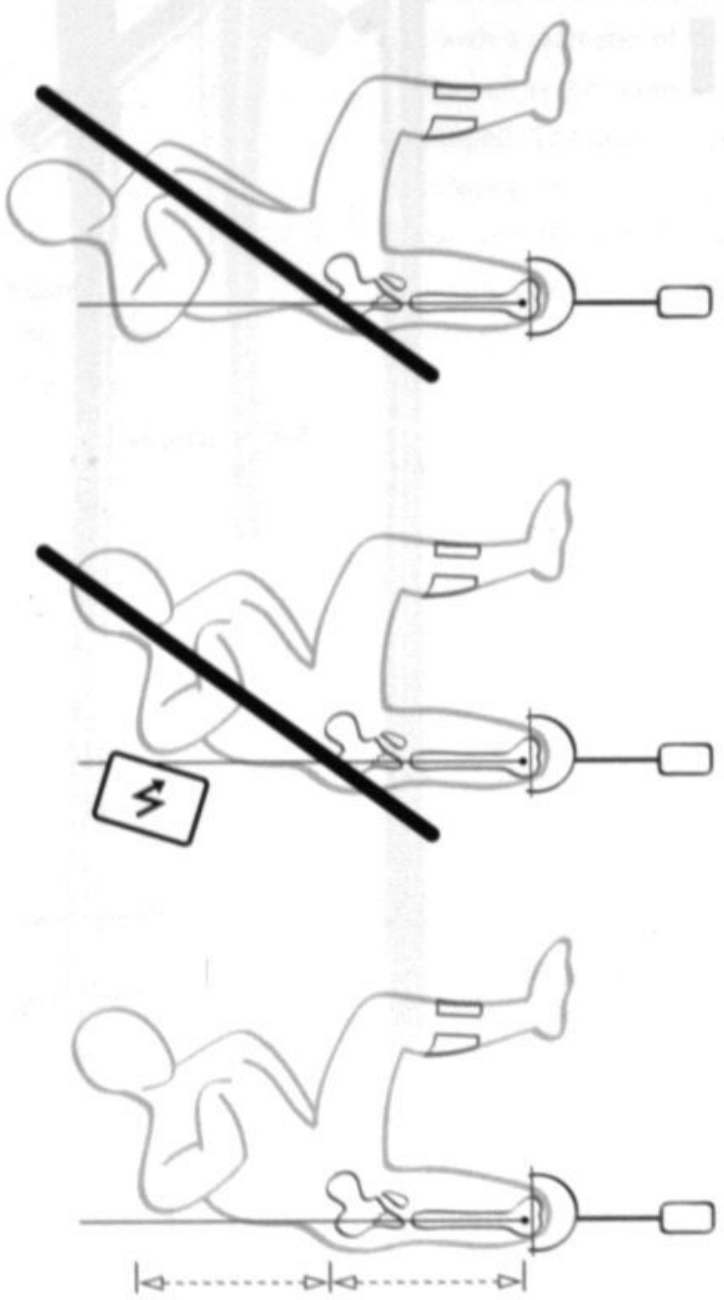

the reamer. To get the reamer from the wire will add to the previous distance. At least $150 \mathrm{~cm}$ of space outside the trochanter is needed. The whole line of insertion, in and outside the body. has to be smoothly formed and cleared, so as to insert the implant without compromising sterility.

\section{Positioning of the patient}

A traction table is used with the patient supine \{figure 4.7\}. The line of insertion has to be free. so the trunk is bent to the side opposite the fracture. The fractured limb is adducted, to facilitate access to the greater trochanter. Too much adduction of the limb can however compromise the reduction. Medical equipment and the arm of the patient have to be 'removed' from the line of insertion. The arm can be laid on the patient's belly or draped to the bar placed above the trunk. The beam of the image intensifier must not be obstructed by metal parts of the table. To facilitate the AP view the T-bars of the feet-holder are directed towards the fractured side.

Traction on the injured limb is applied though the foot in a padded holder, or exceptionally by a supracondylar or tibial extension wire. A padded perineal post serves for counter-traction.

The unaffected limb is placed in a 'heel-to-toe' position, with a maximal ventral-posterior distan-

Figure 4.6

The line of insertion as seen from above the patient. This line has to be freed from obstruction. The line runs smoothly from the expected tip of the nail. through the place of insertion. and is approximately $2 \%$ times the desired length of the nail. ce to facilitate axial imaging. During the introduction of the nail and the lag screw. the healthy limb is abducted as much as possible to allow positioning of the image intensifier between the limbs, and obtain a good axial view of the femoral neck. During distal locking. the feet are brought as close together as possible in the anteroposterior direction but with a maximal difference in height to obtain optimal lateral view of the distal femur.

Another method is to place the unaffected limb in a gynaecological leg holder. Abduction of the affected limb gives room for distal locking. Some surgeons position and drape afresh for distal locking. 


\section{Reduction of the fracture}

Muscle insertion and muscle function cause the typical fracture deformity, as we described in chapter 2 and figure 2.9. Understanding of their mechanism is the basis for successful reduction.

A lateral femoral neck and a simple pertrochanteric fracture are like an open book that can be closed by traction and limited internal rotation. ${ }^{8}$

We divide subtrochanteric fractures in three types. In a type I fracture, the lesser trochanter is separated from the proximal and distal fragment. The lesser trochanter can be part of a wedge fracture, imbedded in a gross comminution zone, or the middle part in a two-stage fracture. Forces resulting from muscle attachments are relatively easy to overcome by traction. A long proximal lateral fragment, containing the greater trochanter, can be anteflexed and difficult to get in line. Reduction can be achieved with a Homann retractor in the wound. or with a Steinmann pin inserted percutaneously in the fragment. In young patients, open reduction and cerclage wiring should be considered. In the elderly the anteflexion is not a problem for mobility, but sometimes the long spike will cause problems in the quadriceps muscle.

In a type II fracture, the lesser trochanter remains part of the head fragment. The proximal fragment is flexed and externally rotated. Reduction is achieved by traction and external rotation of the limb. If closed reduction is not successful, the proximal part can be handled with a partly inserted nail or a Steinmann pin into the femoral neck.

In type III fractures the lesser trochanter is attached to the distal fragment and the proximal fragment can have a long lateral spike. This is the least common type. The distal fragment is externally rotated. shortened. and falls away as a result of gravity. Reduction is attempted by traction and internal rotation, but this is often hard to achieve. Partial insertion of the nail or a Steinmann pin from the lateral side is difficult if the proximal fragment is small. Extra mounted pieces on the traction table, or a big F-clamp from the medial side, can support the distal fragment that falls away by gravity."

The lesser trochanter is an important landmark during the use of the image intensifier. In the axial view the lesser trochanter marks the dorsum of the femur. In the frontal plane, the shape of the lesser trochanter indicates the rotation of the femur \{figure 4.8$\}$.

Traction of the limb has to be moderate to prevent neurapraxia. ${ }^{10.13}$ All con- 


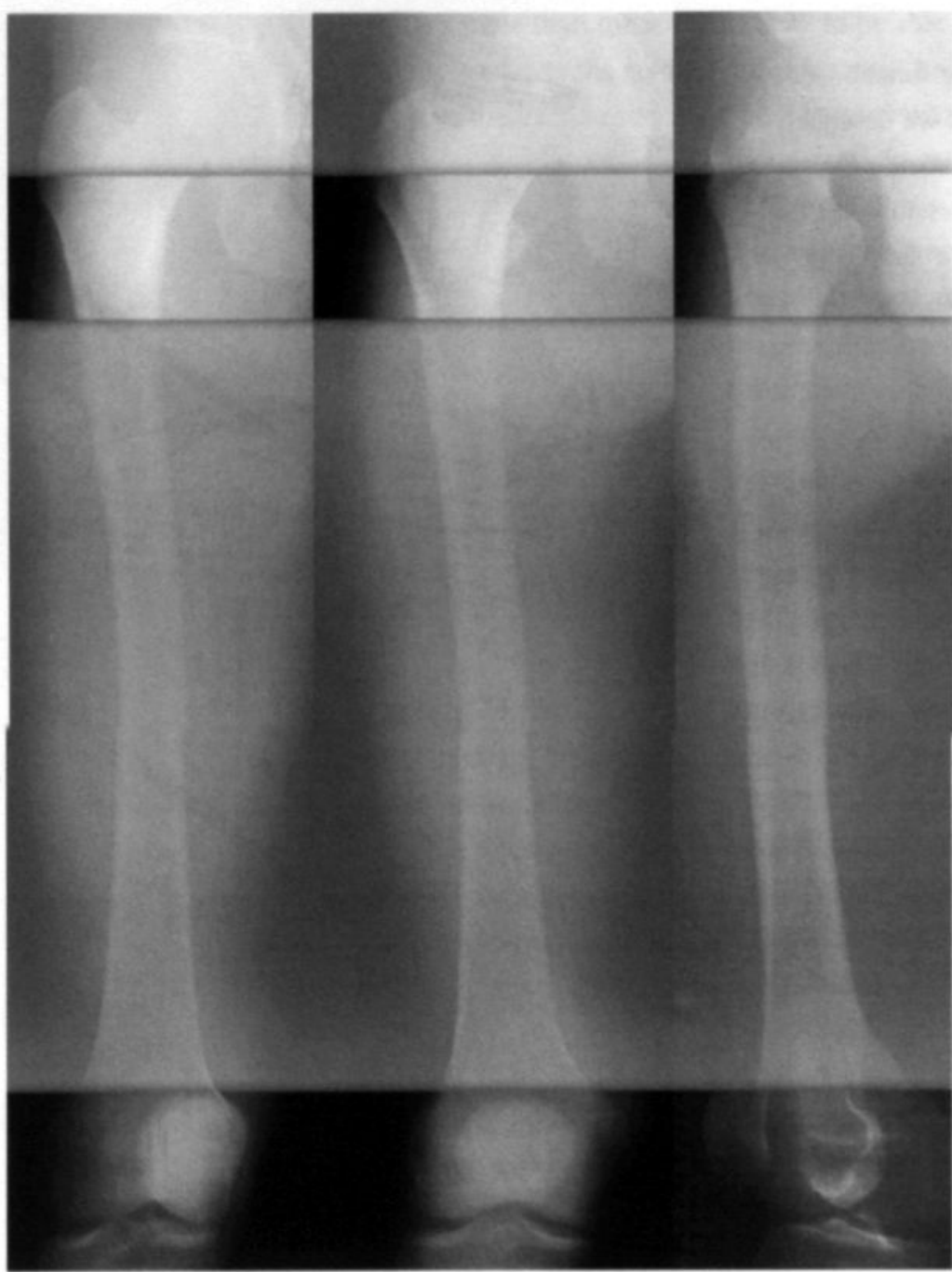

nections of the traction table must be checked before the patient is prepared and draped. Most surgeons use an isolation transparent drape. but regular draping can also be used.

\section{Entry point}

The line of insertion determines the skin incision and entry point in the trochanter. The skin incision is made 3 $4 \mathrm{~cm}$ proximal to the trochanter, in obese people even higher. After splitting the aponeurosis of the fascia lata, the fibres of the gluteus muscle are split to reach the greater trochanter. With growing experience. the entry point on the trochanter can be found with fluoroscopy. and the incision made much smaller \{figure 4.9\}.

The entry point for the insertion of the long Gamma nail is at the tip of the greater

Figure 4.8

The lesser trochanter is a land. mark for the position of the proximal femur. Internal rotation. neutral and external rota. tion position trochanter. The cortex is perforated with an awl under fluoroscopic control. The rectangular funnel awl consists of two parts. The assembled device is introduced into the trochanter along the line of insertion. The obturator is removed. and the guide wire inserted through the funnel into the femoral canal. A curved awl can also be used but the insertion of the guide wire is more difficult. If the skin incision is wide enough the finger can be placed under the awl at the entry point. and after removal of the awl the guide wire can be guided with the finger into the trochanter.

\section{Guide wire}

The guide wire has a rounded tip \{figure 4.10$\}$. If the reamer breaks, the distal part remains on the guide wire and can be removed without opening the femoral canal. Secondly the drill bit can not advance beyond the wire and dislodge. The 
guide wire has to be bent to facilitate manipulation. The last $10 \mathrm{~cm}$ is bowed with a gradual bow of $20^{\circ}$. With this tip the fracture parts can be palpated and manipulated. This gradual-bend guide wire, in contrast to a sharp-bowed tip. can be extracted through the nail without changing it to a non-tipped guide wire.

\section{Reaming}

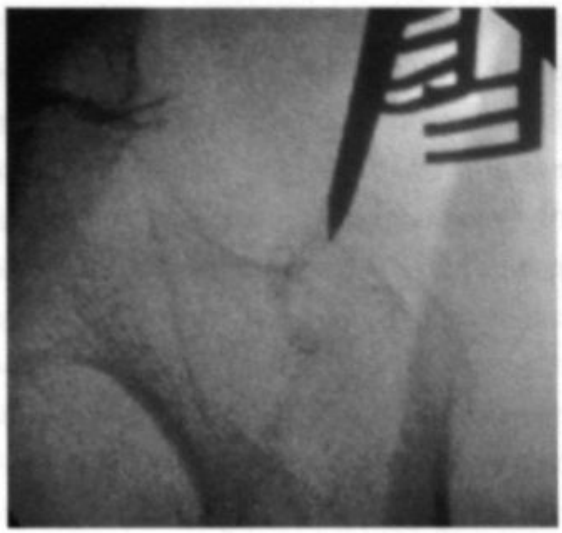

Reaming starts when the guide wire has passed the fracture site, and reduction is adequate. If further reduction is necessary the tricks described in the reduction part have to be used. An adequate entrance into the bone is created with a sharp reamer before the blunt reamers are used. It is no problem when the fracture line through the trochanter equals the line of insertion. Flexible reamers are used, started at $9 \mathrm{~mm}$ diameter and increasing in $0.5 \mathrm{~mm}$ increments. Reaming has to be with a high drill speed and only slight progression of the drill bit down the shaft to prevent heating and dislodging the fracture. The entire isthmus of the medullary canal has to be reamed to avoid stress risers at the junction of reamed and non-reamed bone. Over reaming of $2 \mathrm{~mm}$ is necessary to make smooth insertion of the nail by hand possible. The long Gamma nail is $11 \mathrm{~mm}$ in diameter, which means that the reamer must be $13 \mathrm{~mm}$. Proximally the broad part of the nail must be reamed to at least $17 \mathrm{~mm}$. Different kinds of reamers are available. The main point is to use sharp reamers. which evacuate the bone marrow easily. It is important to let the reamer ream and not to progress too fast. ${ }^{1416}$

The reamer must never be turned in reverse. which causes the twisting spring inside to break. Intramedullary pressure rises most when the guide wire and the first and last reamers go down the femoral canal.

\section{Insertion of the nail}

The length of nail that is needed is measured. This can be done with a second guide wire of the same length. The tip of the inserted guide wire is placed in the same position as is desired later for the tip of the nail. The second wire is placed along the protruding part of the first wire, with its tip at the trochanter. The difference in length between the two wires is the desired nail length [figure $4.11\}$.

It is not necessary when using the long Gamma nail to change
Figure 4.9

The entry point with the rec tangular funnel awl and with the curved awl.

\section{Figure 4.10}

The bended guide wire can be used for palpating and tack the fracture elements. This distal bowed tip can sometimes stuck in the long Camma nail, it is better to make a longer. more gradual bow.
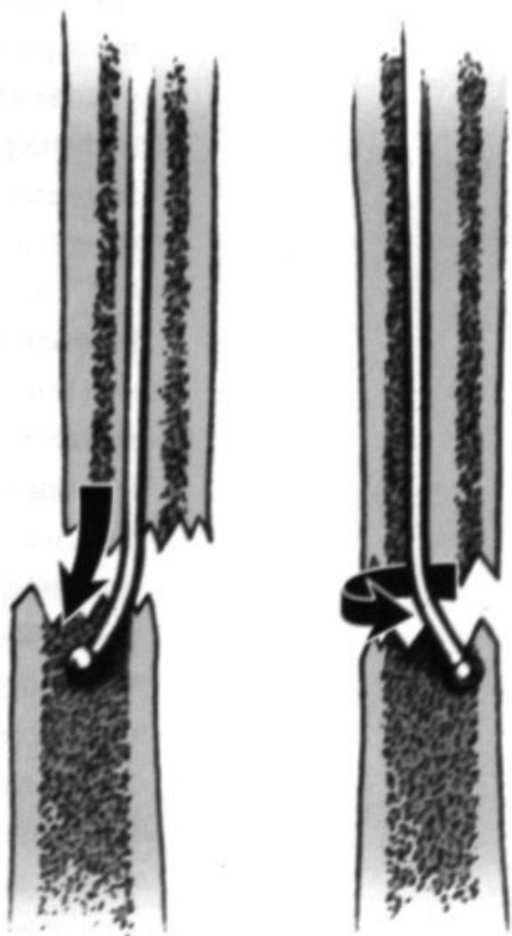


\section{Figure 4.11}

The difference between the two guide wires is the desired length of the long Camma nail. the tipped guide wire for a straight wire if the tip is not angled too sharply.

The nail is mounted on the carbon fibre targeting device. The surgeon must be aware that left and right nails are different and must check proper mounting. Is the correctly angled nail mounted? Do the drill holes match the hole for the lag screw and distal bolts in the nail? Is the assembly tight enough? The nail is inserted by hand. If the nail does not pass easily down the femoral canal one millimetre more must be reamed. The surgeon must always keep in mind that the long Gamma nail is rigid and can perforate the cortex. Light hammering on the nail is allowed only when the last centimetres are difficult to overcome because of the resistance of the entire nail. The nail may not be hammered if it has not passed the isthmus of the femoral canal.

The depth of insertion depends on the expected position of the lag screw, corresponding with the crescent shapes incavation in the nail on the fluoroscopy

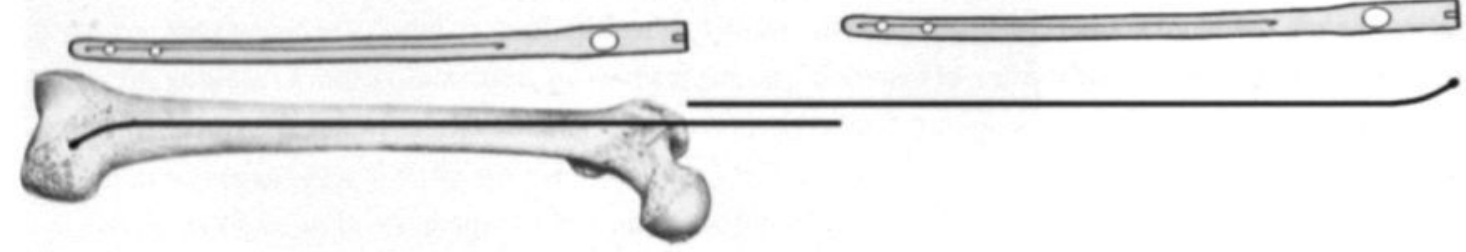

screen. A line is drawn from the opening in the nail, representing the under surface or upper surface of the lag screw. Extension of the line shows the position of the lag screw in the femoral head in an anteroposterior position. To check the position of the nail in the axial view one K-wire is placed in one of the two holes in the target device to ensure the correct anteversion in the axial image. When anteversion is not correct, the nail has to be partially removed, rotated, and reinserted.

\section{Insertion of the lag screw}

If the nail is in the correct position the lag screw is inserted. The optimal position of the lag screw is still controversial. Some suggest that it should be through the middle of the femoral neck into the middle of the femoral head. others prefer the screw to be positioned over the calcar and end in the lower dorsal part of the femoral head. In our opinion, the optimal position of the lag screw is over the calcar and with the tip of the screw in the lower dorsal fragment of the femoral head. The tip of the screw should be in the subchondral bone. about $5 \mathrm{~mm}$ beneath the surface of the cortex, because that is the most solid part of the femoral head. ${ }^{1721}$

Removal of the guide wire from the nail. This has to be done with a firm pull, to allow the bent wire and the rounded tip to enter the nail. The target device with the nail has to be pushed firmly down the femur to prevent it from coming out when the wire is pulled out. It is important to take care that the jig is not rotated 
and that the carbon fibre target device is still adequately mounted on the nail. The targeting sleeve corresponding to the angle of the selected Gamma nail is now slid on to the end of the carbon targeting device. The jig is supported to prevent external rotation until the lag screw is inserted. The incision is marked with the handle of the blunt trocar. The skin and fascia lata are incised widely enough to prevent unwanted forces on the trocar. The trocar blunt sleeve is inserted and secured to the femur by fastening the thumb wheel on the targeting sleeve. The lateral cortex of the femur is opened widely with the large diameter awl to ensure that the self tapered $\mathrm{K}$-wire is not in touch with the cortical bone. If the K-wire has to penetrate the cortex itself the direction of the introduction may change and the reaming for the lag screw will become difficult or impossible. After the guide wire has been removed from the nail the self-tapered $\mathrm{K}$-wire is drilled into the femoral head and the direction checked frequently, particularly in the axial view. The nail has to be kept in place by pushing it down the femoral shaft, during drilling. to prevent the K-wire and drill from slipping over the cortex. If the K-wire is not correctly placed, the wire and the trocar have to be removed and inserted again. If the trocar is not reinserted, the K-wire will probably follow the previous channel, or bow. To prevent this the tapered $\mathrm{K}$-wire should be inserted slowly in 'reverse' mode, or hammered in without drilling. Drilling and screwing over a bowed $\mathrm{K}$-wire can lead to blocking, the use of too much force, and eventually breakage of the K-wire. If the K-wire still follows the previous bowed channel, and it is certain that the position is good after checks in two directions by image intensifier, one can drill over the wire until it sticks, then remove the K-wire, drill a bit further freehand, and place a new unbowed $\mathrm{K}$-wire through the drill into the right position. The K-wire should be placed in the subchondral bone to allow accurate measurement.

The manufacturers advise the use of a measuring gauge through the sleeve. The measured length is confusing because the gauge shows the length of the K-wire minus $10 \mathrm{~mm}$. This length has to be drilled. The correct length of the lag screw is at least $5 \mathrm{~mm}$ longer because the lag screw has to protrude $5 \mathrm{~mm}$ from the lateral cortex to maintain rotational stability and to permit sliding. Lengths can easy be measured with the marked drill, or by using another wire. In all three measurements, it is important to push the sleeve tightly on to the femur.

After the $\mathrm{K}$-wire has been inserted correctly the hole for the lag screw is prepared, with regular checks on the image intensifier to make sure that the K-wire has not dislocated and entered the pelvis or abdominal cavity during drilling or insertion the lag screw. The lag screw has a special design. The thread has the same diameter as the unthreaded part, and the core of the threaded part is therefore smaller than that of the unthreaded part. The "lag screw step drill' creates a hole with two sizes. The front has the diameter of the core and length of the threaded part, the distal part of the drill has the diameter of the unthreaded part 
of the lag screw. This allows full contact of the screw over the complete length, and stable anchorage at the threaded tip. In most other screws, the thread is superimposed on the core and insertion of the screw weakens the contact area with the unthreaded part of the screw. The drill has a lock to prevent the cortex of the femoral head being perforated, but repeated fluoroscopy is advised to ensure that this does not happen. When the $\mathrm{K}$-wire has bent too much and the drill does not pass easily, movements back and forth can be tried. If this does not succeed, the drill can be inserted without a K-wire when the sleeve stays in contact with the bone, or the wire can be replaced as indicated earlier.

A lag screw of the correct length is mounted on the lag screwdriver and inserted. The handle of the lag screwdriver has to end parallel or perpendicular to the targeting device so that the set screw will engage in one of the four lag screw grooves.

The set screw is inserted from the tip of the trochanter with the set screwdriver and socket wrench. This may be a little stiff because the threads of the nail are coated with nylon to prevent spontaneous loosening. When the set screw is tightened it should be impossible to rotate the lag screw. If this is verified the screw is unscrewed one quarter of a turn to ensure free gliding of the lag screw, and the inability to rotate the lag screw must be checked again. If the set screw is improperly placed the lag screw can migrate completely, which happened to one of our patients.

The proximal end can now be plugged to prevent ingrowth of tissue into the nail. 


\section{Distal locking}

Distal locking causes many problems. It is done by a freehand technique: some aiming devices were developed that do not need an image intensifier, but most surgeons still use the image intensifier. The screws are inserted from the lateral side. ar this side the distance of the image intensifier from the limb has to be maximal. The view on the monitor must be maximised and radiation minimised. The hole in the nail has to be circular on the projection, so a true perpendicular position of the image intensifier is necessary. If the hole looks elliptical, in either the vertical or the horizontal plane, the $\mathrm{C}$-arm of the image intensifier must be adjusted \{figure 4.12 \}.

We use a special conical targeting device. The position of the incision is located with the image intensifier and the skin and fascia are incised widely enough to prevent traction on the targeting device. The device is placed on the lateral cortex, so that the hole in the nail is in the centre of the circle. The targeting device is held firmly against the femur and tapped gently to engage with the cortex. The hole is started with a special centre drill to prevent slipping of the $5.5 \mathrm{~mm}$ drill from the round femur. In the introduction period of the Gamma nail a hammer with an awl were used to prevent slipping. but this resulted in a number of distal fractures. The use of the awl should be abandoned.

A radiolucent drill can be used instead. The drill bit is aimed at the centre of the hole in the nail in the wide ring of the radiolucent drill. Drilling must be at high speed and with little pressure to prevent slipping from the cortex.
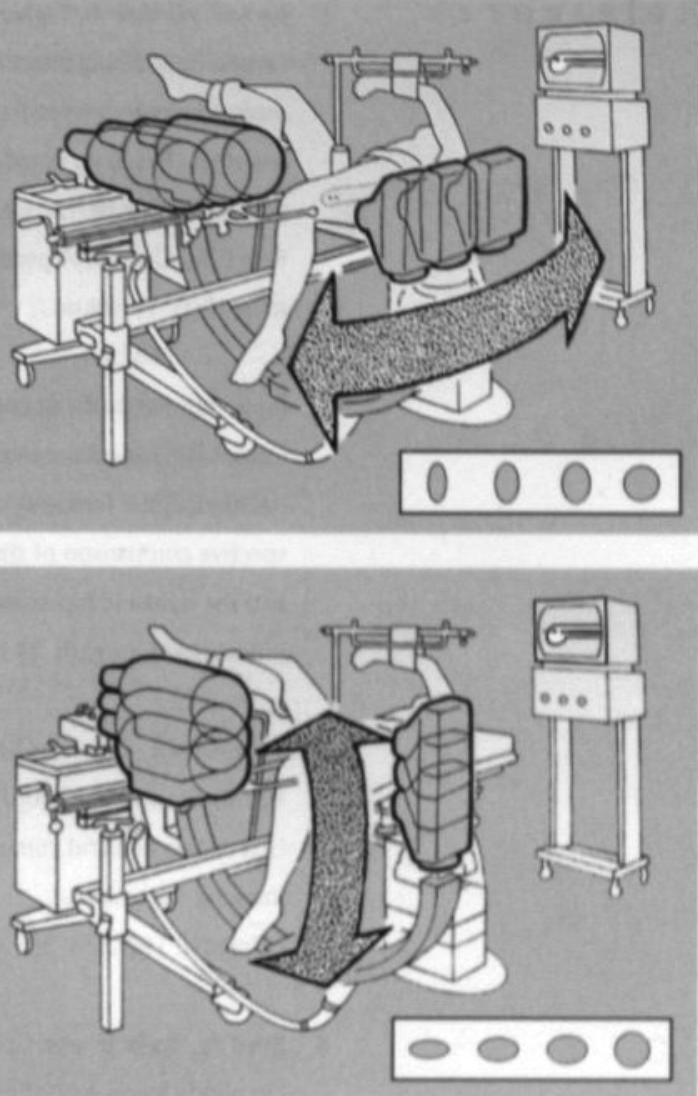

Figure 4.12

Distal locking aiming with the image intensifier. Upper is the horizontal, under is the vertical adjustment. The Carm of the image intensifier has to be moved untill a round hole has appeared. 
I. Kempf I. Grosse A. Taglang G, and Favreul E. Le clou gamma dans le traitement a foyer ferme des fractures trochanteriennes. Resultats et indications a propos d'une serie de 121 cas.

Rev. Chir. Orthop. Reparatrice. Appar. Mot. 1993: 79: 29-40.

2. Bridle SH, Patel AD, Bircher M, and Calvert PT. Fixation of intertrochanteric fractures of the femur. A randomised prospective comparison of the gamma nail and the dynamic hip screw.

J. Bone Joint Surg. Br. 1991: 73: 330-334.

3. Stapert JWJL. Geesing CLM. Jacobs PB. Wit RJ de, and Vierhout PAM.

First experience and complications with the long Gamma nail.

J. Trauma. 1993: 34: 394-400.

4. Boyd RJ. Burke JF, and Colton T. A double-blind clinical trial of prophylactic antibiotics in hip fractures. J. Bone Joint Surg. Am. 1973: 55: $1251-1258$.

5. Bodoky A. Neff U. Heberer M. and Harder F. Antibiotic prophylaxis with two doses of cephalosporin in patients managed with internal fixation for a fracture of the hip.

J. Bone Joint Surg. Am. 1993: 75: 61-65.

6. Burnett JW. Gustilo RB, Williams DN, and Kind $A C$

Prophylactic antibiotics in hip fractures.

A double-blind. prospective study.

J. Bone Joint Surg. Am.

1980: 62: 457-462.
7. Boxma H. Broekhuizen T. Patka P, and

Oosting $\mathrm{H}$. Randomised controlled trial of single-dose antibiotic prophylaxis in surgical treatment of closed fractures: the Dutch Trauma Trial.

Lancet. 1996; 347: 1133-1137.

8. Bannister GC, Gibson AG. Ackroyd CE. and Newman JH. The closed reduction of trochanteric fractures.

J. Bone Joint Surg. Br. 1990: 72: 317

9. Shewring DJ. Doig SG, and Carvell JE. Use of an F-clamp for fracture reduction during closed intramedullary nailing of the femur. Injury. 1991: 22: 146-147.

10. Britton JM. and Dunkerley DR. Closed nailing of a femoral fracture followed by sciatic nerve palsy.

J. Bone Joint Surg. Br. 1990; 72: 318

II. Tait GR, and Danton M. Contralateral sciatic nerve palsy following femoral nailing.

J. Bone Joint Surg. Br. 1991: 73: 689-690.

12. Brumback RJ. Ellison TS, Molligan $\mathrm{H}$. Molligan DJ. Mahaffey S, and Schmidhauser C. Pudendal nerve palsy complicating intramedullary nailing of the femur.

J. Bone Joint Surg. Am. 1992: 74: 1450-1455

13. France MP, and Auron BF. Pundendal nerve palsy following fracture table distraction

Clin. Orthop. 1996: 276: 272-276 
14. Müller C. Mclff T. Rahn BA. Pfister U. and Weller S. Intramedullary pressure, strain on the diaphysis and increase in cortical temperature when reaming the femoral medullary cavity. A comparison of blunt and sharp reamers.

Injury. 1993: 24 Suppl 3: 22-30.

15. Müller $C$. Rahn BA, Pfister $U$, and Weller S. Extent of bluntness and damage to reamers from hospitals.

Injury. 1993: 24 Suppl 3: 31-5.

16. Müller $C$, Frigg $R$, and Pfister $U$. Effect of flexibel drive diameter and reamer design on the increase of pressure in the medullary cavity during reaming. Injury. 1993: 24: 40-47.

17. Hartog BD den. Bartal E, and Cooke F. Treatment of the unstable intertrochanteric fracture. Effect of the placement of the screw, its angle of insertion, and osteotomy.

J. Bone Joint Surg. Am.

1991: 73: 726-733.

18. Parker MJ. Cutting-out of the dynamic hip screw related to its position.

J. Bone Joint Surg. Br. 1992: 74:625.

19. Kyle RF. Wright TM, and Burstein AH. Biomechanical analysis of the sliding characteristics of compression hip screws. J. Bone Joint Surg. Am.

1980: 62: 1308-1314.
20. Yoshimini F. Latta L. and Milne EL. Sliding characteristics of compression hip screws in the intertrochanteric fracture: a clinical study.

J. Orthop. Trauma. 1993: 7: 348-353.

21. Davis TR, Sher JL. Horsman A. Simpson M. Porter BB, and Checketts RG. Intertrochanteric femoral fractures. Mechanical failure after internal fixation. J. Bone Joint Surg. Br. 1990; 72: 26-31. 


\section{The use and opinion of the long Gamma nail In the Netherlands}

R. van Doorn. J.W.J.L. Stapert 


\section{Introduction}

In the last four decades, many implants are introduced to treat proximal femoral fractures. Operative treatment started with plates with a rigid anchorage in the femoral head. ${ }^{1-3}$ In the early fifties Richards developed a plate with a dynamic fixation of the femoral head.46 Küntscher developed in that time the intramedullary nail for shaft fractures. ${ }^{7.8}$ Zickel combined an intramedullary implant with a rigid fixation of the femoral head.9.10 The Russell Taylor Reconstruction Nail and the Gamma nail combine an intramedullary nail with a dynamic anchorage in the femoral head. 11.14 In the AO-twisted blade a femoral head fixation is combined with an unreamed intramedullary nail. ${ }^{15}$ Material developments, like the use of titanium, will strengthen the nails with a smaller diameter. ${ }^{16-18}$ Robotic surgery can perhaps help with a better aiming in the femoral head. ${ }^{19} \mathrm{~A}$ simple operation technique, minimal surgical trauma with a faster healing of the patient, and intrinsic stability and durableness of the implant will become more and more important.

The standard Gamma nail was introduced in the Netherlands in $1988 .^{13}$ The long version followed a year later. ${ }^{14}$ The first long Gamma nails were ordered custom made from the factory to treat fractures below the standard Gamma nail. With growing experience, the indication field moved to (impending) pathologic fractures and comminute proximal femoral fractures. The long Gamma nail was rapidly commercial available.

Epidemiological data regarding the introduction of implants in trauma surgery are rare. To reveal the overall opinion about the long Gamma nail and to get an idea about the implementation of the long Gamma nail in the different hospitals a questionnaire was developed. This questionnaire was sent to all departments with members of the surgical or orthopaedic trauma society. The results of this survey are presented in this paper.

\section{Material and Methods}

Members of the Dutch Trauma Society and the Dutch Orthopaedic Trauma Society co-operated. All 450 members, representing 117 surgical and 88 orthopaedic departments. were sent a questionnaire and a description of the study in 1995. Three months later, a recall was made. Twelve surgical and 21 orthopaedic departments without members of the trauma society were excluded from the study. All 37 (100\%) surgical teaching departments, 14 of the $15(93 \%)$ orthopaedic teaching departments, 62 of the $80(78 \%)$ surgical non-teaching departments, and 37 of the 72 (51\%) of the orthopaedic non-teaching departments. responded and were analysed. These departments operate on approximately 15000 femoral fractures a year. which is approximately $80 \%$ of the Dutch total. ${ }^{20}$

The questionnaire has two parts. The first part of the questionnaire semi-quantitatively analysed which operation techniques were used for the different femoral fractures: DCS. DHS. angled blade plate, straight plate. standard Gamma nail, long 
Gamma nail, intramedullary nail, external fixator, or other device. Data were collected for the use of implants used in femoral neck fractures, pertrochanteric, subtrochanteric, proximal I/3 shaft, midshaft, and supracondylar femoral fractures. In this article, only the subtrochanteric and proximal I/3 shaft fractures are described, because the long Gamma nail is mostly used for these fractures. The responders scored the frequency of use on a numeric scale. They could choose a I, 'never usedi, to 5, 'always used'. The responder was called a 'non-user' when a I or 2 was answered, and called a 'user' when a 3, 4. or 5 was written. This way a responder could be a 'user' of more than one implant.

In the second part of the questionnaire data were collected on the subjective feelings about the usefulness of the long Gamma nail for different indications. The question was asked: "Is the long Gamma nail according to you suitable for treatment of the following indication?' The indications asked for were stable pertrochanteric fractures, unstable pertrochanteric fractures. 'normal' subtrochanteric fractures. 'reversed' subtrochanteric fractures, ipsilateral femoral neck and shaft fractures, proximal shaft fractures, midshaft fractures, distal shaft fractures. pathological fractures, corrective osteotomies, and union problems. The last question was if the participants felt that the long Gamma nail had improved fracture treatment at all.

Statistical analyses were performed with the 'Statistical Package for the Social Sciences' (SPSS). The Chi-square test with the continuity-correction was used. Statistical significance was defined with a p-value smaller or equal to 0.05 .

\section{Results}

Use

The long
Gamma nail is
regularly used in
$73 \%$ of surgical
teaching departments and in $31 \%$ of the orthopaedic teaching hospitals, the difference is statisti-

\begin{tabular}{|c|c|c|c|c|c|c|}
\hline & \multicolumn{3}{|c|}{ Teaching hospital } & \multicolumn{2}{|c|}{ Non-teaching hospital } & \multirow[b]{2}{*}{ Overall } \\
\hline & Surgeon & & $\begin{array}{l}\text { Orthopaedic } \\
\text { surgeon }\end{array}$ & Surgeon & $\begin{array}{l}\text { Orthopaedic } \\
\text { surgeon }\end{array}$ & \\
\hline Dynamic Hip Screw & 15 & - & 39 & 31 & 41 & 30 \\
\hline Angled blade plate & 15 & • & $3 i$ & 6 & 37 & 18 \\
\hline Dynamic Condylar Serew & 18 & & 15 & 20 & 18 & 19 \\
\hline Standard Camma nail & 61 & & 54 & ss & 33 & 52 \\
\hline Long Camma nail & 49 & - & 8 & 25 & 19 & 28 \\
\hline Other implant & 6 & & 0 & 0 & 4 & 2 \\
\hline
\end{tabular}

cal significant. In non-teaching hospitals these percentages were 47 and 30 , this is not statistical significant. Forty percent of the respondents used more than one technique for one indication, with a mean of 2.4 techniques.

-Surgeons versus orthopaedic surgeons: Chi-square

Subtrochanteric fractures were treated with a Gamma nail by $68 \%$ of the surgeons and $45 \%$ of the orthopaedic surgeons. The long version was used in respectively $35 \%$ and $15 \%$. $31 \%$ of the surgeons and $67 \%$ of the orthopaedic surgeons (continuity correction) $p<0.05$ 
Table 5.2

The percentage of specialists that regularly use the long Gamma nail for high femoral shaft fractures. used a DHS or angled blade plate. A DCS was used by $20 \%$ of both groups \{table 5.1\}.

For high femoral shaft fractures, an intramedullary nail or a long Gamma nail is used by $94 \%$ of the surgeons and by $69 \%$ of the orthopaedic surgeons. Half of the orthopaedic surgeons use an angled blade plate, whereas only $7 \%$ of the surgeons

Teaching hospital

Non-teaching hospital

\begin{tabular}{|c|c|c|c|}
\hline Surgeon & $\begin{array}{l}\text { Orthopaedic } \\
\text { surgeon }\end{array}$ & Surgeon & $\begin{array}{l}\text { Orthopaedic } \\
\text { surgeon }\end{array}$ \\
\hline
\end{tabular}

\begin{tabular}{|l|c|c|c|c|c|}
\hline & \multicolumn{7}{|c|}{} & & \\
\hline Angled blade plate & 12 & 46 & 4 & 46 & 49 \\
\hline Dynamic Condylar Screw & 12 & 23 & 15 & 12 & 14 \\
\hline Long Gamma nail & 67 & 31 & 49 & 27 & 47 \\
\hline Intrame dullary nail *- & 76 & 73 & 71 & 50 & 68 \\
\hline Plate & 18 & 15 & 24 & 23 & 21 \\
\hline External Fixator & 6 & 8 & 6 & 0 & 5 \\
\hline Other implant & 0 & 0 & 0 & 4 & 1 \\
\hline
\end{tabular}

do. An external fixator is sporadically used as a definitive treatment $\{$ table 5.2\}.

*Surgeons versus orthopaedic surgeons: Chi-square (continuity correction) $p<0.05$

* Nail without stabilisation of the femoral neck.

\section{Opinion}

Figure 5.1

The percentage of users and non-users who judge the long Gamma nail positive for the mentioned indications.

•Chi-square

(continuity correction) $p<0.05$
The subjective feelings about the suitability of the long Gamma nail in the treatment of the different injuries is analysed for users versus non-users, surgeons versus orthopaedic surgeons, and teaching hospitals versus non-teaching hospitals.

The difference between users and non-users was most clear. A statistical significant difference was observed for ipsilateral femoral neck and shaft fractures. high femoral shaft fractures, pathological fractures, corrective osteotomies and union problems \{figure 5.1 \}. $97 \%$ of the users versus $65 \%$ of the non-users found

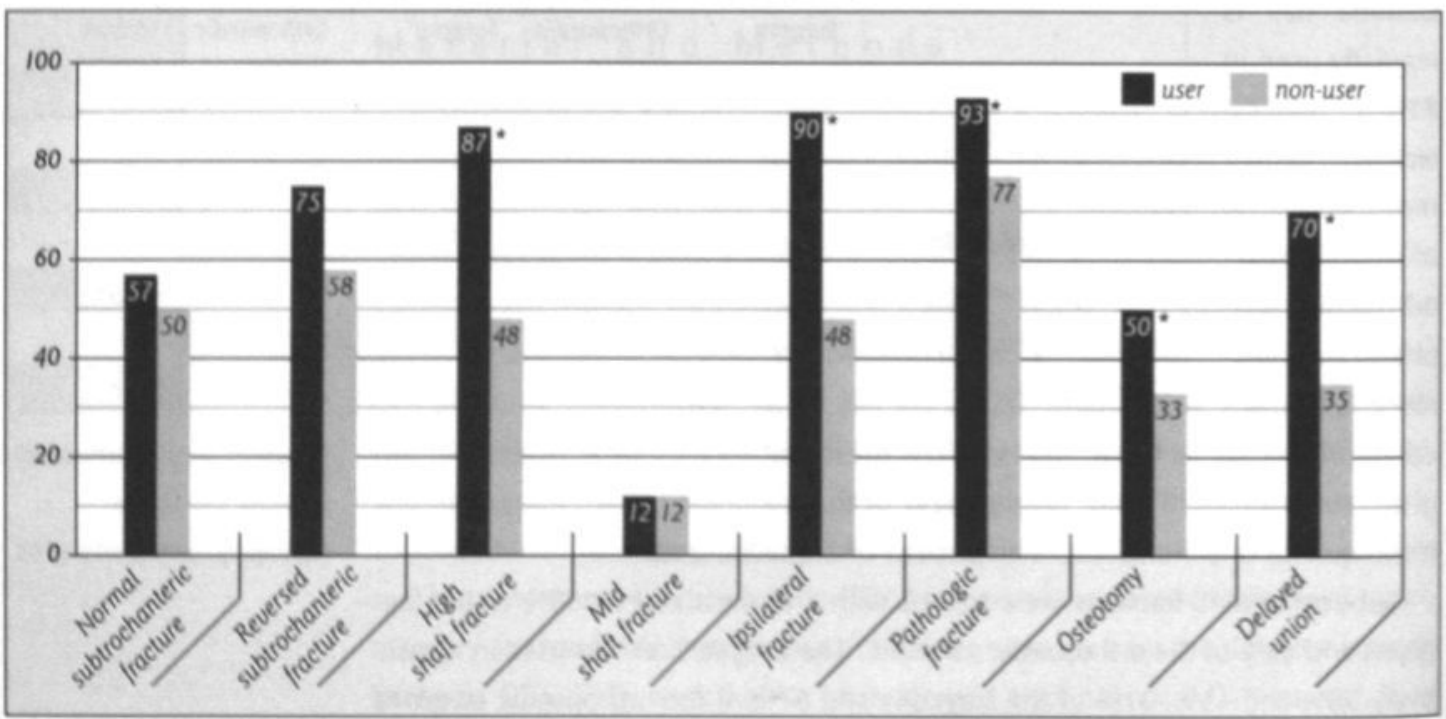


the long Gamma nail an improvement for trauma surgery \{figure 5.1\}. More than three-quarter of the users judged the long Gamma nail suitable for the treatment of reversed subtrochanteric fractures, high shaft fractures, ipsilateral femoral neck and shaft fractures, and pathological fractures.

The opinion of surgeons and orthopaedic surgeons, within the group of users, or non-users. did not differ. Only the opinion about corrective osteotomies differs. In the user group. $60 \%$ of the surgeons versus $8 \%$ orthopaedic surgeons were positive, in the non-user group these percentages were 36 versus 4 \{table 5.3\}.

Between the teaching and non-teaching hospitals, is only the opinion between surgical non-users a different. The surgical non-users in non-teaching hospitals were more positive than their teaching colleagues, regarding reversed subtrochanteric fractures (76\% versus 33\%), ipsilateral femoral neck and shaft fractures ( $52 \%$ versus $11 \%)$, and union problems ( $60 \%$ versus $11 \%)$. Their general opinion if the

Table 5.3

The percentage of specialists who judge the long Camma nail positive for the mentioned indications Gamma nail improved fracture surgery, was not statistical significant different (76\% versus $56 \%)$.

\begin{tabular}{|l|c|c|c|c|c|}
\hline & \multicolumn{3}{c|}{ User } & \multicolumn{2}{c|}{ Non-user } \\
\cline { 2 - 6 } & Surgeon & $\begin{array}{l}\text { Orthopaedic } \\
\text { surgeon }\end{array}$ & Surgeon & $\begin{array}{l}\text { Orthopaedic } \\
\text { surgeon }\end{array}$ & Overall \\
\hline Normal subtrochanteric fracture & 58 & 50 & 56 & 42 & 48 \\
\hline Reversed subtrochanteric fracture & 75 & 75 & 65 & 50 & 65 \\
\hline High shaft fracture & 85 & 93 & 50 & 46 & 65 \\
\hline Mid shaft fracture & 10 & 17 & 15 & 8 & 9 \\
\hline Ipsilateral neck and shaft fracture & 88 & 100 & 41 & 58 & 68 \\
\hline Pathological fracture & 92 & 100 & 74 & 81 & 84 \\
\hline Corrective osteotomy & 60 & 8 & 36 & 4 & 30 \\
\hline Union problem & 71 & 67 & 47 & 19 & 50 \\
\hline
\end{tabular}

\section{Discussion}

Most of the time change in surgical technique, and the introduction of a new implant in trauma surgery is not based on clinical evidence. The authors want to see how the long Gamma nail is implemented in the Netherlands, before results of trials are known. due to a nation wide questionnaire. The response on the sent questionnaire is good, especially from teaching hospitals. In the departments that responded 15.000 patients with femoral fractures are treated annually, which provide a representative picture of the Dutch situation. ${ }^{20}$

The long Gamma nail is five years available at the time the questionnaire is sent. Nearly half of the departments use the long Gamma nail regularly. This fast introduction is partly due to good marketing. The introduction is accomplished with an extensive training program for specialists and theatre nurses. In 16 workshops in different Dutch hospitals 120 orthopaedic surgeons. 250 surgeons. 300 residents, and 700 theatre nurses are trained. ${ }^{21}$ Beside these workshops trained
-Surgeons versus orthopaedic surgeons: Chi-square

(continuity correction) $p<0,05$ 
Howmedica personnel coached real operations. The long Gamma nail is introduced with the same equipment as the standard version. which enhances a quick introduction.

The positive feeling regarding the usefulness of the long Gamma nail in trauma surgery, will not always lead to its daily use. This discrepancy is especially clear in non-teaching hospitals. Most of the time this are smaller hospitals with a lower incidence of proximal femoral fractures. Budgetary reasons, which are separately written on the questionnaire forms, are sometimes a reason not to use the long Gamma nail. Others stated that the long Gamma nail has been an improvement of trauma surgery, but that they are satisfied with their old habits, and implants, and therefore will not change to the long Gamma nail. Surgeons in teaching hospitals used the long Gamma nail more frequent (73\%) than their colleagues in non-teaching hospitals ( $51 \%$ ) or orthopaedic surgeons (30\%).

As can be expected, users are more positive in their opinion about the nail than non-users. Especially the early allowance of weight bearing is an advantage. Besides budget reasons are complications of the standard Gamma nail. from own experience or from hearing, reasons to doubt the superiority of the long Gamma nail. Four users changed to use the Russell Taylor Reconstruction Nail, because the instruments were more solid, and the nail is cheaper.

\section{Conclusion}

The incorporation of the long Gamma nail in the Netherlands is fast. Nearly half the trauma departments use the implant within 5 years after its introduction. Users and non-users differ most in opinion over the usefulness of the long Gamma nail in proximal femoral shaft and ipsilateral femoral neck and shaft fractures. Surgeons and orthopaedic surgeons differ only of opinion regarding osteotomies. In non-teaching hospitals, there is the greatest difference between theoretical thinking and practical incorporation of the long Gamma nail.

Clinical trials are necessary to see if the positive feelings about the long Gamma nail are true. 
1. Murray RC, and Frew JFM. Trochanteric fractures of the femur. A plea for conservative treatment.

J. Bone Joint Surg. Br. 1949: 31: 204-219.

2. Evans EM. The treatment of trochanteric fractures of the femur.

J. Bone Joint Surg. Br. 1949: 31: 190-203.

3. Tronzo RG. Hip nails for all occasions.

Orthop. Clin. North Am.

1974: $5: 479-491$.

4. Kyle RF, Gustilo RB, and Premer RF. Analysis of six hundred and twenty-two intertrochanteric hip fractures. A retrospective and prospective study.

J. Bone Joint Surg. Am. 1979; 61:

216-221.

5. Jensen JS. Tondevold $\mathrm{E}$, and Mossing $\mathrm{N}$. Unstable trochanteric fractures treated with the sliding screw- plate system. A biomechanical study of unstable trochanteric fractures III.

Acta Orthop. Scand. 1978; 49: 392-397.

6. Jensen JS. Sonne Holm S, and Tondevold

E. Unstable trochanteric fractures.

A comparative analysis of four methods of internal fixation.

Acta Orthop. Scand. 1980: 51 : 949-962

7. Hansen ST, and Winquist RA. Closed intramedullary nailing of the femur. Küntscher technique with reaming. Clin. Orthop. 1979: 138: 56-61.

8. Lentz W. Die Geschichte der Marknagelung. Ein kurzer Ruckblick.

Chirurg. 1990: 61: 474-480
9. Zickel RE. An intramedullary fixation device for the proximal part of the femur. J. Bone Joint Surg. Am. 1976; 58: 866-872.

10. Bergman GD. Winquist RA, Mayo KA. and Hansen ST. Subtrochanteric fracture of the femur. Fixation using the Zickel nail (published erratum appears in J. Bone Joint Surg. Am. 1988: 70: 152). J. Bone Joint Surg. Am. 1987; 69: 1032-1040.

11. Taylor JC, Russell TA, and LaVelle DG. The Russell-Taylor Reconstruction Nail. Biomechanics / technique / clinical results. 56th Annual Meeting of the American Academy of Orthopaedic Surgeons, Las Vegas, Nevada, 1989.

12. Blumberg KD. Foster WC, Blumberg JF. Adelaar RS. Deblois ME. Hussey RW et al. A comparison of the Brooker-Wills and Russell-Taylor nails for treatment of patients who have fractures of the fernoral shaft.

J. Bone Joint Surg. Am. 1990; 72: 1019-1024.

13. Boriani S. Bettelli G. Zmerly H, Specchia L. Bungaro P. Montanari $\mathrm{G}$ et al. Results of the multicentric Italian experience on the Gamma nail: a report on 648 cases. (published erratum appears in Orthopedics 1992; 15: 545). Orthopedics 1991: 14: 1307-1314.

14. Stapert JWJL. Geesing CLM. Jacobs PB. Wit RJ de, and Vierhout PAM First experience and complications with the long Gamma nail. J. Trauma. 1993: 34: 394-400. 
15. Krettek $C$, and Tscherne $H$.

Osteosynthese von Femurschaftfrakturen mit dem Unaufgebohrten AO-Femurnagel (UFN). Unfallchirurg. 1994: 97: 549-567.

16. Kyle RF, Cabanela ME, Russell TA.

Swiontkowski MF, Winquist RA.

Zuckerman JD et al. Fractures of the proximal part of the femur.

Instr. Course. Lect. 1995: 44: 227-253.

17. Choueka J, Koval KJ. Kummer FJ.

Crawford G, and Zuckerman JD

Biomechanical comparison of the sliding hip screw and the dome plunger. Effects of material and fixation design.

J. Bone Joint Surg. Br. 1995: 77: 277-283.

18. Eveleigh RJ. A review of biomechanical studies of intramedullary nails.

Med. Eng. Phys. 1995: 17: 323-331.
19. Bouazza Marouf K, Browbank I, and Hewit JR. Robotic-assisted internal fixation of femoral fractures. Proc. Inst. Mech. Eng. H. 1995: 209: 51-58.

20. SIG Zorginformatie. Treatment of femoral fractures in the Netherlands. Bestanden van de Landelijke Medische Registratie over de ziekenhuisopnames 1992 - 1994. Utrecht. SIG, 1996.

21. Berlot M. and Graaf B de. Personal communication. 1996. Participants of Gamma nail symposia. 


\title{
Primary fractures
}

\author{
R. van Doorn. J.W.J.L. Stapert
}

European Journal of Surgery 2000: 166: 240-246 


\section{Introduction}

The subtrochanteric region of the femur is subject to many stresses resulting from bending moments and the compressive forces generated by body weight and the hip muscles. Elevation of a leg while lying in bed produces forces two to three times body weight, and walking three to five times. ${ }^{1.2}$ The result can be malunion. delayed union, and implant failure. ${ }^{3}$ Only a strong implant that is firmly anchored above and below a femoral fracture will allow weight-bearing without impairing healing of the fracture.' For fractures of the proximal femoral shaft and subtrochanteric region the upper anchorage has to be in the femoral head. The Gamma nail provides this anchorage with a $12 \mathrm{~mm}$ screw that can glide in the nail. Two $6.8 \mathrm{~mm}$ bolts secure the nail distally. The nail is inserted through the greater trochanter by a small incision. 46 The Gamma nail comes in two types, the standard nail of $20 \mathrm{~cm}$ and a longer one ranging from $32-42 \mathrm{~cm}$. The standard nail is used mainly for trochanteric fractures. Complex fractures with extension into the femoral shaft are treated with the long version.

We present the experience of Dutch (orthopaedic) surgeons in treating proximal femoral fractures with the long Gamma nail. We will focus on the problems and how to prevent them.

\section{Patients and methods}

The long Gamma nail was first developed in The Netherlands in 1989 and used as a custom-made prototype until 199I. In the five-year period after its introduction we followed up 329 patients who had had long Gamma nails inserted for the treatment of primary proximal femoral fractures in 24 Dutch hospitals. There were 148 men with a mean age of 55 (SD 24, range 17 - 102), and 181 women with a mean age of 77 (SD 13, range 21 - 100). In those younger than 40 years of age. 36 of the 63 fractures ( $57 \%$ ) were caused by high velocity injuries (attempted suicide and motor vehicle crashes): 162 (84\%) of the 193 patients over 70 fractured their legs by falls at home or while walking.

Of the 329 patients 256 (78\%) were operated on the day of admission or the next day. The patient lay supine on a fracture table. Traction was applied to the injured leg by a supracondylar Kirschner wire, or by a padded holder on the foot. A padded perineal post served for countertraction. The unaffected limb was placed beneath the injured one in a 'heel-toe' position, or was flexed and abducted. This allowed proper access for the image intensifier. Adduction of the injured leg and flexing of the trunk towards the unaffected side allowed optimal access to the greater trochanter. The fracture was reduced with the help of the image inten sifier. Excessive traction on the affected limb was avoided. A $3-6 \mathrm{~cm}$ incision was placed above the greater trochanter. The aponeurosis of gluteus maximus and the fibres of gluteus medius were split to reach the trochanter. The entry point of the femoral canal is at the tip of the greater trochanter. The femoral canal was reamed. 
and the nail inserted. The cervical lag screw was placed and secured, using a target device mounted on the nail. The distal end was locked with a free-hand technique.

This closed technique was used in 299 patients, whereas in 30 the fracture had to be exposed. The femoral canal was over-reamed $3 \mathrm{~mm}$ or more in 49 patients, $2 \mathrm{~mm}$ in 240. I mm in 26, and not reamed at all in six. The canal was reamed equal to the size of the nail in five, and in three patients the amount of reaming was not described in the operation record. A $125^{\circ}$ nail was chosen in 21 cases, a $130^{\circ}$ nail in 47 and a $135^{\circ}$ nail in 261 . The diameter of 101 nails was $11 \mathrm{~mm}$, of 223 nails $12 \mathrm{~mm}$, of three nails $14 \mathrm{~mm}$, and of one custom-made nail $9 \mathrm{~mm}$. In one operation record the diameter was not given. Nails were locked distally with two bolts in 207 patients, with one bolt in 97 , and 25 nails were not locked.

Radiographs and records were reviewed. With the consent of the patient or the family, and with the co-operation of their surgeons and general practitioners, data about the present state of the patient or final outcome were collected by telephone interviews. Mobility was scored 'full' when the patient was able to walk more than 500 metre with or without a walking device. 'moderate' if only small distances could be walked with a walking device, or 'bedridden' when the maximum transfer that was possible was from bed to chair. Pain was scored 'absent' when only occasional oral painkillers were used, 'moderate' when they were used regularly, or 'severe' when the pain was difficult to treat with oral painkillers or when narcotic analgesics were used regularly.

\section{Results}

The median length of stay in hospital was 17 days (range I - 124). Nineteen patients died in hospital: three suddenly of unknown cause, three of cachexia, two of cerebrovascular accidents, three of congestive cardiac failure, four of pneumonia, one of respiratory failure (perhaps as a result of embolisation of reamer products), and three of associated injuries. A further eight patients died within four months after operation.

\begin{tabular}{|l|l|r|}
\hline Diaphysis (group 32) & Proximal femur (group 31) & No. \\
\hline Simple fracture (A) & Not involved & 40 \\
\hline & Trochanteric fracture (A) & 6 \\
\hline & Femoral neck fracture (B) & 4 \\
\hline Wedge fracture (B) & Not involved & 118 \\
\hline & Trochanteric fracture (A) & 37 \\
\hline & Femoral neck fracture (B) & 3 \\
\hline Complex fracture (C) & Not involved & 58 \\
\hline No radiographics available & & 33 \\
\hline
\end{tabular}

Traction caused one hydrocele and two temporary peroneal nerve lesions. Five patients developed deep venous thromboses, and one a pulmonary embolism. Ten wounds drained fluid. Three patients had low-grade infections, but the nails could be left in place until union was achieved. One other deep infection was successfully treated by antibiotics, re-reaming the femoral canal, and changing the nail.

Table 6.1

The Arbeitsgemeinshaft für Osteosynthesefragen classifia. tion of 329 fractures.

The fractures were classified according to the Arbeitsgemeinshaft für Osteosynthesefragen (AO) \{table 6.1\} and Seinsheimer $\left\{\right.$ table 6.2\}..$^{18}$ These classifications were difficult to use. The quality of radiographs were sufficient for daily 
Table 6.2

The Seinsheimer classification of 329 fractures. use, but not to allow a correct classification. The AO classification showed 34 different fracture patterns, because both group 31 (proximal femur) and group 32 (diaphysis) were encountered \{table 6.I\}. Sixteen fractures (5\%) could not be

\begin{tabular}{|r|l|r|r|}
\hline Type & Fragments & Type of fracture & No. \\
\hline I & Undisplaced & 0 \\
\hline II A & 2 & Transverse & 0 \\
\hline B & 2 & Spiral, with lesser trochanter part of the proximal fragment & 24 \\
\hline C & 2 & Spiral, with lesser trochanter part of the distal fragment & 24 \\
\hline III A & 3 & Spiral, with lesser trochanter part of the third fragment & 105 \\
\hline B & 3 & Spiral, with lesser trochanter not as part of the third fragment & 13 \\
\hline IV & 24 & No extension in greater trochanter & 48 \\
\hline V & 24 & With extension in greater trochanter & 69 \\
\hline Impossible to classify & 16 \\
\hline
\end{tabular}

classified at all by the Seinsheimer system \{table 6.2\}. The classifications did not help in choosing the operative technique to be used, nor did they predict mobility or complications.

In $221(73 \%)$ of the 302 patients who survived more than four months, enough radiographs were available to estimate the time to union.

Union was defined as callus formation at the fracture site, with the fracture line visible for less than a quarter of the circumference. Fractures were united after a
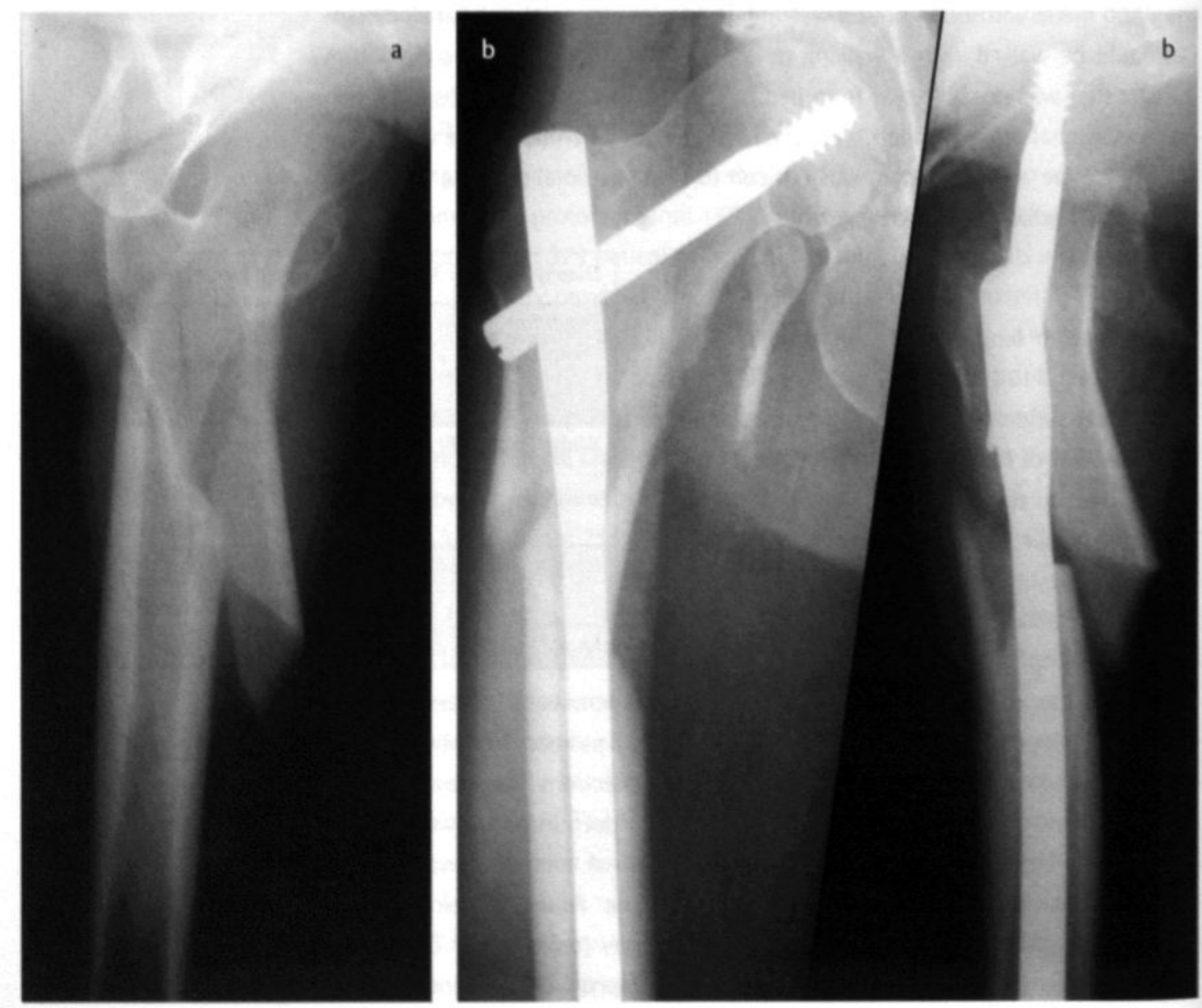
mean of 5.4 (SD 3, range 3 - 28) months. In five patients union took more than a year. Four nails were dynamised by removing distal bolts, and in three the implant was changed to achieve union.

Implant-related complications developed 70 times in 62 patients (19\%). for which operation was needed in 51 patients (16\%). Twenty-three patients had fractures distal to the nail. Seventeen femurs fractured during operation, of which four needed additional procedures. One patient with a severely comminuted proximal fracture and an ipsilateral comminuted supracondylar fracture had a blade plate placed distal to a long Gamma nail. The femur fractured at the junction of the nail and the plate after two weeks. Multiple operations were needed to solve his problems. Five patients fractured their femurs below the nail as a result of falling, four of which were operated on and one was treated conservatively. Nineteen of 223 patients who were treated with $12 \mathrm{~mm}$ nails fractured their distal femur (9\%). compared with 4 of 101 patients with $11 \mathrm{~mm}$ nails (4\%).

Four implants failed. A prototype long Gamma nail fractured at the proximal locking hole of the Grosse-Kempf nail after two months. A second patient fractu-
Figure 6.1 ( $a, b, c, d)$

A 48 year man with liver cirthosis, and on dialysis fell at home (a). A long Gamma nail was inserted in varus and ante. curvation (b). After minor trau. ma he fractured the nail at five months (c). A new Gamma nail remained stable at least 32 months. Notice that the lag screw is in the same position as before, seven months after the reoperation (d).
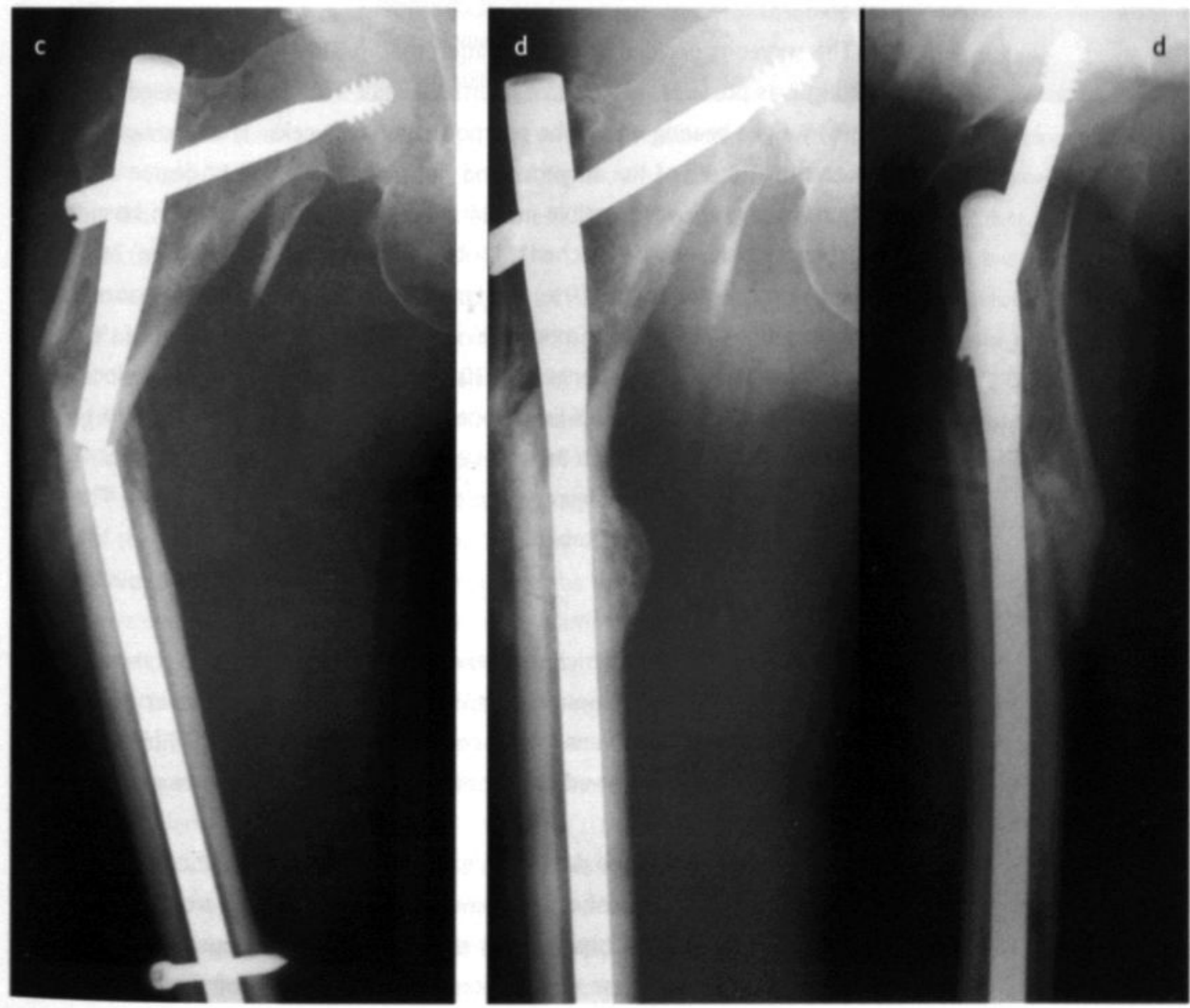
red the nail after five months at the junction between the proximal part and the nail shaft, $8 \mathrm{~cm}$ distal to the lag screw \{figure 6.1 \}. A third patient refused treatment for a delayed union, and fractured the nail after 18 months though the hole of the lag screw. A new long Gamma nail remained stable in all three patients. One patient had a fractured nail after consolidation, with no ill effects.

Four patients with anterior bowing and shortening. and two patients with inward rotation of the distal fragment had repeat operations. Three had a new long Gamma nail inserted, and three an angle blade plate. In one patient a fragment of bone that pierced the quadriceps muscle was removed.

The cervical lag screw was the cause of repeat operations in 16 patients. Two screws were placed beside the nail and were reinserted. Nine lag screws migrated lateral to the nail, and five showed varying degrees of protrusion into the femoral head.

Locking bolts were removed in 19 patients. Nine because they caused pain. four because they migrated, three legs were stabilised in distraction, and three bolts fractured. Three of the 25 unlocked nails had to be locked at a second operation.

The surgeons decided during operation that in $210(64 \%)$ patients full weightbearing was possible, in 76 (23\%) partial weight-bearing was advised, and in 43 (13\%) weight-bearing was to be postponed for six weeks. This decision was related to the attitude of the surgeon, and not to fracture type or degree of comminution. Follow-up was possible in 304 patients ( 19 patients died in hospital and 6 patients could not be reached). Mobility was scored as 'good' in 241 (80\%) patients, 'moderate' in $59(19 \%)$ patients, or 'bedridden' in 4 ( $1 \%)$ patients. Pain was 'absent' in 264 (87\%): 'moderate' in 38 (12\%); and 'severe' in 2 (1\%).

In the group of 162 patients over 70 years old who had had low velocity accidents $15(9 \%)$ died, nine $(6 \%)$ developed wound infections, and $16(10 \%)$ femurs fractured distal to the nail. In 36 high velocity accidents in patients under 40 years of age the corresponding figures were one (3\%). zero, and one (3\%). The functional outcome was comparable.

\section{Discussion}

This is a nation-wide series that reflects a learning curve with a new implant. Problems during the operation led to three serious and eight minor complications. Serious postoperative implant-related complications occurred in 14 patients (4\%). In II the problem was solved in a single operation, whereas three needed several operations.

There are few published data specifically about the treatment of extensive subtrochanteric fractures. Most reports have been in series about trochanteric fractures. In those series was noticed that the patients with extensive fractures have more problems than those with limited fractures. Results of the main implants 
used are summarised in table 6.3. These results are underestimated because not all series give details of all scored items. Dynamic Condylar Screws have replaced angle blade plates, because they are easier to use and are stronger. Their main problems. however, are fatigue fractures of the plates and protrusion of the screw into the acetabulum.9-13 Although extensive dissection is required to achieve proper alignment, deep infections and wound problems are not reported more common

\section{Table 6.3}

Percentage of complications in our series and other publica. tions. than after nailing procedures. The first nails that were used in these proximal fractures were the Küntscher-y, and Zickel nails. The reason that they are not used any longer is not clearly explained in literature, they seem to have more problems with union than the newer nails. ${ }^{14-18}$ The RussellTaylor Reconstruction Nail is reported to have no major implant-related reoperations.

\begin{tabular}{|c|c|c|c|c|}
\hline & $\begin{array}{l}\text { Dynamic } \\
\text { Condylar } \\
\text { Screw }=13\end{array}$ & $\begin{array}{l}\text { Zickel } \\
\text { nail itis }\end{array}$ & $\begin{array}{l}\text { Russel-Taylor } \\
\text { Reconstruction } \\
\text { Nail } 9: 24\end{array}$ & $\begin{array}{l}\text { Present } \\
\text { series }\end{array}$ \\
\hline Patients & 139 & 172 & 120 & 329 \\
\hline Implant fracture & 6 & 1 & 1 & 1 \\
\hline Reoperation major* & 6 & 3 & 0 & 5 \\
\hline Reoperation minor ** & 0 & 0.5 & 3 & 9 \\
\hline Deep infection & 2 & 1 & 3 & 1 \\
\hline Wound problem & 1 & 2 & 0 & 3 \\
\hline Malunion & 1 & 19 & 10 & 2 \\
\hline Delayed union & 6 & 2 & s & 2 \\
\hline Thromboembolic*** & 2 & 2 & 4 & 2 \\
\hline
\end{tabular}
only three proximal screws, and one distal screw being removed for minor discomfort. ${ }^{19-24}$ Only Gibbons, who reported 21, and Taylor, who reported 54. described more than 12 patients with extensive fractures stabilised with a Russell-Taylor Reconstruction Nail.

In our series $23(7 \%)$ distal femoral fractures occurred. of which $9(3 \%)$ were operated on. In a review of 12 series describing 2284 standard Gamma nails 3\% of distal femoral fractures were encountered. They were caused by inadequate reaming. ${ }^{25.26}$ using a too large diameter nail. ${ }^{25.27 .28}$ hammering on the nail. ${ }^{5.27}$ hammering the locking holes with an awl. ${ }^{29}$ insertion of distal locking screws next to the nail, 5.6 .2730 and the blunt tip of the nail causing stress when not located in the middle of the femoral canal. ${ }^{5.6 .25}$ For locking the long Gamma nail a free-hand locking technique is necessary. Different devices can be used, but it is most important to have sufficient practice in using them. Pre-hammering with an awl as done in the early days is hazardous. and a centre drill has been developed in The Netherlands to prevent the $5.5 \mathrm{~mm}$ drill from jumping away from the right spot. This is standard in the operation set nowadays. ${ }^{29}$ In our series two tendencies. which are, however. not statistically significant, are noticed. Elderly patients fracture the distal femur more often than the younger (10\% compared with $3 \%$ ). In the group of 227 nails with a diameter of $12 \mathrm{~mm}$ or more, $19(8 \%)$ fractures occurred, compared to 4 of the $104(4 \%)$ thinner nails. Nowadays the standard nails are II mm in diameter, but further experience is needed to see if this tendency is true. The distance from the nail to the knee does not make any difference in the
- major reoperations include fractures proximal or distal to the implant. femoral head ne. crosis. and protrusion into the acetabulum.

*. minor reoperations include removing or inserting screws. **including ARDS, possible fat embolism syndrome. 
incidence of fractures. Omission of distal locking to prevent distal fractures will cause other problems. Four ( $16 \%$ ) of the 25 patients who were not locked initially needed to be locked at a second operation. Three femurs were locked in distraction and three bolts fractured. There was no difference in outcome whether one or two bolts were inserted. To combine those features we suggest the production of nails with one oval and one round distal hole. With the use of one bolt the nail can be locked in either a static or dynamic mode.

Various systems are used to classify proximal femoral fractures, they all show a poor reproducibility and repeatability. ${ }^{31.34}$ We did not objectively test this in our series, but noticed that a second time a radiograph is seen the fracture is easily classified different. Moreover $5 \%$ of the fractures could not be classified according to Seinsheimer classification at all, although this is the best suitable classification system. The most disappointing aspect is that the classifications did not give any guidance about the operative technique to be used, nor did they predict mobility or complications.

Rockwood stated that bony union of these fractures is slow because the cortical bone is less vascular than the cancellous bone in the trochanteric area itself. ${ }^{35}$ Trafton thought that slower healing was caused by an inadequate reduction with traction on the fracture side or by massive periosteal stripping. and had nothing to do with the bone itself. ${ }^{36}$ Smith insisted that intramedullary nailing leaves the periosteum intact and reaming is a kind of bone graft. ${ }^{37}$ The endosteal blood flow is harmed by reaming. the discussion whether this effect consolidation is still going on. ${ }^{38.39}$ In our series the mean time to consolidation was five months, which is comparable with other nailing and plating techniques. ${ }^{12.15}$ In five patients (2\%) consolidation took more than a year. Implants can fail at any time, but the longer they have to bear weight the change of failure increase. Delayed union and non union has therefor to be prevented. The decision about when to interfere when union is delayed remains difficult. Dynamisation by removing the distal bolts is often sufficient. It is a relatively small operation, but can result in shortening. Changing the nail to a thicker one. or putting in cancellous bone are more extensive procedures. Seinsheimer described problems with union in $44 \%$ and failure of implants in patients with fractures in which medial support was lacking (his type IIla fractures). Our 65 Seinsheimer type IIla fractures in which the consolidation time was known healed in a mean time of 5.2 months. This is no different from the rest of the group, and confirms that with the use of a long Gamma nail medial support is not vitally important.

Young patients with high energy trauma differ from old people who fall at home. It is remarkable that we saw only one respiratory insufficiency. not in the multiply injured patients, but possibly caused by reamer products in an elderly lady after a fall at home. Although our data are not significant it seems that old people fracture the distal femur more easily. A precise explanation is not known. 
but it should make the surgeon more alert when operating on the elderly.

Early mobilisation is advisable for all patients to reduce morbidity. In young people high velocity trauma is the main cause of proximal femoral fractures, and full mobilisation is often dependent on other injuries as well. Sometimes mobilisation in a swimming pool can help. In elderly patients early mobilisation always means full weight-bearing, because most of them are unable to walk with partial weight-bearing. In our series $64 \%$ were allowed to go straight to full weight bearing, and only $13 \%$ needed to have a period of no weight-bearing. $80 \%$ of the patients considered their restoration of mobility to be good.

Treating patients with extensive proximal femoral fractures remains a challenge. The long Gamma nail can solve a lot of problematic cases with an acceptable complication rate. Experience is important to prevent technical complications. 
1. Tencer Af, Johnson KD, Johnston DW. and Gill K. A biomechanical comparison of various methods of stabilization of subtrochanteric fractures of the femur. J. Orthop. Res. 1984: 2: 297-305.

2. Procter $P$. The biomechanics of trochanteric hip fractures. In: Marti RK, Dunki Jacobs PB, editors. Proximal femoral fractures. Operative techniques and complications. Medical Press, London. 1993. Chapter 19: 423-438.

3. Wiss DA. Matta JM, Sima W, and Reber L. Subtrochanteric fractures of the femur. Orthopedics. 1985: 8: 797-800.

4. Halder SC. The Gamma nail for peritrochanteric fractures. J. Bone Joint Surg. Br. 1992: 74: 340-344.

5. Boriani S, Bettelli G. Zmerly H. Specchia L. Bungaro P. Montanari G et al. Results of the multicentric Italian experience on the Gamma nail: a report on 648 cases. (published erratum appears in Orthopedics 1992: 15: 545). Orthopedics 1991: 14: 1307-1314.

6. Heinz T. and VĖcsei V. Komplikationen und Fehler bei der Anwendung des Gammanagels. Ursachen und Pravention. Chirurg. 1994: 65: 943-952.

7. Müller ME, Nazarian S, Koch P, and Schatzker J. The comprehensive classification of fractures of long bones. Springer-Verslag. Berlin. Heidelberg. New York, 1990.
8. Seinsheimer $F$. Subtrochanteric fractures of the femur.

J. Bone Joint Surg. Am. 1978: 60: 300-306.

9. Fölsch CO, and Kunze KG.

Die Osteosynthese subtrochanterer

Femurfrakturen mit der Dynamischen Kondylenschraube.

Zentralbl. Chir. 1993: 1 18: 357-360.

10. Rosso R, Babst R, Marx A. Hess P. Heberer M, and Regazzoni P. Proximale Femurfrakturen. Besteht eine Indikation fur die Kondylenschraube (DCS)? Helv. Chir. Acta. 1992: 58: 679-682.

11. Sanders RW, and Regazzoni P. Treatment of subtrochanteric femur fractures using the dynamic condylar screw.

J. Orthop. Trauma. 1989; 3: 206-213.

12. Senter B. Kendig R, and Savoie FH. Operative stabilization of subtrochanteric fractures of the femur.

J. Orthop. Trauma. 1990; 4: 399-405.

13. Vanderschot $P$, Vanderspeeten $K$. Verheyen L, and Broos PL. A review on 161 subtrochanteric fractures. Risk factors influencing outcome: age, fracture pattern and fracture level.

Unfallchirurg. 1995: 98: 265-271.

14. Brien WW. Wiss DA. Becker V. and Lehman T. Subtrochanteric femur fractures: a comparison of the Zickel nail. 95 degrees blade plate and interlocking nail.

J. Orthop. Trauma. 1991: 5: 458-464. 
15. Reynders PA, Stuyck J. Rogers RK, and Broos PL. Subtrochanteric fractures of the femur treated with the Zickel nail.

Injury. 1993: 24: 93-96.

16. Thomas WG, and Villar RN.

Subtrochanteric fractures: Zickel nail or nail-plate?

J. Bone Joint Surg. Br. 1986; 68: 255-259.

17. Zickel RE. An intramedullary fixation device for the proximal part of the femur. J. Bone Joint Surg. Am. 1976: 58: 866-872.

18. Waddell JP. Subtrochanteric fractures of the femur: a review of 130 patients.

J. Trauma. 1979; 19: 582-592.

19. Bose W]. Corces A, and Anderson LD. A preliminary experience with the RussellTaylor reconstruction nail for complex fernoral fractures.

J. Trauma. 1992: 32: 71-76.

20. Gibbons CL. Gregg Smith SJ. Carrell TW. Murray DW, and Simpson AH. Use of the Russell-Taylor reconstruction nail in fernoral shaft fractures.

Injury. 1995: 26: 389-392.

21. Koldenhoven GA, Burke JS, and Pierron R. Ipsilateral femoral neck and shaft fractures. South. Med. J. 1997: 90: 288-293.

\section{Ostermann PA, and Henry SL.}

Die Behandlung ipsilateraler Femurshaftund Schenkelhalsfracturen mit dem Russell-Taylor Rekonstructionnagel.

Chirurg. 1994: 65: 1042-1045.
23. Smith JT. Goodman SB, and Tischenko G. Treatment of comminuted femoral subtrochanteric fractures using the RussellTaylor reconstruction intramedullary nail. Orthopedics. 1991: 14: 125-129.

24. Taylor JC. LaVelle DG, and Walker BJ. Long bone fracture management at the Cambell Clinic: Experience gained from 1700 fractures treated with the R-T Interlocking Nail System. Cambell Clinic. 1991: 1-17.

25. Bridle SH. Patel AD, Bircher M, and Calvert PT. Fixation of intertrochanteric fractures of the femur. $A$ randomised prospective comparison of the gamma nail and the dynamic hip screw.

J. Bone Joint Surg. Br. 1991: $73: 330-334$

26. Guyer P. Landolt M, Keller H, and Eberle C. Der Gamma-Nagel bei per- und intertrochantaren Femurfrakturen--Alternative oder Erganzung zur DHS? Eine prospektive randomisierte Studie anhand von 100 Patienten mit per- und intertrochantaren Femurfrakturen an der Chirurgischen Klinik des Stadtspitals Triemli. Zurich. September 1989-Juni 1990.

Aktuelle. Traumatol. 1991: 21: 242-249.

27. Aune AK, Ekeland A. Odegaard B. Grogaard B, and Alho A. Gamma nail vs compression screw for trochanteric femoral fractures. Is reoperations in a prospective, randomized study of 378 patients.

Acta Orthop. Scand. 1994: 65: 127-130. 
28. Forthomme JP, Costenoble V, Soete P, and Docquier J. Traitement des fractures trochanteriennes du femur par le clou gamma (a propos d'une serie de 92 cas). Acta Orthop. Belg. 1993: 59: 22-29.

29. Lacroix H. Arwert H. Snijders C]. and Fontijne WP. Prevention of fracture at the distal locking site of the Gamma nail. $A$ biomechanical study.

J. Bone Joint Surg. Br. 1995: 77: 274-276

30. Fried $W$, Colombo Benkmann M. Dockter S. Machens HG, and Mieck U. Gammanagel-Osteosynthese per- und subtrochanterer Femurfrakturen. 4-JahresErfahrungen und ihre Konsequenzen fur die weitere Implantatentwicklung. Chirurg. 1994: 65: 953-963.

31. Andersen E. Jorgensen LG, and Hededam LT. Evans' classification of trochanteric fractures: an assessment of the interobserver and intraobserver reliability.

Injury. 1990: 21: 377-378.

32. Gehrchen PM, Nielsen JO. Olesen B. and Andresen BK. Seinsheimer's classification of subtrochanteric fractures.

Poor reproducibility of 4 observers evaluation of 50 cases.

Acta Orthop. Scand. 1997: 68: 524-526.

33. Johnstone DJ, Radford W], and Parnell E] Interobserver variation using the AOIASIF classification of long bone fractures.

Injury. 1993: 24: 163-165
34. Burstein AH. Fracture classification systems: do they work and are they useful? J. Bone Joint Surg. Am. 1993; 75: 1743-1744.

35. Delee JC. Subtrochanteric fractures. In: Rockwood CA. Green DP, editors. Fractures in adults and fractures in children. 4th edition. Lippincott-Raven, Philadelphia, 1996. Chapter 26: 1741-1755.

36. Trafton PG. Subtrochanteric-intertrochanteric femoral fractures.

Orthop. Clin. North Am. 1987: 18: 59-71.

37. Wenda K. Ritter G. Ahlers J. Issendorff WD von. Brunner UH. Kessler SB et al. Nachweis und Effekte von Knochenmarkeinschwemmungen bei Operationen im Bereich der Femurmarkhohle Defektbehandlung langer Rohrenknochen durch Distraktionsosteogenese (llizarov) und Marknagelung. Theoretische Grundlagen, tierexperimentelle Ergebnisse. klinische Relevanz.

Unfallchirurg. 1990: 93: 244-250.

38. Runkel M. Wenda K. Ritter G, Rahn BA and Perren SM. Knochenheilung nach unaufgebohrter Marknagelung. Unfallchirurg. 1994: 97: 1-7.

39. Kessler SB, Hallfeldt KK, Perren SM, and Schweiberer $L$. The effects of reaming and intramedullary nailing on fracture healing Clin. Orthop. 1986: 212: 18-25. 


\section{Pathological fractures}

R. van Doorn. J.W.J.L. Stapert

European Journal of Surgery 2000: 166: 247-254 


\section{Introduction}

Patients with bone metastases usually die of other complications of the original cancer, but a pathological femoral fracture results in gross reduction in the quality of life.' The goal of osteosynthesis is to diminish pain and restore mobility quickly. ${ }^{2}$ If the disease is terminal, osteosynthesis aims to ease the burden of nursing. ${ }^{3}$

In a survey of English. German, and Dutch publications from 1975 to 1995 we found 21 reports on clinical studies of more than 10 patients, which described

Table 7.1

Complications in other publications and in our series Figures are number of patients. complications and functional results of operations for impending and actual pathological fractures of the femur. Eight reported 249 prostheses and 272 plate osteosynthesis., ${ }^{411}$ six reported 220 Zickel nails, ${ }^{11-16}$ and seven described 206 other intramedullary nails. ${ }^{17 \cdot 23}$

\begin{tabular}{|c|c|c|c|c|c|c|c|}
\hline & \multirow[t]{2}{*}{ Prosthesis } & \multirow[t]{2}{*}{ Plates } & \multirow[t]{2}{*}{ Zickel } & \multirow[t]{2}{*}{ Other nail } & \multicolumn{2}{|c|}{ Total } & \multirow{2}{*}{$\begin{array}{l}\text { Present } \\
\text { series }\end{array}$} \\
\hline & & & & & $n$ & $\%$ & \\
\hline Patients & 249 & 272 & 220 & 206 & 947 & 100 & 101 \\
\hline Fracture of femur & 5 & 12 & $s$ & 9 & 31 & 3.3 & 1 \\
\hline Fracture of femoral neck & & 0 & 1 & 6 & 7 & 0.7 & 0 \\
\hline Fracture of implant & 1 & 13 & & 1 & is & 1.6 & 2 \\
\hline Luxation and migration of material & 16 & 7 & 11 & 7 & 41 & 4.3 & 2 \\
\hline ARDS & 1 & & 1 & 3 & $s$ & 0.5 & 3 \\
\hline Thrombo-embolism & * & * & 5 & 4 & 28 & 3.0 & 3 \\
\hline Deep infection & 1 & 7 & 0 & 2 & 10 & 1.1 & 1 \\
\hline
\end{tabular}

Stabilisation is said to have failed when a second major operation to restore stability is necessary or when the bone remains unsta-

*Together 19 events: no specification of the complication occurred in the prosthesis or plate group.

\section{References:}

Prosthesis and plate osteosyn. thesis $4 "$. Zickel nails "1:16. intramedullary nails inzs ble. Stabilisation failed in a tenth of the patients regardless of the type of osteosynthesis used (table 7.1). Complications included adult respiratory distress syndrome (ARDS) after prostheses and nailing procedures, and deep infections. which were more common after plate osteosynthesis (table 7.1). In-hospital mortality varied from 0 to $18 \%$ and mean time in hospital from two to seven weeks.

Functional results of stabilising impending and actual fractures were usually combined. Seventy percent of the patients in the plated group became mobile. $76 \%$ in the Zickel nail group, and $80 \%$ in the prosthesis group. Continued pain was reported in a mean of $17 \%$ of patients ( $2 \%-28 \%)$. and there was no significant difference between the several implants.

The long Gamma nail is an intramedullary device. It consists of a curved nail in the femoral canal, a cervical lag screw, which is screwed through the nail into the femoral head, and two distal locking bolts that anchor the nail in the femur. In this way the femoral head is brought in continuity with the condyles. The device allows immediate full weight bearing.

The aim of this study was to find out the complications, survival, and functional results of the long Gamma nail in The Netherlands compared with those of other methods that have been published. 


\section{Patients and methods}

In a 5-year period. 101 patients with metastatic lesions in 110 femurs had long Gamma nails inserted. The operations were done by 44 surgeons in 20 hospitals throughout The Netherlands. There were 62 patients with actual pathological fractures, 27 with impending pathological fractures and 12 in whom a previous stabilisation of a pathological fracture had failed. Nine patients had bilateral operations.

The 12 patients whose primary stabilisation operation had failed included five after a standard Gamma nail, four after a Grosse-Kempf nail, and one each after Ender nails, Dynamic Hip Screw, and single bone-cemented plate. Four standard Gamma nails were complicated by fractures of the distal femoral shaft, three during the operation and one after three months. One Gamma nail broke after two months. Failures of the other seven implants were caused by local tumour problems, the time from the first operation until failure being 13 months (range 3 25).

All records were reviewed. Primary malignancy, duration of illness (defined as the time between the detection of the primary cancer and operation on the femur), time in hospital, complications, re-operations, and survival were recorded. Radiographs of five patients were missing and the others were reviewed. Location and diameter of the metastasis, amount of cortical destruction, and technical aspects of the stabilisation were noted.

With the consent of the patient or the family, and with the co-operation of surgeons and general practitioners, data about the present state of the patient or outcome were collected by telephone interview. Patients were followed for at least for

\section{Table 7.2}

Aetiology of the primary cancer related to the sex, age, duration of illness, and survival.

\begin{tabular}{|c|c|c|c|c|c|c|c|c|}
\hline $\begin{array}{l}\text { Aetiology of the } \\
\text { primary cancer }\end{array}$ & No. & $\begin{array}{l}\text { Actual } \\
\text { fracture }\end{array}$ & $\begin{array}{l}\text { Impending } \\
\text { fracture }\end{array}$ & $\begin{array}{l}\text { Secondary } \\
\text { procedure }\end{array}$ & female (\%) & $\begin{array}{l}\text { Mean age } \\
\text { (years) }\end{array}$ & $\begin{array}{l}\text { Mean (range) } \\
\text { duration of } \\
\text { illness (months) }\end{array}$ & $\begin{array}{l}\text { Mean (range) } \\
\text { survival (months) }\end{array}$ \\
\hline Breast & si & 34 & 9 & 8 & 100 & $60^{*}$ & $49(0.288)^{*}$ & $14(0.72)^{* *}$ \\
\hline Lung & 10 & 6 & 4 & & 30 & 65 & $6(0.15)$ & $3(0-9)$ \\
\hline Renal & 12 & 4 & 6 & 2 & 42 & 64 & $68(0.206)^{*}$ & $18(0.82)^{* *}$ \\
\hline Multiple myeloma & 7 & 4 & 3 & & 14 & 70 & $10(0 \cdot 40)$ & $13(0.45)$ \\
\hline $\begin{array}{l}\text { Adenocarcinoma } \\
\text { of unknown origin }\end{array}$ & 5 & 4 & & 1 & 60 & 76 & $2(0.6)$ & $4(0-14)$ \\
\hline Other & 16 & 10 & s & 1 & so & 68 & $19(0.60)$ & $8(0.26)$ \\
\hline TOTAL & 101 & 62 & 27 & 12 & 71 & 63 & $37(0.288)$ & $12(0-82)$ \\
\hline
\end{tabular}

18 months (mean 45 months, range 18-82), or until death (mean 9.3 months. range 0-72). We recorded functional results in patients who survived more than one month $(n=75)$. Mobility was scored "full" when the patient was able to walk more than 500 metres with or without a walking aid. "moderate" if only small distances could be walked with a walking aid, or "bedridden" when the maximum
- $p<0.05$ compared with the other groups (Spearman test). * $<<0$. os compared with lung carcinoma (Kaplan-Meies log rank test). 
transfer that was possible was from bed to chair. Pain was scored "absent" when only occasional oral painkillers were used, "moderate" when they were used regularly, or "severe" when the pain was difficult to treat with oral painkillers or when narcotic analgesics were used regularly.

Data were analysed with the Statistical Package for the Social Sciences. Both the Kaplan-Meier curve with log-rank test, and the Spearman ranking test were used. Significance was accepted when the probability was less than 0.05 .

\section{Results}

Details of patients are given in table 7.2. Patients with breast cancer were younger than the others $(p=0.019)$. Patients with breast and urogerital cancer had had their cancers longer than the others $(p=0.004)$ and they survived longer than those with lung carcinoma did (mean 18, 14, and 3 months, respectively $p=$ 0.009 : figure 7.1 ). The five patients with adenocarcinoma of unknown origin had a short duration of illness and survival.

The lesser trochanter and proximal femoral shaft were the commonest sites of

Table 7.3

Location of the metastases in 105 femurs of 96 patients.

In the remaining 5 the radio. graphs were missing. metastases (table 7.3). Metastases in the greater trochanter were larger $(p=0.030)$ than those in the lesser trochanter or in the femoral shaft (table 7.4). Twelve fractures occurred in diffusely invaded femurs. The location, diameter, and cortical involvement of the metastases were not related to the results. The femoral neck was involved in 18 patients. Six patients had lesions distal to the nail, but this did

\begin{tabular}{|l|c|c|c|c|}
\hline & No. & $\begin{array}{l}\text { Actual } \\
\text { fracture }\end{array}$ & $\begin{array}{l}\text { Impending } \\
\text { fracture }\end{array}$ & $\begin{array}{l}\text { Secondary } \\
\text { procedure }\end{array}$ \\
\hline Femoral neck* & 18 & 13 & 3 & 2 \\
\hline Lesser trochanter & 30 & 14 & 12 & 4 \\
\hline Greater trochanter & 12 & 6 & 3 & 3 \\
\hline Shaft & 31 & 18 & 12 & 1 \\
\hline Lesser and greater trochanter & 7 & 5 & & 2 \\
\hline Lesser trochanter and shaft & 7 & 5 & 1 & 1 \\
\hline Greater trochanter and shaft & 3 & 1 & 2 & \\
\hline Diffuse through the femur & 15 & 12 & 2 & 1 \\
\hline TOTAL & 105 & 61 & 32 & 12 \\
\hline
\end{tabular}
not affect the results.

One patient with a fracture and two patients with impending fractures showed symptoms of hypoxemia during operation and developed different stages of ARDS. One pulmonary embolus, one deep venous thrombosis, and one thrombosis of the vena cava were recorded. One deep infection. after failure of a standard Gamma nail, was treated with antibiotics.

Mean time to discharge to (nursing) home was 17 days (range 1-67). Fourteen

- not the primary indication to operate. therefore not counted in 'TOTAL' patients died in hospital. Three were found dead in bed of unknown cause. one had a cardiac arrest. one died of ARDS, one of Gram-negative sepsis, and eight others died after a period of cachexia.

\section{Implant related complications}

One operation was terminated when a fracture below the distal locking bolt was suspected. A postoperative radiograph confirmed the fracture, and a Partridge banding was done at a second operation. Thirty surgeons mentioned 37 difficul- 
ties during operation: II had problems with passing the guide wire, four with reaming, two with placing the nail. six with inserting the cervical lag-screw, 12 with distal locking. and on two occasions instruments failed. One nail was inserted too deep and perforated the ventral aspect of the patella-femoral joint, without complaints. Eight of 27 patients with impending fractures completed the fracture during operation, without consequences for mobilisation.

Two nails broke. The patient with failed Ender nails was completely mobilised after a long Gamma nail had been inserted. After seven months, she fell at home and broke the nail at the site of the cervical lag screw, $3 \mathrm{~cm}$ above the fractured metastasis. A new long Gamma nail enabled her to achieve full weight bearing until her death, 65 months later. A second patient with a trochanteric metastasis of a urogerital tumour was irradiated in 1983, and the femur fractured in 1993. After 14 months, and two fractured Grosse-Kempf nails ( 13 and $14 \mathrm{~mm}$ ), cancellous bone was added and an $11 \mathrm{~mm}$ long Gamma nail was inserted. The nail was dynamised after six months, which resulted in $1.5 \mathrm{~cm}$ shortening. Two months later, the nail broke in its small part, at the site of the ununited metastasis (figure 7.2). A custom-made long Gamma nail of $14 \mathrm{~mm}$ was inserted without distal locking. This implant remained stable until the patient died at 38 months.

four complaints needed minor interventions. Two of the 18 non-locked nails needed to be locked secondarily, one because of pain, the other because of rota-

Figure 7.1

Survival of patients suffering from breast carcinoma, uroge. nital carcinoma. lung carcinoma and others

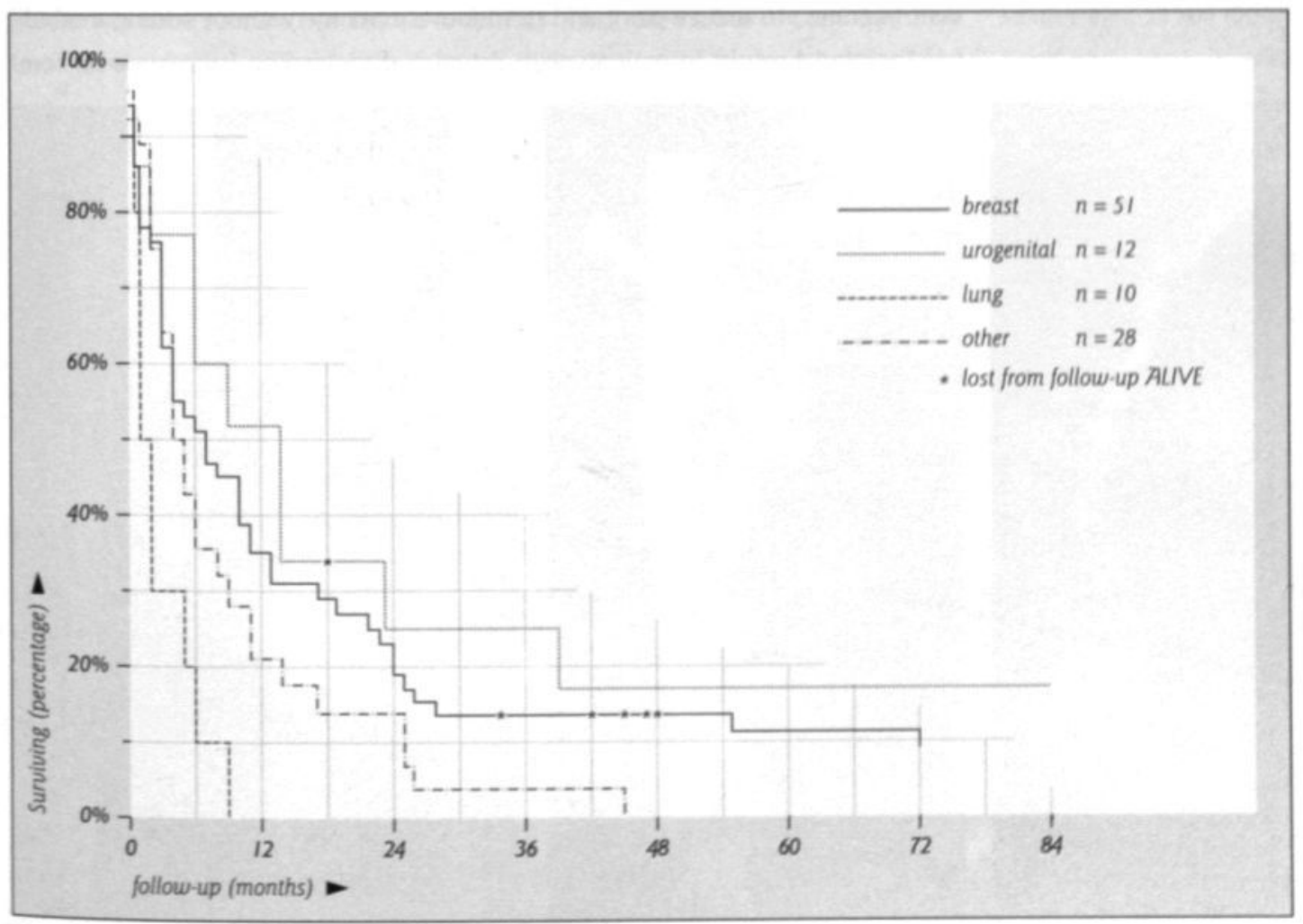


tional instability. In one patient the locking bolts were removed because of local pain. One nail was removed because of pain in the bursa overlying the cervical lag

\begin{tabular}{|c|c|c|c|c|c|c|c|}
\hline & \multirow[t]{2}{*}{ No. } & \multicolumn{3}{|c|}{ Actual fracture } & \multicolumn{3}{|c|}{ Impending fracture } \\
\hline & & $<5 \mathrm{~cm}$ & $6-8 \mathrm{~cm}$ & $>8 \mathrm{~cm}$ & $<5 \mathrm{~cm}$ & $6-8 \mathrm{~cm}$ & $>8 \mathrm{~cm}$ \\
\hline Lesser trochanter & 26 & 10 & 6 & 0 & 5 & 5 & 0 \\
\hline Greater trochanter & 9 & 0 & 5 & 1 & 0 & 2 & 1 \\
\hline Shaft & 29 & 8 & 3 & 0 & 9 & 5 & 4 \\
\hline TOTAL & 64 & 18 & 14 & 1 & 14 & 12 & 5 \\
\hline
\end{tabular}
screw.

\section{Functional results}

The 50 patients with actual fractures and 25 patients with impending fractures, who survived more than one month. were studied for

\section{Table 7.4}

Diameter of metastases limited to one region. for the impen. ding and actual fracture group. functional results (figure 7.3). All the 50 patients with fractures were bedridden and had pain before operation, and all of them improved after operation. Nine patients in the impending group were fully mobile before operation. II moderately mobile, and five bedridden. After operation. is became fully mobile. seven moderately mobile, and three remained bedridden. Two patients did not achieve their preoperative mobility. Ten of the 25 patients had severe pain, 14 moderate pain, and one had no pain before operation. Postoperatively nine patients had moderate pain and 14 had no pain.

\section{Discus s ion}

The aim of prophylactic osteosynthesis is to improve the quality of life, to prevent fractures, to reduce pain, and to improve mobility, without adding morbidity. ${ }^{2}$ Functional results in patients with actual and impending fractures were com-

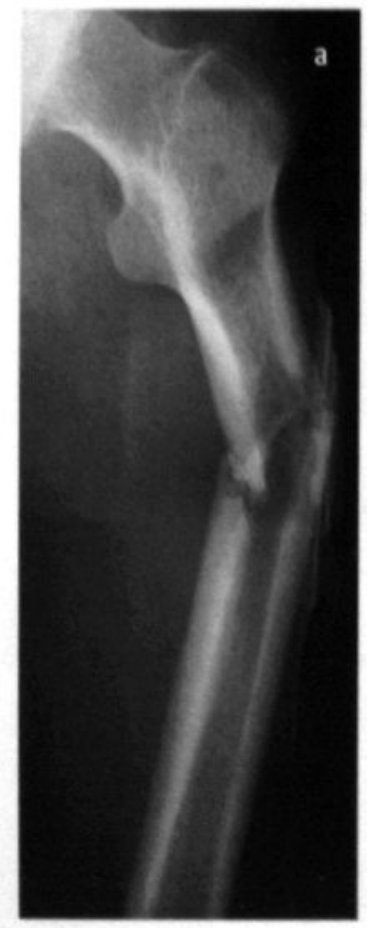

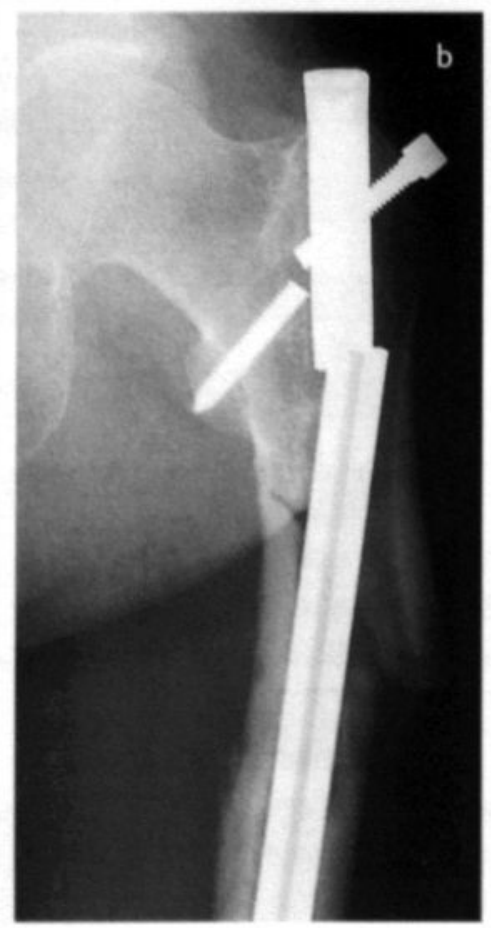

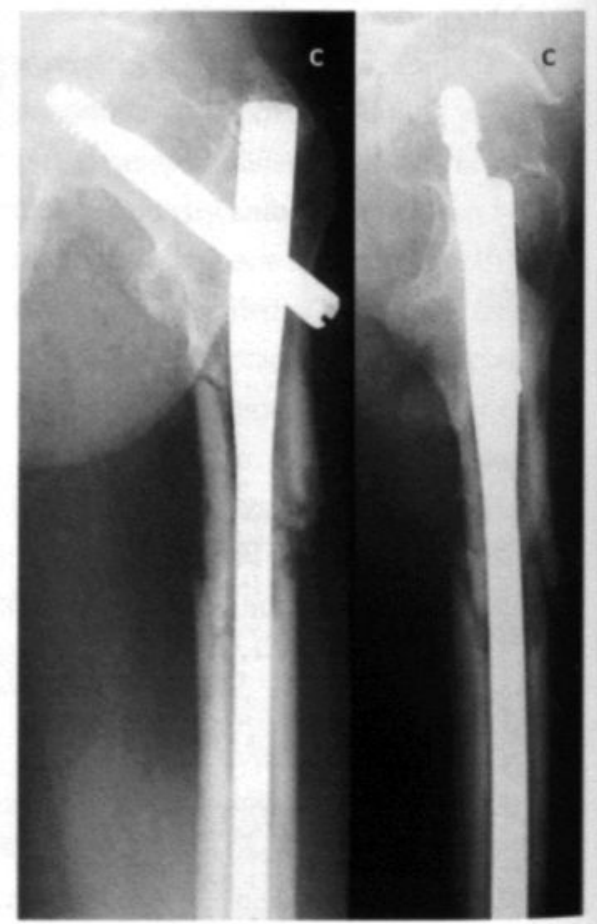


parable, although two of the latter became less mobile (figure 7.3). Prophylactic nailing was easier than nailing a fractured femur because alignment was intact. ${ }^{424.25}$ Five fractures had to be exposed to achieve alignment and three closed reductions were considered difficult. Eight femurs in the impending group (24\%) fractured easily during operation, which indicated that a fracture was indeed impending. We did not find that prophylactic nailing resulted in fewer complications. ${ }^{42426}$ One must, however, be aware that it is possible for prophylactic nailing to worsen the quality of life, so strict indications and individualisation are necessary. Common practice is to operate on patients with metastases that destroy more than $2.5 \mathrm{~cm}$ of the cortex, or affect more than half the diameter of the shaft. or when a painful lesion does not respond to radiotherapy.5.25.26 Dijkstra showed that worsening pain leads to fracture after a short time. ${ }^{n}$ Mirels differentiated functional and non-functional pain. ${ }^{28}$ Functional pain is aggravated by limb movement and weight bearing. This pain is caused by micro-fractures, which in the end lead to a complete fracture. Radiotherapy is therefore not recommended. Nonfunctional pain is caused by direct tumour expansion, oedema, and raised intramedullary pressure. It rarely gives rise to fractures and responds well to radiotherapy.

The lesser trochanter and the proximal femoral shaft were involved twice as often as the greater trochanter, but these lesions were smaller than those in the greater trochanter were $(p=0.030$, table 7.4$)$. This shows that the compression force on the medial aspect of the femur is more important for load bearing than

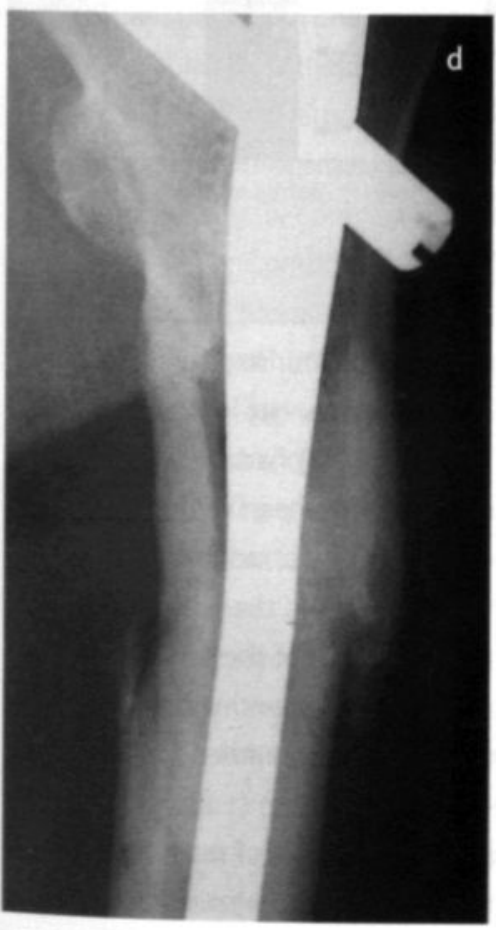

the tension force on the greater trochanter. ${ }^{29}$ The femur was diffusely involved in $20 \%$ of those with fractures, compared with $6 \%$ of the prophylactic group (table 7.3). These patients do not complain before the fracture, and do not seek medical help, but do have a big chance of fracturing. A mottled appearance of scattered lesions on the contrary, which we seldom saw, seems to have a lower incidence of fractures than a solitary lesion. ${ }^{16}$ To trans-

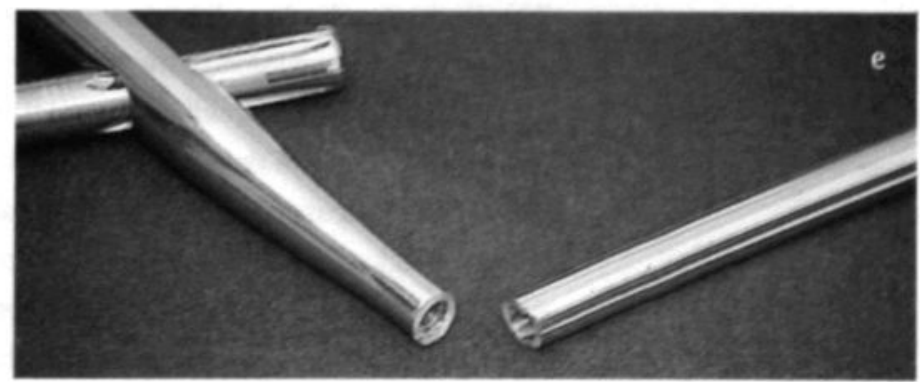
after a year (b). A long Camma nail was inserted together with a cancellous bone graft (d). The $12 \mathrm{~mm}$ Camma nail frac. tured (arrow) after 9 months. The nail was replaced with a $14 \mathrm{~mm}$. custom made long Camma nail, which remained stable until death after 30 months (d). The broken long Gamma nail (e).

Figure 7.2

A 65 year old man with a Grawitz tumour. 9 years after his first symptoms he fractured his left femur (a). The fracture was stabilised with $a 12 \mathrm{~mm}$ Grosse-Kempl nail, because of a fracture the nail was replaced by a $14 \mathrm{~mm}$ Grosse. Kempf nail. which fractured 
late these remarks into daily practice, it seems reasonable to operate on patients who complain of increasing functional pain, regardless on the site and size of the metastasis, or patients who show diffuse involvement, or small solitary lytic lesions in the compression stress zone (the lesser trochanter and femoral shaft). regardless of pain. Only lesions causing non-functional pain can be irradiated without osteosynthesis.

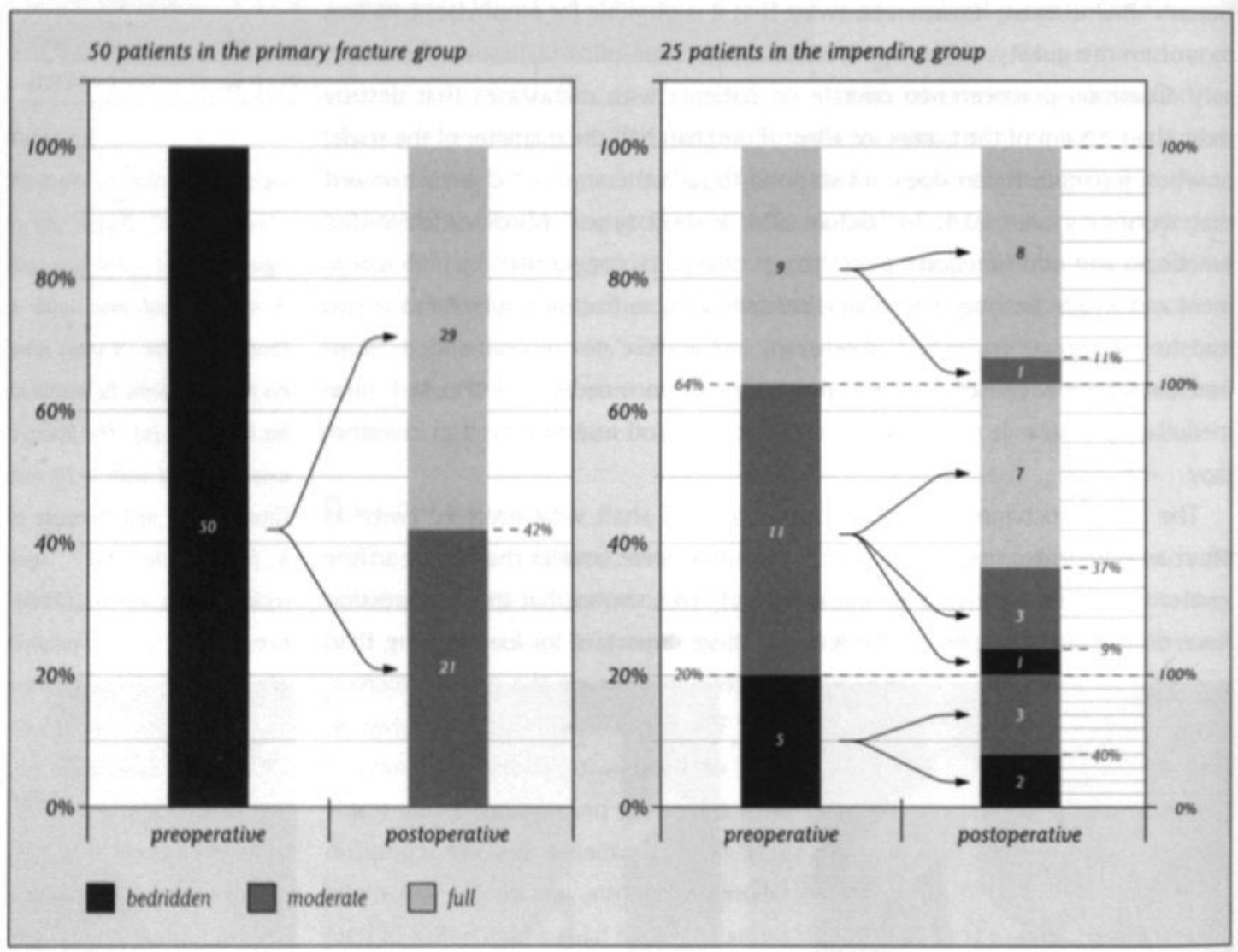

Figure 7.3

Mobility of patients surviving more than a month. Preoperative versus postoperative status. Left are 50 patients in the primary fracture group. right are 25 patients in the impending group.
When the decision to operate is made, the whole femur has to be stabilised. Van der Hulst found that $18 \%$ of femoral neck fractures had occurred through metachronic metastases. ${ }^{18}$ In our series, 18 patients (17\%) had metastases in the femoral neck and six showed lesions distal to the stabilised part of the shaft (table 7.3). In three patients, a long Gamma nail was placed as a secondary procedure after proximal progression of the tumour. which destabilised the previous implant. A standard Gamma nail. which does not stabilise enough of the femoral shaft, or a straight nail, which does not stabilise the femoral neck, are therefore not suitable in metastatic disease. Postoperative radiotherapy is recommended to prevent entmetastasis and further local spread. ${ }^{20}$

In three patients, one of who died, symptomatic emboli of reaming-products during the operation were suspected. Only five patients $(0.5 \%)$ with postoperati- 
ve ARDS have been described in recent publications..$^{1219.20 .2330}$ This conflicts with the attention given in some reports, particularly concerning the side effects of prophylactic nailing. ${ }^{3132}$ So. the complication is not common, or fat embolism is considerably under-reported. Reaming slowly without much force, and the use of sharp reamers, reduces the intramedullary pressure and perhaps prevents embolism. ${ }^{33.34}$ Pulmonary metastases caused by the nailing procedures have not been described, and were not seen in our series.

\section{Implant related complications}

We found three major implant-related failures, compared with $10 \%$ of major technical complications in other reports (table 7.1). One distal femur fractured during operation and needed to be re-operated on. Such distal fractures are described as a complication of the standard Gamma nail. ${ }^{\text {ss }}$ These fractures occur as a result of hammering the nail, inserting too thick a nail, pre-hammering the distal drill holes with an awl, or after multiple locking attempts. ${ }^{36}$ Nails placed in a suboptimal axis provoke stress risers at the tip of the nail, which can result in a distal fracture later on. ${ }^{35}$ Five long Gamma nails were inserted in this series after fractures below a standard Gamma nail. The Gamma nails are thinner nowadays, the awl for distal locking is replaced by a centre drill, and the use of a hammer has been abandoned. These measures, together with greater experience, should allow the incidence of distal fractures to diminish.

All implants will ultimately fail. Materials, diameter, rigidity, and design contribute to the strength of the implant. Many fractures do not heal, so the implant should be able to withstand the strain of weight bearing for the rest of the patient's life. This is particularly important when survival can be long. as in the case of breast and urogerital cancer. In our series. two patients fractured their long Gamma nails. This is comparable with the reported results of prostheses, other nails, and Double Compound Plate Osteosynthesis. ${ }^{4+1.23}$ Single plates, even with bone cement, are prone to fracture. ${ }^{5.7}$ Brink reported four $(0.2 \%)$ fractures of the standard Gamma nail in The Netherlands. ${ }^{37}$ The nails fractured at the site of insertion of the cervical lag-screw. This has also been reported by Zafiropoulos and was the site in one of our own patients. ${ }^{38}$ The other nail broke at the transition of the broad to the small part, which has not been described before (figure 7.2). Both areas are below the trochanteric region. corresponding to the location of most pathological fractures. When problems with stabilisation are feared and the marrow canal is wide enough. a 12 or $14 \mathrm{~mm}$ long Gamma nail can be ordered.

Osteosynthesis material can loosen and migrate after all kinds of stabilisation procedures for pathological fractures (table 7.1). Loosening can result from tumour growth. (avascular) necrosis of the femoral head. collapse of the bridged fracture. or technical errors. Repeated drilling to obtain an optimal position of screws weakens the femoral head, femoral neck, or diaphyseal cortex. Protrusion of the 
cervical screw into the acetabulum gives rise to pain, which necessitates a second operation. The cervical part of the Zickel nail is fixed to the nail, so protrusion into the acetabulum is common (5\%). The sliding cervical lag screw of the Gamma nail prevents this protrusion. Lateral migration of the screw is prevented by correct use of the set screw, which allow only limited gliding. Loosening of the locking bolts can cause rotational instability, or pain from collapse at the fracture site. The best way to prevent this migration is to drill securely, use deep threaded screws and, when there is severe osteoporosis, use a counter nut inserted from the medial side.

\section{Functional results}

The functional results are hard to compare with those reported elsewhere because most authors use their own scoring systems. About $70 \%$ of the patients treated with plates become mobile, and $80 \%$ after nailing or prosthesis. Pain is recorded in $2 \%-28 \%$ of the patients regardless of the implant used. In our series. $92 \%$ of the patients became mobile, and $93 \%$ had little or no pain. Our study was. of course, retrospective and the data were collected by non-standardised telephone interviews. These may bias the results, but they are promising.

\section{Conclusion}

The long Gamma nail is an improvement in the treatment of impending and actual pathological femoral fractures. Major technical complications occurred in $5 \%$ of the patients, compared to $10 \%$ in literature for other operative methods. General complications and in-hospital mortality were comparable with other reports. ARDS remains an area of concern. Problems after prophylactic nailing may worsen the quality of life for individual patients, so strict criteria about when to operate on lesions that threaten to fracture must be adopted. The most important indication for prophylactic nailing of a femur is a patient who complains of functional pain. The functional results compare well with other reports: $92 \%$ of the patients became mobile, and $93 \%$ had no or acceptable pain. 
1. Habermann ET, and Lopez RA. Metastatic disease of bone and treatment of pathological fractures.

Orthop. Clin. North Am. 1989: 20:

469-486.

2. Werken $C$ van der, Dolman A and Maat B.

Palliatieve behandeling van skeletmetastasen bij patiēnten met mammacarcinoom.

Ned. Tijdschr. Geneeskd. 1987: 131: 609-612.

3. Friedl W. Indication, management and results of surgical therapy for pathological fractures in patients with bone metastases. Eur. J. Surg. Oncol. 1990; 16: 380-396.

4. Broos PL, Reynders PA, Bogert W van den, and Vanderschot P. Surgical treatment of metastatic fracture of the femur improvement of quality of life. Acta Orthop. Belg. 1993: 59 Suppl I: 52-56.

5. Dijkstra PDS, Wiggers T, Geel BN van. and Boxma $\mathrm{H}$. Impending and actual pathological fractures in patients with bone metastases of the long bones.

A retrospective study of 233 surgically treated fractures.

Eur. J. Surg. 1994: 160: 535-542.

6. Hertlein H. Schurmann M. Piltz S. Kauschike T, and Lob G.

Operative Behandlungsstrategien bei Femurmetastasen.

Zentralbl. Chir. 1993: 118: 532-538.
7. Korkala $\mathrm{OL}$, and Karaharju EO.

Metastatic fractures of long bones.

Int. Orthop. 1991: 15: 105-109.

8. Kurock W. Sennerich T, and Issendorff WD von. Versorgung pathologischer Femurfrakturen bei malignen Knochentumoren und Skeletmetastasen. Langenbecks. Arch. Chir. 1989; 374: 291-298.

9. Rompe JD, Eysel P, Hopf C. and Heine J. Metastatic instability at the proximal end of the femur. Comparison of endoprosthetic replacement and plate osteosynthesis. Arch. Orthop. Trauma. Surg. 1994: 113 : 260-264.

10. Rosenberger J, and Zieren HU.

Die Therapie maligner pathologischer Frakturen. Ergebnisse einer retrospektiven Untersuchung.

Unfallchirurgie. 1989: 15: 279-284.

II. Yazawa Y, Frassica FJ. Chao EYS, Pritchard DJ. Sim FH, and Shives TC. Metastatic bone disease. A study of the surgical treatment of 166 pathologic humeral and femoral fractures.

Clin. Orthop. 1990: 251: 213-219.

12. Fasano FJ. Olysav DJ, and Stauffer ES. Intramedullary stabilization of neoplastic destructive disease involving the subtrochanteric region of the femur. Orthopedics. 1988: 11: 1699-1704. 
13. Mickelson MR, and Bonfiglio M.

Pathological fractures in the proximal part of the femur treated by Zickel-nail fixation.

J. Bone Joint Surg. Am. 1976: 58:

$1067-1070$.

14. Sangeorzan BJ. Ryan JR, and

Salciccioli GG. Prophylactic femoral

stabilization with the Zickel nail by closed technique.

J. Bone Joint Surg. Am. 1986; 68: 991-999.

15. Taylor A, and Rush J. The zickel nail in the treatment of metastatic bone disease in the upper end of the femur.

Aust. N. Z. J. Surg. 1992; 62: 382-384.

16. Zickel RE, and Mouradian WH. Intramedullary fixation of pathological fractures and lesions of the subtrochante. ric region of the femur.

J. Bone Joint Surg. Am. 1976: 58:

$1061-1066$.

17. Behr JT, Dobozi WR, and Badrinath K.

The treatment of pathologic and impending pathologic fractures of the proximal femur in the elderly.

Clin. Orthop. 1985: 198: 173-178.

18. Hulst RRW] van der. Wildenberg FAJM

van den. Vroemen JP, and Greve JW.

Intramedullary nailing of (impending)

pathologic fractures.

J. Trauma. 1994: 36: 211-215.
19. Karachalios T. Atkins RM, Sarangi PP.

Crichlow TP, and Solomon L.

Reconstruction nailing for pathological subtrochanteric fractures with coexisting femoral shaft metastases.

J. Bone Joint Surg. Br. 1993: 75: 119-122.

20. Doorn R van. Hulst RRW] van der, and Wildenberg FAJM van den. Intramedullaire fixatie bij (dreigende) femurfracturen door tumormetastasen.

Ned. Tijdschr. Geneeskd. 1994: 138:

2101-2105.

21. Weikert DR, and Schwartz HS. Intramedullary nailing for impending pathological subtrochanteric fractures. J. Bone Joint Surg. Br. 1991: 73: 668-670.

22. Papagiannopoulos G. Karpinski MR, Newton G, and Cargill AO. Medullary femoral nailing of pathological fractures using the Derby nail. A preliminary report of 22 cases. Injury. 1986: 17: 240-247.

23. Williams WW. Hudson I. Hall AJ. Strachan JC. Kernohan JG, and Jameson Evans DC. KY nailing of impending and pathological fractures of the proximal femur. Int. Orthop. 1992: 16: 93-95.

24. Nieder E, Engelbrecht E, Steinbrink K. and Keller A. Modulares System fur den Femurtotalersatz Endo-Modell.

Chirurg. 1983: 54: 391-399

25. Fidler $M$. Incidence of fracture through metastases in long bones.

Acta Orthop. Scand. 1981: 52: 623-627. 
26. Haentjens $P$, Casteleyn $P$, and Opdecam $P$. Evaluation of impending fractures and indications for prophylactic fixation of metastases in long bones.

Review of the literature.

Acta Orthop. Belg. 1993: 59 Suppl 1: 6-11.

27. Dijkstra PDS, Oudkerk M, and Wiggers T. Prediction of pathological subtrochanteric fractures due to metastatic lesions.

A retrospective study of 54 lesions at risk to fracture.

Arch. Orthop. Trauma. Surg. 1997: 116: $221-224$

28. Mirels $\mathrm{H}$. Metastatic disease in long bones. A proposed scoring system for diagnosing impending pathologic fractures.

Clin. Orthop. 1989: 249: 256-264

29. Schatzker J. and Waddell JP. Subtrochanteric fractures of the femur. Orthop. Clin. North Am. 1980: II: $539-554$

30. Johnstone DJ, Radford WJ, and Parnell EJ. Interobserver variation using the AO/ASIF classification of long bone fractures. Injury. 1993: 24: 163-165.

31. Karachalios T. Geeurickx A, and Newman JH. Fatal air embolism after prophylactic intramedullary nailing. A case report. J. Bone Joint Surg. Am. 1992: 74 : $1101-1102$

32. Duis $\mathrm{HJ}$ ten. The fat embolism syndrome. Injury. 1997: 28: 77-85.
33. Wenda K, Runkel M, Degreif J. and Ritter G. Pathogenesis and clinical relevance of bone marrow embolism in medullary nailing: demonstrated by intraoperative echocardiography.

Injury. 1993: 24 Suppl 3: 573-81.

34. Pape HC, Dwenger A, Regel G.

Schweitzer G. Jonas M. Remmers D et al. Pulmonary damage after intramedullary femoral nailing in traumatized sheep. Is there an effect from different nailing methods? J. Trauma. 1992; 33: 574-581.

35. Aune AK, Ekeland A. Odegaard B. Grogaard B, and Alho A. Gamma nail vs compression screw for trochanteric femoral fractures. Is reoperations in a prospective, randomized study of 378 patients.

Acta Orthop. Scand. 1994: 65: 127-130.

36. Lacroix H. Arwert H. Snijders CJ. and Fontijne WP. Prevention of fracture at the distal locking site of the Gamma nail.

A biomechanical study.

J. Bone Joint Surg. Br. 1995: 77: 274-276.

37. Brink WA van den, and Janssen IMC. Failure of the Gamma nail in a highly unstable proximal femur fracture: Report of four cases encountered in the Netherlands.

J. Orthop. Trauma. 1995: 9: 53-56.

38. Zafiropoulos G. and Pratt DJ. Fractured Gamma nail. Injury. 1994: 25: 331-336. 
To solve problems after failure of a standard Gamma nail

R. van Doorn. J.W.J.L. Stapert

European Journal of Trauma 2001: 27: 123-128 


\section{Introduction}

In The Netherlands 6000 per- and subtrochanteric fractures are treated annually.' Half the Dutch trauma units use the standard Gamma nail regularly for these fractures. ${ }^{2}$ The most frequent complication in the use of the standard Gamma nail reported is a fracture distal to the nail. ${ }^{3-14}$ The technical complications are dealt with prolonged immobilisation, stabilising the fracture with cerclage wires or screws. In a few cases the Gamma nail is replaced by an intramedullary nail in combination with separate bolts inserted into the femoral head. Their results are described fragmentary. To treat a fracture distal to a standard Gamma nail for a pathologic fracture the senior author in 1989 weld the proximal part of the Gamma nail on a Grosse-Kempf nail, this construction is the prototype long Gamma nail. ${ }^{15}$ After some modifications the long Gamma nail became an $11 \mathrm{~mm}$ intramedullary nail with an antecurvation of $10^{\circ}$ and a $4^{\circ}$ lateral curve. A $12 \mathrm{~mm}$ cervical lag screw is placed with angles of $125^{\circ}, 130^{\circ}$ or $135^{\circ}$ through the nail. Distally two $6.28 \mathrm{~mm}$ locking bolts can be inserted. Different nail lengths make distal locking as far as the condyles possible. We studied the use of the long Gamma nail in the
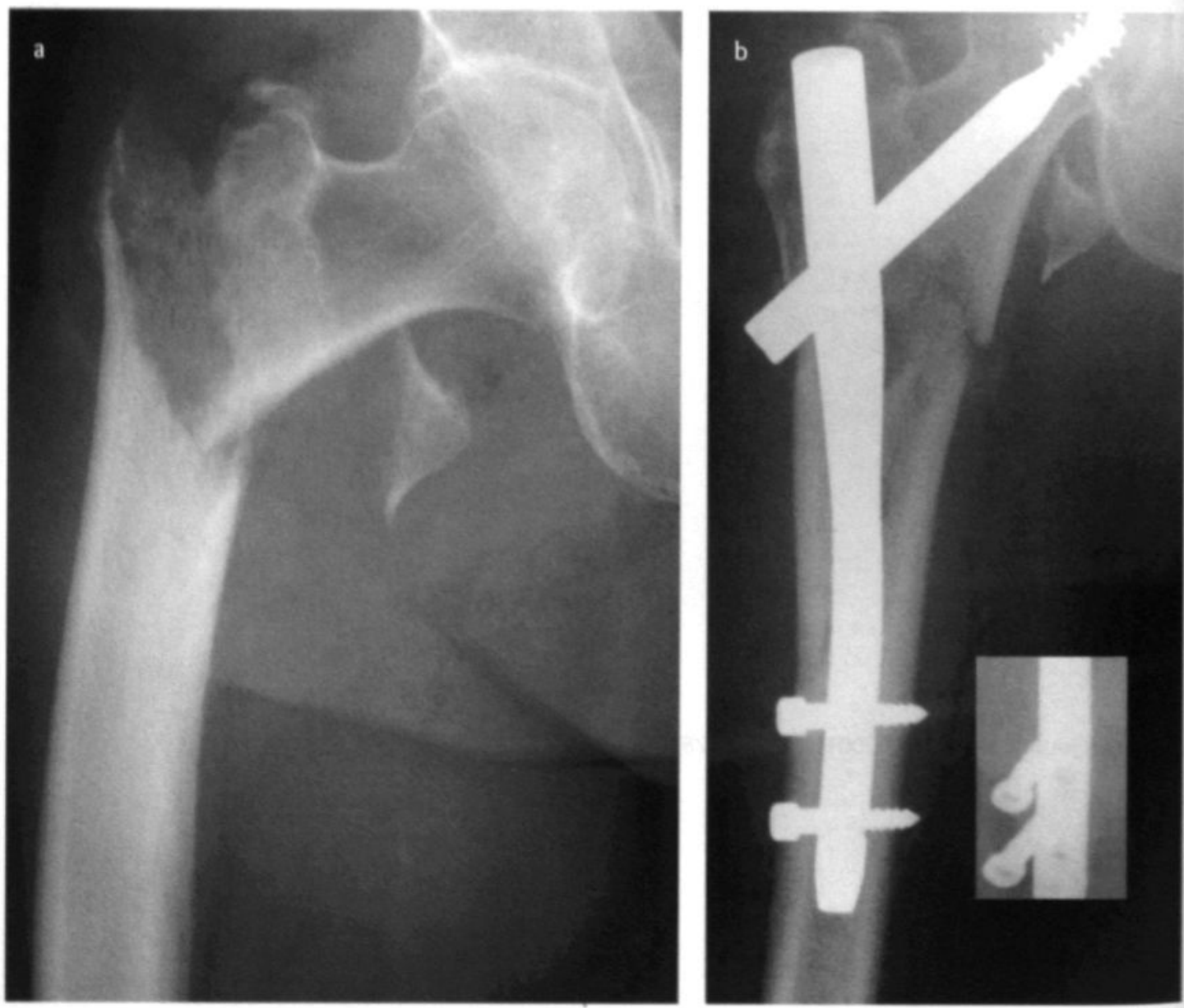
first five-year after its introduction in The Netherlands. From this material patients were selected who were treated with a long Gamma nail after a failed osteosynthesis with a standard Gamma nail.

The incidence of per- and subtrochanteric fractures, the widespread use of the standard Gamma nail and the incidence of problems make a proper problem solving technique important. The goal of this study is to describe the functional results and complications with the use of the long Gamma nail to solve these problems, and decide if this implant is adequate to solve the problems.

\section{Patients and methods}

From 1990 till 1995, 499 patients treated with a long Gamma nail (Howmedica Inc. Haarlem. The Netherlands) in 24 Dutch hospitals, were studied. Fifty-three of these patients were treated after failure of a standard Gamma nail, and are subject of this article. The group consist of 12 men with a mean age

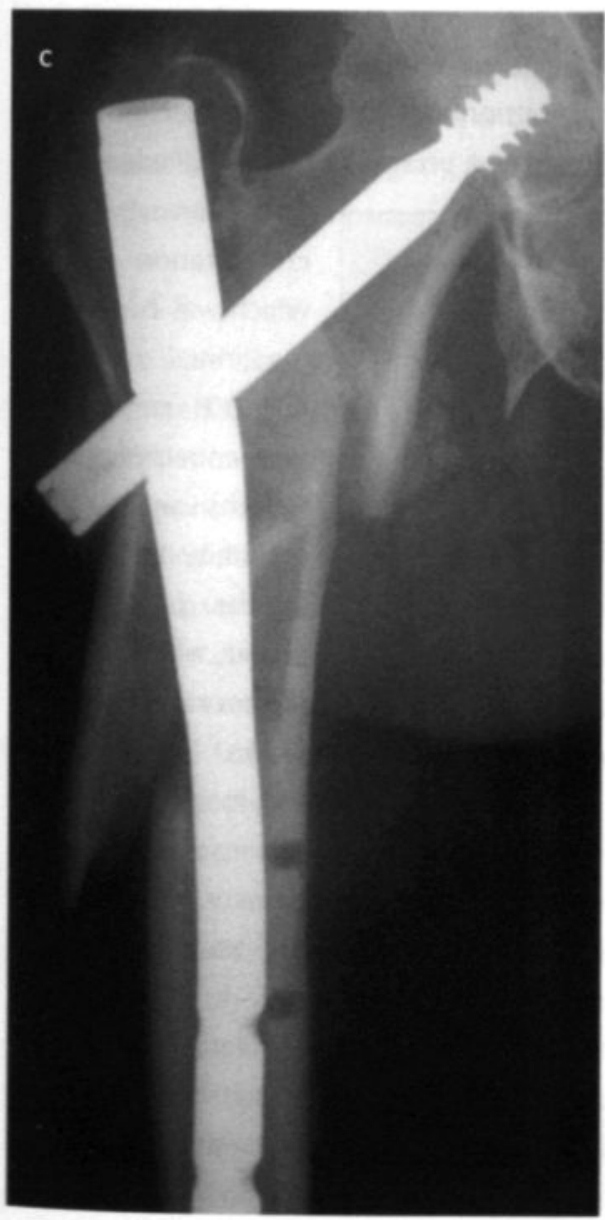

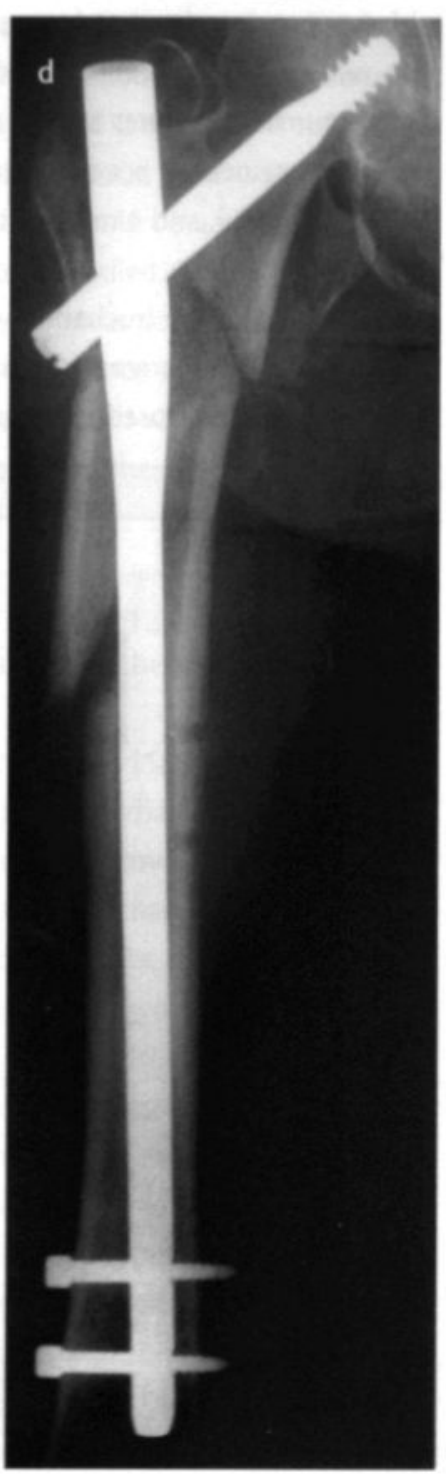

Figure 8.I.

An 80 year old female who felt at the street (a). A wrong target device must be used, only after operation was noticed that the distal bolts were displaced (b) The bolts were removed. the fracture collapsed and extern. ally rotated (c). With some difficulties $a$ long Camma nail was placed, the fracture consolidated within 4 months, she had no complains (d). 
Figure 8.2 .

Time (weeks) after the initial stabilisation with a standard Gamma nail of 71 (range $28-85$ ), and 41 women with a mean age of 81 (range $39-100$ ). 45 patients had a fracture distal to the nail; four had a fractured trochanter: three had a malreduced fracture \{figure 8.1$\}$; and one patient with a pathologic lesion fractured the nail after two months.

Six fractures distal to the standard Gamma nail occurred after hammering on the nail during insertion, two further nails jammed the medial cortex. Distal locking was responsible for 12 peroperative or early postoperative fractures: 4 times an awl or the screw was hammered to obtain grip. 3 bolts missed the nail, one fracture occurred through an empty hole, and 4 fractures occurred around the distal bolt without adequate explanation. Once reaming had been very hard, after minor trauma this patient fractured the leg. Twenty-four patients fractured the distal femur not directly related to a peroperative problem. One distal bolts migrated. after removal the femur fractured during a rotation. Twelve patients sustained minor trauma: 7 fractures started at the bolt and 5 from the tip of the nail. Eleven patients sustained an adequate trauma: 3 fractures started from the bolt, 4 from the tip of the nail, and 4 more distal in the femur ( 3 of which had real severe osteoporosis).

In one patient the trochanter was fractured during reposition with an inserted nail, one nail was hammered during insertion that fractured the trochanter, and two trochanters collapsed in the postoperative period. The three malreduced frac-

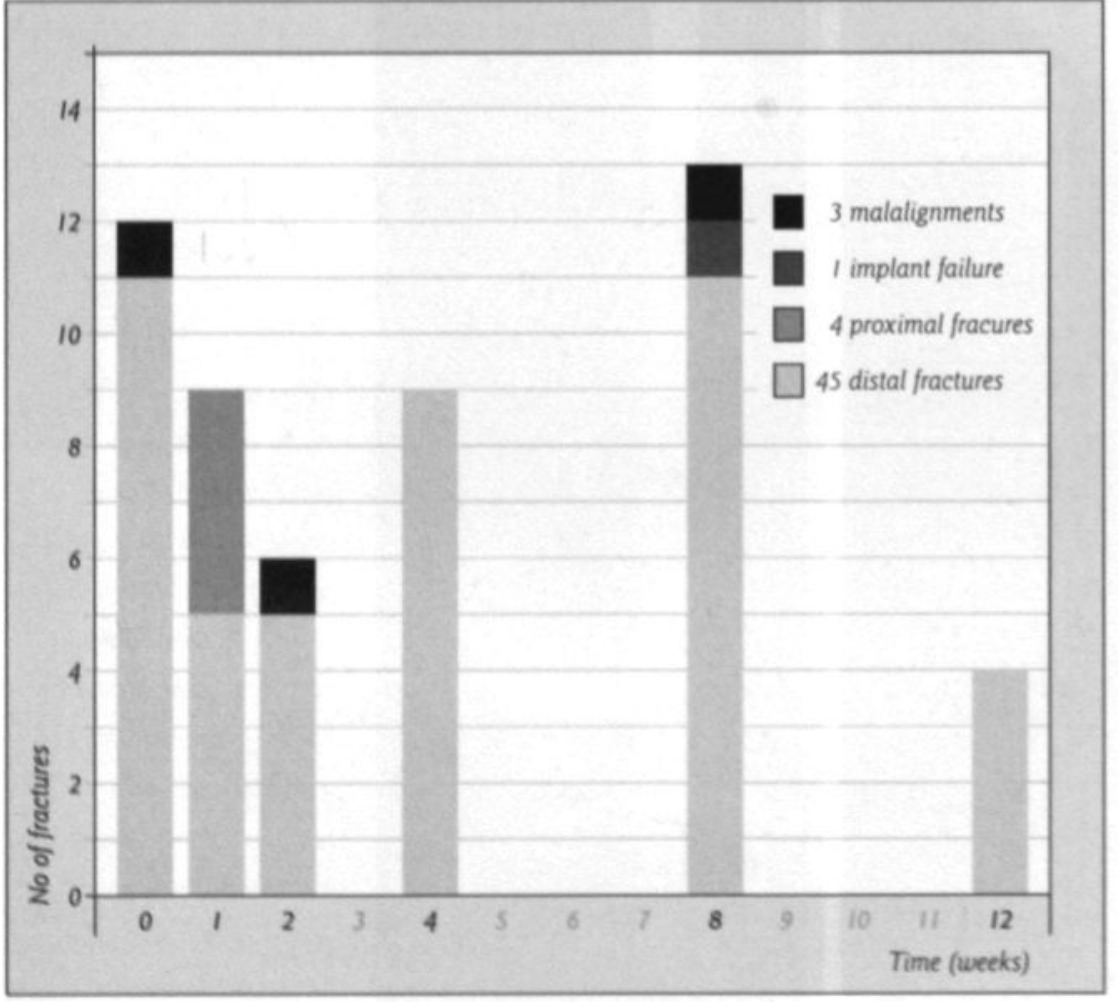

tures consist of one endorotation of $45^{\circ}$ which was corrected in the initial operation. one $30^{\circ}$ endorotation was corrected after 2 months and a varus deformity exaggerated in the postoperative period, which lead to a replacement after 3 weeks. In 12 patients the long Gamma nail was inserted during the primary operation with the standard gamma nail. In nine patients the long gamma nail was inserted within the first week, in 11 cases within the first month. 
and in 17 patients within the first four months \{figure 8.2 \}. The mean follow-up was 27 months (range I - 77). 30 patients survived more than two years.

The first author revealed all patients' records, and all but three sets of radiographs for procedures and complications. 27 radiographs were of adequate quality and performed regularly enough to assess consolidation. Radiographic consolidations was defined as callus formation at the fracture site, with the fracture line visible for less than a quarter of the circumference. The first author also performed a telephone interview to assess mobility and pain. after conclusion of the therapy. 26 patients were interviewed alive, after a mean follow-up of 40 months (range 12 - 77), of 25 patients who died after discharge from the hospital the general practitioner was interviewed about the best obtained functional status, one patient died in hospital and one was lost for follow up, both were excluded for the assessment of functional results. No adequate information about the prehospital mobility and pain was obtained. Mobility was scored 'complete' if the patient could walk without complaints, with or without the aid of a walking device. Mobility was scored 'limited' if only small distances could be walked with a walking device, and the patients were not completely satisfied. Mobility was scored 'bedridden' if only small transfers were possible. Pain was scored 'absent', 'moderate', or 'severe'. 'Moderate' pain was defined when minor painkillers were used, and the quality of live was slightly disturbed. 'Severe' pain was defined when narcotic drugs were used, or pain substantially diminished the quality of live.

\section{Results}

Patients were discharged from hospital after a median of 20 days (range 3 120): 14 stayed longer than a month in hospital, mainly because they were waiting for admission in a nursing home.

The surgeons decided during operation that 31 nails ( $58 \%)$ would be stable enough to allow full weight bearing. In II (2I\%) cases partial weight bearing. and in $11(21 \%)$ cases for six weeks no weight bearing was allowed. One patient died in hospital and another was lost to follow-up. Of the remaining 51 patients. 40 (76\%) became completely mobile, 10 (19\%) limited mobile, and one (2\%) remained bedridden. Forty-nine patients had no pain (96\%), two had moderate pain. and none suffered severe pain.

From 27 sets of radiographs consolidation could be assessed. 19 femora united within 4 months, 6 within 6 months, and 2 within 9 months. One nail was dynamized to achieved union at 9 months with a shortening of $2 \mathrm{~cm}$. In one other patient a $2 \mathrm{~cm}$ shortening occurred. Alignment could be assessed in 50 sets of radiographs. One antecurvation of $40^{\circ}$, and three of $20^{\circ}$ were seen. Three recurvation of $5^{\circ}-10^{*}$, and six varus or valgus deformities of $5^{*}$ were found. It is impossible to assess rotation on these radiographs, because the knee and femoral head were not depicted together. 
Minor complications like urine tract infections, adequately treatable pneumonia's or decompensation cordis were not noted because of the different quality of the records. Four serious general postoperative complications were seen. One cachectic patient died in hospital. One deep venous thrombosis was found on duplex echography. One pulmonary embolus was diagnosed by ventilation perfusion scan. Both problems were solved with heparin and acenocoumarol during three months. One patient developed an extensive decubital ulcer. which resulted in a below knee amputation.

Six (11\%) peroperative complications occurred. Three femurs fractured distal to the nail. In one patient the distal locking bolts were inserted next to the nail and one nail was introduced outside of the trochanter. These problems were treated conservatively with prolonged immobilisation. One cervical lag screw migrated laterally out of the femoral head and resulted in a $20^{\circ}$ varus deformity of the proximal fragment. The fracture was reduced and fixed with a dynamic condylar screw.

Two implant related problems occurred in later. One patient fractured the femur distal to the nail at six months after an adequate fall. The previous proximal femoral fracture was united, and a Grosse-Kempf nail was inserted. One patient developed an asymptomatic necrosis of the femoral head after 23 months. A total hip prosthesis was inserted.

Different protocols of prophylactic antibiotics were used in the different hospitals. Most surgeons used one dose or one day of cephalosporine. Two deep infections were treated with antibiotics intravenously. One on clinical grounds only, in another a positive blood culture with a haemolytic streptococcus was found. Another low-grade infection was suspected after the fracture had healed, the nail was removed but the culture remained sterile.

\section{Discussion}

In The Netherlands 6000 per- or subtrochanteric fractures are treated annually. Half the hospitals use the standard Gamma nail regularly to treat this fractures.? Knowledge of the implant and its complications is therefore mandatory. Twelve articles report about 2284 standard Gamma nails (50-648 patients per article). ${ }^{3-14}$ General complications and trombo embolic events are not reliable reported. The percentage of fractures distal to the nail varies from zero to $11 \%$ : a total of 65 (2.8\%) distal fractures are described. Cervical lag screw protrusion is mentioned 24 (1\%) times. Deep infections and union problems are reported in less than $1 \%$. No femoral head necrosis is seen. The technical problems are dealt with prolonged immobilisation, stabilising the fracture with cerclage wires or screws. In a few cases the Gamma nail is replaced for an intramedullary nail in combination with separate bolts inserted into the femoral head. Results of these salvage procedures are fragmentary, and not adequate to draw conclusions from.

Our study is biased because the patients were gained from a series regarding 
the long Gamma nail. Questioning the surgeons revealed that they mostly treat problems after their standard Gamma nails with a long version. Another point is that the results are retrospectively recorded, and the patients are interviewed but not examined. Non-the less we think this series is worthwhile because it describe that much patients.

The 53 patients show an overall complication rate of $28 \%$. Four general, six peroperative, two late implant related, and three infective problems. Six (11\%) of those complications were life threatening or required reoperation.

Five of the six peroperative complications were preventable: three distal fractures, one misplacement of a locking bolt and one nail missing the trochanter. It is obvious that a conscientious operation technique is important. Only one patient showed migration of the lag screw shortly after operation. We were concerned that repeated drilling and bringing the cervical lag screw, or another device, in another position in the head weakens the anchorage. Theoretically this can result in protrusion into the acetabulum, or lateral migration of the lag screw. In most radiographs however we noticed that the cervical lag screw followed the old canal if a similar angled nail was used. No literature data are available to strengthen our theoretical point, but seeing our results we advise to use one angled Gamma nail system in a single clinic, and stick to one implant as much as possible.

The late complications were a distal fracture and a femoral head necrosis. The femur fractured distal to the nail after an adequate fall. Distal fractures due to an adequate trauma are seen in all kinds of prosthesis and osteosynthesis. ${ }^{16}$ We suggest to use the longest possible nail in order to reach the supra-condylar area. A long nail transmits the forces acting on it more gradually to the femoral shaft. and reduces the change of a secondary fracture. Necrosis of the femoral head has been described in intertrochanteric fractures. as a result of disruption of the vessels by high-energy trauma. ${ }^{17}$ Intramedullary nailing can disturb the blood supply to the femoral head if the nail is placed in the fossa piriformis. ${ }^{18.19}$ The Gamma nail is curved and has to be inserted at the tip of the greater trochanter. No femoral head necrosis is described by the use of the standard Gamma nail, but their follow-up is mostly less than two years. ${ }^{3 \cdot 14}$ In our 30 patients that survived more than two years, one femoral head necrosis was seen in them.

In this series of secondary osteosynthesis three deep infections (6\%) were observed. none of which needed aggressive treatment. The series of standard Gamma nails report less than I\% deep infections. This seems to be underreported: Boxma describes deep infection rates of primary osteosynthesis of $0 \%$ to $15 \%$. These infection rates depend on the site of the fracture. for the trochanteric region $5 \% .{ }^{20}$ Compared to these figures our infection rate is acceptable.

Union- and alignment problems were only minor. despite the difficult patient group treated.

The percentage of patients who immediately after operation start to mobilise 
partial or full weight bearing is $79 \%$. Particularly in older patients, mobilisation is important to prevent general complications. Partial weight-bearing is difficult for those elderly patients, so the aim of operation has to be to provide a full weight bearing construction. The amount of patients who became complete $(76 \%)$ or limited (19\%) mobile is good.

Despite the fact that this study is retrospective, it seems that the long Gamma nail can resolve problems caused by the standard Gamma nail with an acceptable risk and good clinical results. A conscientious operation technique is needed to prevent unnecessary complications. When an operation with a standard Gamma nail is planned, a long version should be available so that problems encountered during the operation may be dealt with immediately. 
1. SIG Zorginformatie. Treatment of femoral fractures in the Netherlands. Bestanden van de Landelijke Medische Registratie over de ziekenhuisopnames 1992 - 1994. Utrecht, SIG. 1996.

2. Doorn $R$ van, and Stapert JWJL. De lange Gamma-nagel beoordeeld door leden van de Nederlandse Trauma verenigingen. Ned. Tijdschr. Trauma. 1999: 7: 16-21.

3. Arnaout A. Beya B. Delplace J. Vial D. and Lecestre P. Osteosynthese des fractures de la region trochanterienne par clou gamma, a propos de 76 cas revus. Acta Orthop. Belg. 1993: 59: 30-39.

4. Asche A. and Asche H. Die GammaNagelung. Ein neues Verfehren zur Stabiliserung pertrochantärer Oberschenkelfrakturen. Operative Orthopädie und Traumatologie. 1992: 4: 237-248.

5. Aune AK, Ekeland A. Odegaard B. Grogaard B. and Alho A. Gamma nail vs compression screw for trochanteric femoral fractures. 15 reoperations in a prospective, randomized study of 378 patients. Acta Orthop. Scand. 1994: 65: 127-130.

6. Boriani S. Bettelli G. Zmerly H. Specchia L. Bungaro P. Montanari G et al. Results of the multicentric Italian experience on the Gamma nail: a report on 648 cases. (published erratum appears in Orthopedics 1992: 15: 545).

Orthopedics. 1991: 14: 1307-1314.
7. Bridle SH. Patel AD, Bircher $M$, and Calvert PT. Fixation of intertrochanteric fractures of the femur. A randomised prospective comparison of the gamma nail and the dynamic hip screw.

J. Bone Joint Surg. Br. 1991: 73: 330-334.

8. Friedl W, Colombo Benkmann M, Dockter S. Machens HG, and Mieck U. Gammanagel-Osteosynthese per- und subtrochanterer Femurfrakturen, 4-Jahres. Erfahrungen und ihre Konsequenzen für die weitere Implantatentwicklung. Chirurg. 1994: 65: 953-963.

9. Guyer P, Landolt M, Keller $\mathrm{H}$, and Eberle C. Der Gamma-Nagel bei per- und intert rochantaren Femurfrakturen-Aiternative oder Erganzung zur DHS? Eine prospektive randomisierte Studie anhand von 100 Patienten mit per- und intertrochantaren Femurfrakturen an der Chirurgischen Klinik des Stadtspitals Triemli. Zurich. September 1989-Juni 1990.

Aktuelle. Traumatol. 1991: 21: 242-249.

10. Forthomme JP. Costenoble V, Soete P. and Docquier J. Traitement des fractures trochanteriennes du femur par le clou gamma (a propos d'une serie de 92 cas). Acta Orthop. Belg. 1993: 59: 22-29.

II. Halder SC. The Gamma nail for peritrochanteric fractures.

J. Bone Joint Surg. Br. 1992: 74: 340-344.

12. Heinz $T$, and Vècsei V. Komplikationen und Fehler bei der Anwendung des Gammanagels. Ursachen und Prävention. Chirurg. 1994: 65: 943-952. 
13. Kempf I, Grosse A. Taglang G, and Favreul $\mathrm{E}$. Le clou gamma dans le traitement a foyer ferme des fractures trochanteriennes. Resultats et indications a propos d'une serie de 121 cas.

Rev. Chir. Orthop. Reparatrice. Appar. Mot. 1993: 79: 29-40.

14. Radiord PJ, Needoff M, and Webb JK. A prospective randomised comparison of the dynamic hip screw and the gamma locking nail.

J. Bone Joint Surg. Br. 1993: 75: 789-793.

15. Stapert JW]L, Geesing CLM. Jacobs PB. Wit RJ de, and Vierhout PAM. first experience and complications with the long Gamma nail.

J. Trauma. 1993: 34: 394-400.

16. Mabrey JD, and Wirth MA. Periprosthetic fractures of the hip. In: Rockwood CA. Green DP, editors. Fractures in adults and fractures in children. 4th edition. Lippincott-Raven. Philadelphia. 1996. Chapter 10: 576-586.

17. Shih Ly, Chen TH, and Lo WH. Avascular necrosis of the femoral head. An unusual complication of an intertrochanteric fracture.

J. Orthop. Trauma. 1992: 6: 382-385.
18. O'Malley DE, Mazur JM, and Cummings RJ. Femoral head avascular necrosis associated with intramedullary nailing in an adolescent.

J. Pediatr. Orthop. 1995: 15: 21-23.

19. Thometz JG, and Lamdan R.

Osteonecrosis of the femoral head after intramedullary nailing of a fracture of the femoral shaft in an adolescent. A case report.

J. Bone Joint Surg. Am. 1995: 77 : 1423-1426.

20. Boxma H, Broekhuizen T. Patka P, and Oosting H. Randomised controlled trial of single-dose antibiotic prophylaxis in surgical treatment of closed fractures: the Dutch Trauma Trial. Lancet. 1996: 347: 1133-1137. 


\section{Lengthening and derotational osteotomy}

R. van Doorn, R. Leemans, J.W.J.L. Stapert

European Journal of Surgery 1999: 165: I142-1146 


\section{Introduction}

Deformities of the upper leg can cause pain in the ankle, knee, hip, and spine, or at the site of deformation. ${ }^{12}$ Many patients complain about an abnormal walking pattern, altered body posture, or impaired function. ${ }^{3}$ The altered forces can induce cartilage deformities of the knee and hip joints that eventually result in osteoarthritis. ${ }^{4}$

Deformities are congenital, acquired during growth or they may develop after trauma, infection, or tumour resection. ${ }^{3}$ Subtrochanteric fractures can lead to shortening. anteflexion, and exorotation. ${ }^{5}$ Rotation is difficult to assess with image intensification, which can lead to malfixtion. Failure in the locking procedure can result in a rotational error during recovery. ${ }^{*}$

Differences in leg-length can be treated with adjustment of the shoe, operative shortening of the healthy leg. or lengthening of the affected leg. ${ }^{2.7}$ Rotation errors can be solved only by operation. Lengthening is achieved by callus distraction techniques or one-stage procedures. Different callus distraction techniques are used to lengthen more than $5 \mathrm{~cm}$. Ilizarov did perform a minimally invasive asteotamy and fixed the fragments with a ring fixator throughout the healing time. ${ }^{8}$ Wagner developed a two-stage procedure. He distracted the bone with a monotube fixator and used secondary plating and bone grafting.' Betz et al. developed a complete intramedullary system. which can be lengthened from outside the body. ${ }^{9}$ One-stage procedures have been done since the beginning of this century. ${ }^{710.14}$ In one session the definitive correction is made and stabilised with plates or an intramedullary device. These procedures are demanding for soft tissues and implants. Most authors state that you should not exceed $4 \mathrm{~cm}$ lengthening in one session.

Osteotomies can be done at the site of the fracture to correct the original anatomy. A correction at a distance from the malunion can create a good functional relation between knee and femoral head. Metaphyseal bone heals better than diaphyseal bone, and a larger contact area between the fragments can be created. ${ }^{15}$ On the other hand, the metaphysis is closer to the hip joint, which creates great lever arm forces. A strong implant is necessary to prevent implant failures and allow full weight-bearing. Z-shaped osteotomies with long bony contact give good consolidation and are suitable for one-stage lengthening. Twisting a transverse osteotomy creates rotation and allows full weight-bearing. ${ }^{10.14}$

We describe our experience with a combined lengthening and derotational Z osteotomy in a one-stage procedure, using a Gamma nail for stabilisation.

\section{Patients and methods}

A Gamma nail was used to correct length and rotation of five upper legs in five patients. All were men with a mean age of 36 years (range 29 - 48). The mean time that elapsed between trauma and correction was 39 months (range $10-85$ ). 
All had had multiple injuries with different femoral fractures. Two patients had had previous corrective osteotomies. With all patients the risk of a one-stage procedure was discussed. They all agreed to be operated on. History and radiographs were reviewed and patients interviewed. Preoperative planning was undertaken with clinical examination in combination with measurements from radiographs or computed tomograms (CT).

Patients were operated on under general anaesthesia and placed on a traction table. An image intensification system was used. Prophylactic antibiotics were given for $\mathbf{2 4}$ hours. The medullary canal was reamed to allow introduction of a Gamma nail. The guide wire was left in place during the osteotomy. The femur was reached by a lateral approach, and a Z-osteotomy of the length that was to be corrected was made with an oscillating saw \{figure 9.1\}. After inserting the Gamma nail and lag-screw, distraction was applied using a traction table or a distracter. The distraction device was anchored with one Steinmann pin opposite the lesser trochanter and one in the distal femur. When the actual length had been achieved the rotation error was corrected. The distal locking-bolts were inserted

Figure 9.1.

Stepwise diagram of the lengthening and derotational osteotomy.

a) Making a Z-osteotomy of the planned lengthening

b) Pulling the femur apart till the planned lengthening is achieved.

c) Rotating the two parts the desired angle. using the free hand technique.

Cancellous bone was obtained from the iliac crest and placed around the osteotomy. Postoperative exercises were done as soon as possible under supervision of a physiotherapist. Control radiographs were taken every 6-8 weeks until consolidation had been achieved. We planned to remove the hardware after full consolidation.

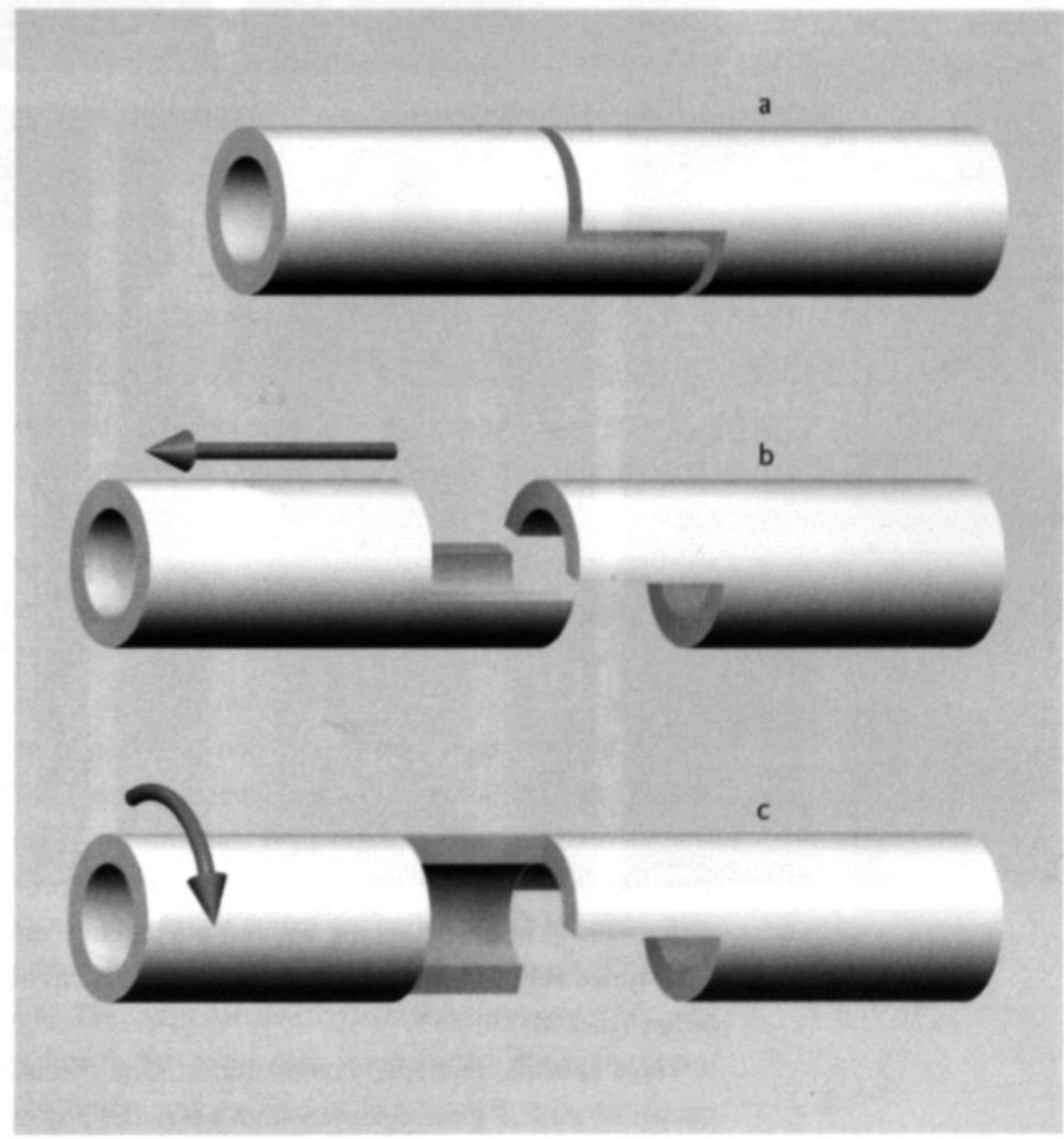




\section{Results}

The results of the individual patients are given in table 9.1. Mean planned lengthening was $3 \mathrm{~cm}$ (range $2-4 \mathrm{~cm}$ ), mean lengthening obtained was $2.5 \mathrm{~cm}$ ( 1.5 - $3.5 \mathrm{~cm}$ ). Mean planned and obtained derotation was 300 (range 20 - 450). In two patients a distracter was used to reach $4 \mathrm{~cm}$ lengthening (cases I and 4).

Gamma nails with a diameter of $12 \mathrm{~mm}$ and an angle of 1350 were used.

\begin{tabular}{|c|c|c|c|c|c|c|}
\hline & Case No. 1 & Case No. 2 & Case No. 3 & Case No. 4 & Case No. 5 & Mean \\
\hline Age (years) & 29 & 48 & 30 & 45 & 29 & 36 \\
\hline $\begin{array}{l}\text { Initial } \\
\text { fracture }\end{array}$ & Transcondylar & $\begin{array}{l}\text { Per/Sub- } \\
\text { trochanteric }\end{array}$ & Transcondylar & femoral neck & $\begin{array}{l}\text { Two stage } \\
\text { femoral }\end{array}$ & \\
\hline $\begin{array}{l}\text { Primary } \\
\text { treatment }\end{array}$ & $\begin{array}{l}\text { External } \\
\text { fixator }\end{array}$ & $\begin{array}{l}\text { Camma } \\
\text { nail }\end{array}$ & Condylarplate & $\begin{array}{l}\text { Screw } \\
\text { fixation }\end{array}$ & Conservative & \\
\hline $\begin{array}{l}\text { Previous } \\
\text { correction }\end{array}$ & & & & $\begin{array}{l}\text { Pauwel's } \\
\text { osteotomy }\end{array}$ & $\begin{array}{l}\text { Callus distraction } \\
\text { with monotube }\end{array}$ & \\
\hline $\begin{array}{l}\text { Planned } \\
\text { lenghtening }\end{array}$ & $4 \mathrm{~cm}$ & $2.5 \mathrm{~cm}$ & $2 \mathrm{~cm}$ & $4 \mathrm{~cm}$ & $2 \mathrm{~cm}$ & $3 \mathrm{~cm}$ \\
\hline $\begin{array}{l}\text { Planned } \\
\text { rotation }\end{array}$ & $30^{\circ}$ & $45^{\circ}$ & $20^{\circ}$ & $30^{\circ}$ & $25^{\circ}$ & $30^{\circ}$ \\
\hline $\begin{array}{l}\text { Time from } \\
\text { injury to } \\
\text { correction } \\
\text { (months) }\end{array}$ & 85 & 10 & 17 & 25 & 58 & 39 \\
\hline $\begin{array}{l}\text { Time to } \\
\text { consolidation } \\
\text { (months) }\end{array}$ & 6 & $11^{\circ}$ & 3 & $16^{* *}$ & 4 & 8 \\
\hline $\begin{array}{l}\text { Follow up } \\
\text { (months) }\end{array}$ & 69 & 64 & 52 & so & 42 & ss \\
\hline
\end{tabular}

\section{Table 9.1.}

Details of all patients who underwent femoral lengthening and derotational osteotomy stabilised with a Gamma nail. - including three months after cancellous bone graft and dynamisation:

** including four months after dynamisation.
Two were $22 \mathrm{~cm}$, and three were $32 \mathrm{~cm}$ long. One lag screw was $90 \mathrm{~mm}$, two were $100 \mathrm{~mm}$. and two were $110 \mathrm{~mm}$ long. All were locked distally with two locking bolts.

Mean follow-up was 43 months (range $30-57$ ). Mean time to consolidation was 8 months (range 3 - 16). Three patients had the Gamma nail removed 24. 25. and 40 months after correction.

Before operation all patients had limited endorotation and all were limping without a shoe-inlay. Cases 1 and 5 had back pain, case 2 pain in the leg when walking. and case 4 had gluteal and iliopsoas atrophy.

After operation all complaints of limited rotation and pain resolved. All patients were fully mobilised within two months, and only one (case 2) used a crutch when walking outside. Limping without a shoe-inlay disappeared initially in all. but recurred after dynamisation in two. One patient was not satisfied with the procedure (case 4).

Three patients developed complications. One medullary canal could not be reamed because of gross deformity from a previous post-traumatic lengthening by 

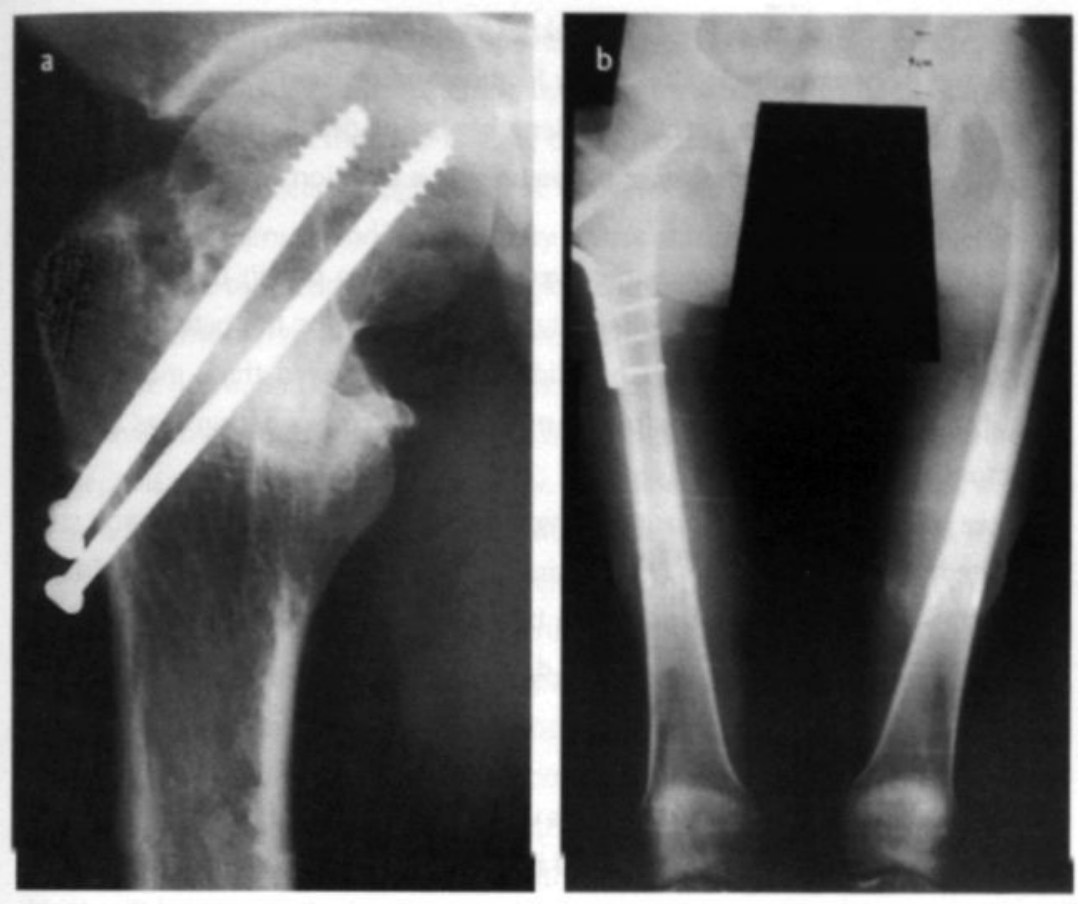

Figure 9.2.

Example of the osteotomy in case 4. who had a fracture of the neck of the femur, which was stabilised with three screus (a). A Pauwels osteotomy was done, which resulted in a shortened leg with internal rotation (b) Lengthening of 4 $\mathrm{cm}$ and rotation of $30^{\circ}$, stabili. sed with a long Gamma nail (c). After 12 months delayed union required dynamisation. and consolidation was achie. ved 4 months later (d).

After 24 months the long Camma nail was removed (e).
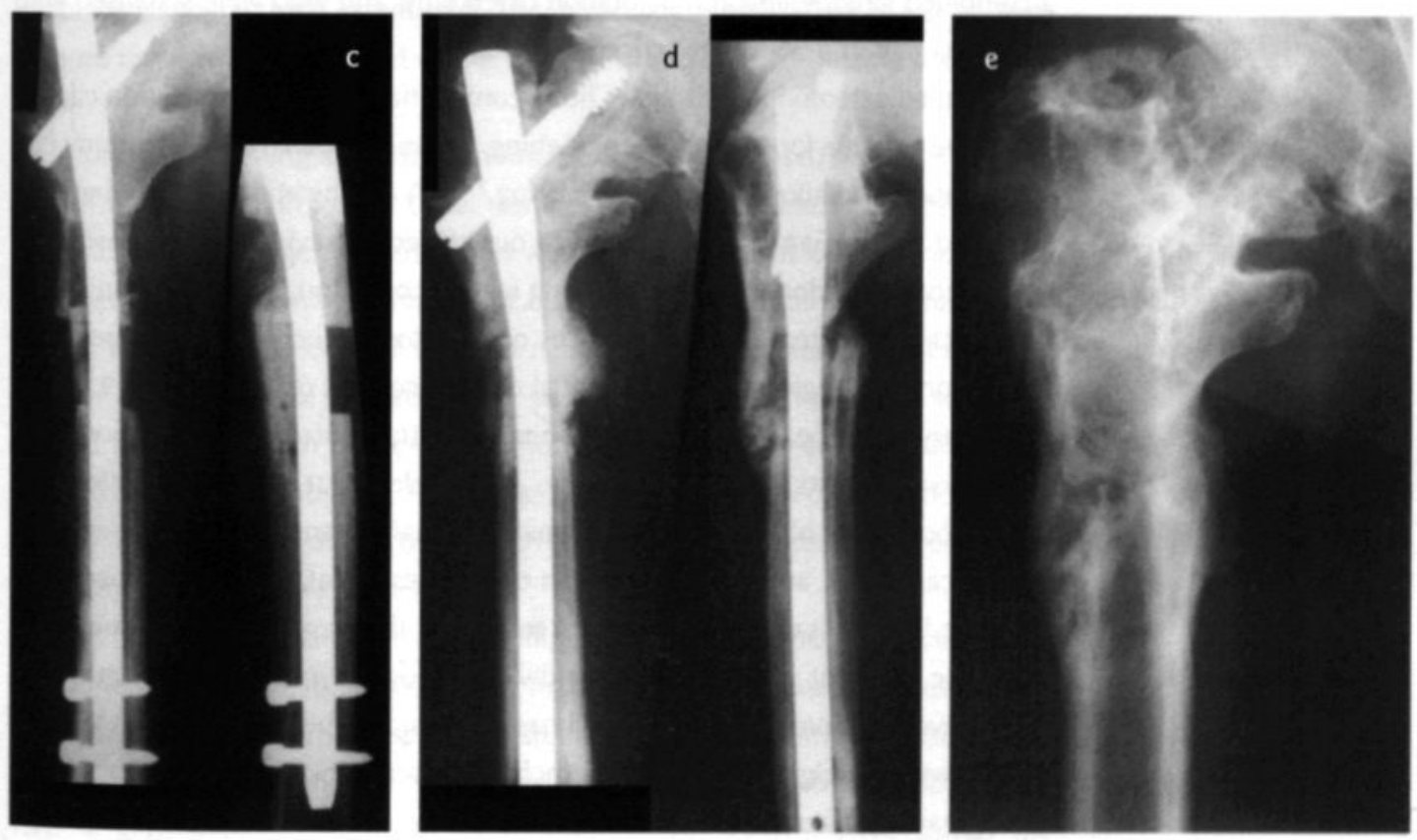

callus-distraction. In this case the ventral cortex perforated above the deformity. The planned $32 \mathrm{~cm}$ Gamma nail was too long so a 22 one was inserted without stabilising the perforation. The postoperative course was uneventful. In one patient a laceration of the third branch of the deep femoral artery during the osteotomy was overlooked. The lesion was repaired in the immediate postoperative 
period. One patient complained of weakness as a result of partial atrophy of the gluteal and iliopsoas muscle after screw fixation and revision Pauwel's osteotomy for a fracture of the femoral neck. After lengthening he developed a neuropraxia of the peroneal nerve. Full recovery of his preoperative function was regained in eight months.

In two cases additional measures were necessary to obtain union. In case 2 cancellous bone was not grafted initially, but after months the osteotomy required grafting and dynamisation. Consolidation was achieved three months later. Case 4 required dynamisation after 12 months, and consolidation was achieved four months later.

Three patients lost some planned lengthening. In one patient soft tissue stress prohibited rotation after $4 \mathrm{~cm}$ lengthening. The osteotomy was shortened half a centimetre, which he did not notice. In two patients I and $1.5 \mathrm{~cm}$ loss of length was noticed after the above mentioned dynamisations. Each needed a shoe-inlay.

\section{Discussion}

Most authors have described patients with different kind of deformities and different kinds of corrections. We reviewed five post-traumatic patients who had had a combined lengthening and derotation osteotomy, and who were stabilised with a Gamma nail in a one-stage procedure.

Z-shaped osteotomies with long bony contact have good consolidation capacity and are suitable for one-stage lengthening. Twisting a transverse osteotomy creates rotation and allows full weight-bearing. ${ }^{21.12} \mathrm{~A}$ combination of both methods stabilised with a Gamma nail has not to our knoledge previously been described. A Z-osteotomy is done of the length that require correction. After lengthening the two parts are twisted to let the cortices come into as much contact as possible. Derotation of 450 gives a circumferential cortical contact of $25 \%$ \{figure 9.1\}.

Primary bone healing of laminar bone is by trabecular bone formation. The metaphysis consists of trabecular bone, so it is clear that it will heal faster than cortical bone. The blood supply is optimal from many branched arteries, deep ingrowing capillaries, and minimal tension on the vessels as a result of loose bone structure. ${ }^{15}$ The disadvantage of an osteotomy in the proximal femoral metaphysis is the adjacent hip joint. The hardware for osteosynthesis must withstand strong lever arm forces. A Gamma nail has good grip in the femoral neck and head and allows full weight-bearing in subtrochanteric and proximal femoral fractures." A long nail is preferred because the forces are better transmitted to the distal locks with less stress distal to the nail." In some cases, however, such as when old osteosynthesis material or gross deformity in the distal femoral shaft are present a standard Gamma nail is an alternative.

All patients could walk with full weight bearing eight weeks postoperatively. and only one patient used a crutch when he walked outside. 
One patient complained of impaired iliopsoas and gluteal function after previous operations. After lengthening by $4 \mathrm{~cm}$ he developed a temporary peroneal neuropraxia. Since the early days of operative lengthening the importance of the soft tissues has been recognised. The force needed for distraction depends on the desired lengthening and the elasticity of the soft tissue envelope. Nerves are most vulnerable to traction. Herron et al. free the entire length of the femoral nerve and palpate the nerve during distraction." This extensive dissection can easily damage the nerve. particullary when there is a lot of scar tissue. No definitive opinion is available abouts the maximal possible lengthening that can be obtained. It will depend on the body-build, aetiology, and time after malunion. Most authors advise a maximum of $4 \mathrm{~cm}$. Johnson, and Murray et al. described $5 \mathrm{~cm}$ lengthening without problems. ${ }^{13.4}$ Peroperative electromyograpy can possibly give objective criteria about when to stop lengthening. ${ }^{18}$ After lengthening, rotation causes even more stress to the tissues. In one patient the force needed for rotation was so great that the osteotomy had to be shortened half a centimetre. An advantage of one-stage procedures is that after recovery no more stress iput o the tissues. Historically the patients are mobilised with care to improve wound healing. Kempf et al. gave patients two days bedrest with flexed hip and knees, after which the joints were progressively extended. ${ }^{12}$ The immediate mobilisation of our patients gave no problems. Assessment of the value of bedrest has to be an issue of interest.

In one case reaming a grossly abnormal distal femur caused a ventral perforation of the cortex, and further distal reaming was not possible. A $22 \mathrm{~cm}$ Gamma nail that did not bridge the perforation was inserted without clinical consequences. Preoperative planning is important but cannot prevent all per-operative problems. The availability of a full range of nail-lengths guarantees optimal stabilisation for a wide range of indications. A second technical complication was bleeding of the third branch of the deep femoral artery, which is anteromedial to the femoral head and acetabulum. A lesion at this site is a known complication in hip surgery. Abundant use of soft tissue protectors, careful dissection, and use of the oscillation saw with care are necessary.

Late complications are non-union, implant failure, infection, refracture, and loss of length. ${ }^{19}$ We had no infections, implant failures, or late fractures. In two patients consolidation took more than six months. In one patient consolidation was reached four months after dynamisation. In a second patient, who did not have a graft initially, cancellous bone grafting and dynamisation solved the problem in three months. The two patients lost $1 \mathrm{~cm}$ and $1.5 \mathrm{~cm}$ length respectively, after dynamisation. Different lengthening techniques show different percentages of union problems. Eldridge described $10 \%$ of non-union and $12 \%$ of refracture after implant removal in the Wagner method. and $1 \%$ of non-union and $3 \%$ of late refracture with llizarov-like methods. ${ }^{19}$ For one-stage femoral procedures 
Cauchoix and Morel described II non-union in 72 (young) adults, three of them ended with shortening, and eight other patients had refractures. ${ }^{10} \mathrm{Kempf}$ et al. had union problems in two of 24 femoral procedures. Johnson in six of 19. and Murray et al. in four of 17 femoral procedures. ${ }^{12 \cdot 14}$ Loss of length was not related to delayed union. Second procedures with bone-grafting. reaming. and renewed fixation were necessary to achieve consolidation. A cancellous bone graft will improve bone healing in large bone defects. Kempf et al. stated that a cancellous bone graft needs dynamisation to prevent resorption, but length can be lost when it is done too early. ${ }^{12}$ In contrast to our technique, most lengthening methods do not give bony contact between the two bone elements in the weight-bearing axis of the femur. We thought that our technique would prevent shortening after dynamisation, but two patients had shortening of $1 \mathrm{~cm}$ and $1.5 \mathrm{~cm}$, respectively. Before dynamisation actual shortening was not visible on plain radiographs. If it is necessary to achieve consolidation, shortening makes correct planning difficult. It is better to prevent delayed union and dynamisation by using a primary bone graft in every case of one-stage correction.

\section{Conclusion}

Corrective osteotomies have a high complication rate. The Gamma nail technique is not the ultimate solution but a suitable choice for one-stage lengthening and rotation osteotomies. A full rage of lengths of Gamma nail are available, which allow grossly deformed distal femurs to be corrected as well. Cancellous bone graft and meticulous operation techniques are required to prevent complications. With this procedure patients can achieve full weight-bearing in a short time. When dynamisation is required for consolidation. loss of length can be a problem and needs to be solved. 
1. Wagner W. Surgical lengthening or shortening of femur and tibia. Technique and indications. Orthopăde. 1972: 1: 59-74.

2. Winquist RA. Hansen ST, and Clawson DK. Closed intramedullary nailing of femoral fractures. A report of five hundred and twenty cases.

J. Bone Joint Surg. Am. 1984: 66: 529-539.

3. Morscher E. Etiology and pathophysiology of leg length discrepancies. In:

Hungerford DS, editors. Progress in

Orthopaedic Surgery I. Springer Verslag.

Berlin, Heidelberg. New York, 1977. 9-19.

4. Tetsworth KD, and Paley D. Malalignment and degenerative arthropathy. Orthop.

Clin. North Am. 1994: 25: 367-377.

5. Papagiannopoulos G. Stewart HD. and Lunn PG. Treatment of subtrochanteric fractures of the femur: a study of intramedullary compression nailing.

Injury. 1989: 20: 106-110.

6. Braten M. Terjesen T, and Rossvoll I. Torsional deformity after intramedullary nailing of femoral shaft fractures.

Measurement of anteversion angles in 110 patients.

J. Bone Joint Surg. Br. 1993: 75: 799-803.

7. Moseley CF. Leg lengthening: the historical perspective.

Orthop. Clin. North Am. 1991: 22 : 555-561.

8. Ilizarov GA. Clinical application of the tension-stress effect for limb lengthening. Clin. Orthop. 1990: 250: 8-26.
9. Betz A. Baumgart R, and Schweiberer L. Erstes voll implantierbares intramedullares System zur Callusdistraktion. Marknagel mit programmierbarem Antrieb zur Beinverlangerung und Segmentverschiebung. Grundlagen und erste klinische Ergebnisse. Chirurg. 1990; 61: 605-609.

10. Cauchoix J, and Morel G.

One stage femoral lengthening. Clin. Orthop. 1978: 136: 66-73.

11. Herron LD, Amstutz HC, and Sakai DN. One stage femoral lengthening in the adult.

Clin. Orthop. 1978: 136: 74-82.

12. Kempf I. Grosse A, and Abalo C. Locked intramedullary nailing. Its application to femoral and tibial axial, rotational, lengthening, and shortening osteotomies. Clin. Orthop. 1986: 212: 165-173

13. Murray DW. Kambouroglou G, and Kenwright J. One-stage lengthening for femoral shortening with associated deformity.

J. Bone Joint Surg. Br. 1993: 75: 566-571.

14. Johnson EE. Acute lengthening of shortened lower extremities after malunion or non-union of a fracture.

J. Bone Joint Surg. Am. 1994: 76: 379-389.

15. Aronson J. and Shen X. Experimental healing of distraction osteogenesis comparing metaphyseal with diaphyseal sites. Clin. Orthop. 1994: 301: 25-30. 
16. Boriani S. Bettelli G. Zmerly H. Specchia L. Bungaro $\mathrm{P}$. Montanari $\mathrm{G}$ et al. Results of the multicentric Italian experience on the Gamma nail: a report on 648 cases.

(published erratum appears in

Orthopedics 1992: 15: 545).

Orthopedics. 1991: 14: 1307-1314.

17. Stapert JWJL. Geesing CLM, Jacobs PB, Wit RJ de, and Vierhout PAM.

First experience and complications with the long Gamma nail.

J. Trauma. 1993: 34: 394-400.
18. Kaljumăe U. Mãrtson A. Haviko T, and Hãnniken $\mathrm{O}$. The effect of lengthening of the femur on the extensors of the knee. An electromyographic study. J. Bone Joint Surg. Am. 1995: 77: 247-250.

19. Eldridge JC. and Bell MJ. Problems with substantional limb lengthening. Orthop. Clin. North Am. 1991: 22: 625-631. 


\section{Summary}


In this thesis the results of treatment with a long Gamma nail are described. The patients have a variety of serious problems in the proximal femur.

The patient should be the central point in the choice of treatment: it is important to allow immediate weight bearing. with as few as possible short-term and long-term complications. The study is retrospective and therefore has limitations, but it is valuable because the number and diversity of patients reflects daily practice. The long Gamma nail seems to meet the set goals. We appreciate the willingness of the Dutch (orthopaedic) trauma surgeons to supply us with all the data.

Chapter $\mathrm{I}$ is an introduction and sets the goals that have to be reached in the treatment of the various groups of patients.

In chapter 2 the anatomy of the thigh in relation to the long Gamma nail is described. The vascular supply to the femoral head is mainly through vessels in the capsule. Insertion of a nail in the piriform fossa, and a combined femoral shaft and neck fracture. can cause damage to these vessels and lead to necrosis of the femoral head. Branches of the deep femoral artery can be injured by reduction of a fracture, by osteotomy, and by misplaced Homan retractors. The sciatic nerve is in danger when the dissection is dorsal to the greater trochanter. Over-enthusiastic use of the traction table can cause neurapraxia. Preoperative judgement of the shape of the femur is essential. Extreme anterior bowing. varus and valgus deviations, and obliteration of the femoral canal make the use of an intramedullary device impossible. The action and attachment of muscles result in the typical dislocation patterns of fractures. It is necessary to understand these mechanisms (which can be documented in a classification system) to reduce the fracture correctly.

In chapters 3 and 4 the history of the treatment of femoral fracture are described and the development and technique of insertion of the long Gamma nail. Practical tricks can add to the surgeons' experience.

In chapter 5 we describe the use of the long Gamma nail in The Netherlands and report the opinions of the Dutch orthopaedic and trauma surgeons about the indication for and value of the long Gamma nail. Data were gathered from 93 (77\%) of the surgical trauma departments and SI (57\%) of the orthopaedic trauma departments. The long Gamma nail was used in $57 \%$ of the surgical and $30 \%$ of the orthopaedic trauma departments. Opinions about its usefulness differed significantly between users and non-users concerning combined fractures ( $90 \%$ compared with $48 \%$ ). high femoral shaft fractures ( $87 \%$ compared with $48 \%$ ). pathological fractures ( $93 \%$ compared with $77 \%$ ). corrective osteotomies ( $50 \%$ 
compared with 33\%), and problems with union (70\% compared with 35\%). Surgeons and orthopaedic surgeons differed only in their opinion about corrective osteotomies ( $47 \%$ compared with $6 \%$ ). Users saw more indications for and were more satisfied with the long Gamma nail. This opinion was not related to the specialisation or the kind of hospital.

In chapter 6 the results of the treatment of 329 patients with extensive proximal femoral fractures with the long Gamma nail are described. Nineteen patients died in hospital and six patients were lost to follow up. Of the remaining 304, 241 patients (79\%) became completely mobile. 59 (19\%) were partly mobile, and four remained bedridden. Two-hundred-and-sixty-four patients did not complain of pain. 38 had pain that could be treated with non-narcotic drugs, and two had treatment-resistant pain. Six patients had thromboembolic complications, but no fat embolism was reported. There were 23 patients with fractures distal to the nail. nine of whom were reoperated on. Four nails fractured, one of which was broken during routine nail extraction. Seven malalignments were corrected. The lag screw caused problems in 16 patients and the distal boits in 22. Four patients had deep infections, which necessitated the removal of three nails after consolidation. and the fourth with reaming of the femoral canal and application of gentamycine bands. In 221 of the 302 patients who survived more than four months radiographs were available to estimate the time to consolidation. The mean time was 5.4 months (range 3 ñ 28). In seven patients additional operations were required to achieve consolidation. The 162 patients over 70 years old whose fractures resulted from a low velocity accident had more fractures distal to the nail and a higher mortality than the 36 younger patients who had high velocity accidents ( $10 \%$ compared with $0.3 \%$ and $9 \%$ compared with $0.3 \%$, respectively).

In summary: eighteen (5\%) serious technical complications were observed. four ( $1 \%)$ deep infections, and seven patients (2\%) needed additional operations to achieve consolidation. Functional results were good, and $99 \%$ of the patients became completely or partially mobile, with treatable or no pain.

In chapter 7 the results of 101 patients with 110 impending or pathological fractures treated with a long Gamma nail are shown. Minimal follow-up was 1.5 years or to death. The mean survival was 12 months (range 0-82 months), depending on the nature of the primary cancer. Fourteen patients died in hospital, three had thromboembolic complications, and three had symptoms that could be attributable to fat embolism. One femur fractured distal to the nail, two nails fractured, one lag screw migrated, one distal bolt migrated, and two of the unlocked nails needed to be locked secondarily. One deep infection was treated with antibiotics. Of these patients $92 \%$ became completely or partially mobile and pain was acceptable or absent in $93 \%$. 
In chapter 8 the results of 53 patient who were primarily treated with a standard Gamma nail and had a complication that was treated with a long Gamma nail are described. The most common complication (in 45 patient) was a fracture distal to the standard Gamma nail. In four patients the implant had separated from the greater trochanter, three patients needed treatment for malalignment, and in one patient the standard nail fractured. One patient died in hospital, one was lost to follow-up, and the other 51 patients were followed up for a mean of 27 months (range I- 77 months). Two patients had thromboembolic complications, but no fat embolism occurred. One patient had a severe decubitus ulcer which resulted in a below knee amputation. Three distal femurs fractured during operation, they were treated conservatively. One distal femur fractured after an adequate fall. Once the distal bolts were placed beside the nail, one lag screw migrated out of the nail. One femoral head became necrotic. Two deep infections were treated with antibiotics and in another the nail was removed after consolidation. There were three malalignments. The mean time to consolidation was 4.6 months, once dynamisation was necessary to achieve consolidation. Forty patients $(76 \%)$ became completely mobile, ten (19\%) patients were partially mobile, and one remained bedridden. Forty-nine patients ( $96 \%$ ) had. no pain. and two had treatable pain.

In chapter 9 five patients in whom a derotation and lengthening osteotomy was necessary after previous treatment of a femoral fracture are shown. A mean lengthening of $3 \mathrm{~cm}$ and derotation of $30^{\circ}$ was obtained. The mean follow-up was 43 months (range 30 - 57). There were no infections or thromboembolic complications. One lesion of the third branch of the deep femoral artery required reoperation and one patient developed temporary peroneal neurapraxia. Two patients needed bone grafting and dynamisation to achieve consolidation. which resulted in shortening of $1 \mathrm{~cm}$ and $1.5 \mathrm{~cm}$, respectively. The rotation errors were all resolved. It seems to be important to add a bone graft at the initial operation. 
In summary, the long Gamma nail is used for the treatment of severe problems in the proximal femur. The in-hospital mortality depends on the composition of the population of patients, and was between $0 \%$ and $14 \%$. Thromboembolic complications occurred in fewer than $3 \%$. Three patients with pathological fractures, eventually, had fat-embolism. In $5 \%$ of the patients serious technical complications occurred, which were mainly the result of errors in the operative technique. Deep infections developed in $1 \%$ of the patients operated on primarily, and in $6 \%$ of those who had secondary interventions. In $2 \%$ of the patients additional interventions were necessary to achieve consolidation. The osteosynthesis allowed immediate weight bearing in $70 \%$, but this depended on the opinion of the surgeon. In some hospitals fewer than $50 \%$ of the patients with long Gamma nails were allowed to be weight bearing, in others more than $90 \%$. The functional results were good. More than $90 \%$ of the patients became mobile with acceptable or no complaints of pain. 
Samenvatting en conclusies 
In dit proefschrift worden de resultaten beschreven van het gebruik van de lange Gamma nagel. Deze pen is geschikt voor de osteosynthese van ernstige letsels in het proximale femur.

De patient dient centraal te staan bij de keuze van onze behandel methoden. Van belang voor de patiënt is een behandeling die directe belastbaarheid mogelijk maakt en weinig complicaties veroorzaakt op korte en lange termijn. Uit onze retrospectieve gegevens, welke aan de basis liggen van dit proefschift. blijkt dat de lange Gamma nagel hieraan voldoet. Deze studie is beschrijvend en retrospectief. Dit heeft beperkingen. Deze studie is waardevol omdat hij. mede door het grote aantal patiēnten en hoeveelheid gegevens die we hebben verzameld, aangeeft wat er in de praktijk van alle dag gebeurt. We waarderen in het bijzonder dat de deelnemende chirurgen en orthopeden zonder schroom hun gegevens beschikbaar hebben gesteld.

Hoofdstuk I vormt de inleiding van het proefschrift en stelt de doelen vast die aan de behandeling van de verschillende patiëntengroepen worden gesteld.

In hoofdstuk 2 wordt de anatomie van het bovenbeen beschreven. En aantal anatomische zaken die speciaal van belang zijn voor de lange Gamma nagel, wordt hieronder kort weergegeven. De vascularisatie van de femurkop vindt voornamelijk plaats door vaten in het kapsel. Bij een mediale collumfractuur in combinatie met een schachtfractuur moet met kopnecose rekening worden gehouden. Een aantal takken van de arteria femoralis profunda kan worden gelaedeerd bij onoordeelkundige open repositie, osteotomieen en mis geplaatste Homann retractors. De nervus ischiadicus loopt gevaar bij dissectie achter het trochanter major gebied. Overrekkingsletsels kunnen optreden door te ruw aanspannen op de tractie tafel. De vorm van het femur dient te worden beoordeeld op congenitale afwijkingen: extreme antecurvatie: varus / valgus deviaties; en obliteratie van het femurkanaal door een osteoblastische metastase. Deze misvormingen kunnen de toepassing van een intramedullaire pen onmogelijk maken. De spieren met hun aanhechting veroorzaken typische dislocatie patronen. Inzicht is uitermate belangrijk om een adequate gesloten repositie te kunnen bewerkstelligen. Het zou bijzonder nuttig zijn indien een fractuurklassificatie richting zou geven aan de repositiemethode.

Hoofdstuk 3 en 4 gaan in op de geschiedenis van de fractuurbehandeling en de lange Gamma nagel. De insertietechniek wordt beschreven met een aantal practische tips en truuks. De chirurg of orthopeed kan hier wellicht profijt van hebben.

Hoofdstuk 5 geeft het inzicht in het gebruik in de Nederlandse klinieken. Tevens wordt de opinie van de leden van de trauma verenigingen in Nederland over het indicatie gebied van de lange Gamma vermeld. Gegevens werden verkre- 
gen over 93 (77\%) van de chirurgische maatschappen en 51 (57\%) van de orthopedische maatschappen die actief zijn binnen de ongevalschirurgie. De lange Gamma nagel werd in $57 \%$ van de chirurgische en $30 \%$ van de orthopedische maatschappen gebruikt. De mening over de bruikbaarheid van de lange Gamma nagel verschilt significant tussen gebruikers en niet-gebruikers betreffende meeretage fracturen ( $90 \%$ versus $48 \%$ ), hoge femurschacht fracturen ( $87 \%$ versus $48 \%$ ). pathologische fracturen ( $93 \%$ versus $77 \%$ ), correctie osteotomiein ( $50 \%$ versus $33 \%$ ) en delayed unions (70\% versus 35\%). Chirurgen en orthopedisch chirurgen verschillen alleen van mening over het gebruik van het implantaat bij correctie osteotomieên ( $47 \%$ versus $6 \%$ ). Gebruikers zien meer indicaties voor het gebruik van de lange Gamma nagel dan niet-gebruikers. De opinie is niet gerelateerd aan het beoefende specialisme of het soort ziekenhuis waarin men werkt.

Hoofdstuk 6 beschrijft de behandel resultaten van 329 patiēnten met een uitgebreide proximale femurfractuur. Negentien patiênten overleden in het ziekenhuis, zes patiênten waren niet meer traceerbaar voor follow-up. 241 (80\%) patiēnten werden volledig mobiel. 59 (19\%) gedeeltelijk mobiel en vier bleven bedlegerig. 264 patiënten hadden geen pijnklachten, 38 hadden pijn die goed behandelbaar was met niet-narcotische pijnstillers, en twee hadden therapie resistente pijn. Zes patiënten vertoonden trombo-embolische complicaties, er werden geen vetemboliel̂n gezien. Er traden 23 distale fracturen op waarbij negen maal heroperatie volgde. Vier pennen braken, een van deze pennen bleek gebroken bij een routinematige pen extractie. Zeven standsafwijkingen werden gecorrigeerd. De lag screw gaf bij 16 patiënten problemen, de distale grendels bij 22 patiënten. Bij vier patiënten trad een diep infect op: bij drie werd de pen na consolidatie verwijderd. eenmaal werd de pen gewisseld met opboren van het femurkanaal en gentakralen. Bij 221 van de 302 patiënten die langer dan vier maanden overleefden waren voldoende foto's voorhanden om de consolidtie te meten. De gemiddelde tijd tot consolidatie was 5.4 maanden (spreiding 3-28). Bij zeven patiënten waren additionele operaties nodig om consolidatie te bewerkstelligen. Opvallend is dat bij de 162 patiënten ouder dan 70 jaar met een laag energetisch trauma relatief meer fracturen distaal van de pen worden gezien dan bij de 36 jongeren met een hoog energetisch letsel ( $10 \%$ versus $0.3 \%$ ). Tevens was de mortaliteit hoger ( $9 \%$ versus $0.3 \%)$. Samenvattend waren er $18(5 \%)$ ernstige technische complicaties, vier (1\%) diepe infecties en zeven (2\%) extra maatregelen nodig om tot consolidatie te komen. Functionele resultaten zijn goed: $99 \%$ werd geheel of gedeeltelijk mobiel, met weinig tot geen pijnklachten.

Hoofdstuk 7 toont de resultaten van 10 I patiënten met 110 dreigende of pathologische femurfracturen die met een lange Gamma nagel werden behandeld. De minimale follow-up was 1.5 jaar of tot overlijden. De gemiddelde overlevingduur 
bedroeg 12 maanden (range 0 - 82), deze was afhankelijk van de aard van de primaire tumor. 14 patiënten overleden in het ziekenhuis, drie trombo-embolische complicaties werden gezien, drie patiënten maakten mogelijk vetemboliel̂n door. Eenmaal trad peropertief een fractuur op distaal van de pen, twee pennen braken, eenmaal migreerde de collum schoef, eenmaal migreerde een distale grendel en twee van de 18 niet vergrendelde pennen moesten alsnog worden vergrendeld. Een diep infect werd antibiotisch behandeld. $92 \%$ van de patiennten werden weer geheel of gedeeltelijk mobiel. Pijn was afwezig of acceptabel in $93 \%$.

Hoofdstuk 8 beschrijft de resultaten van een studie over 53 patiënten die primair met een standaard Gamma nagel zijn behandeld en waarbij een opgetreden complicatie secundair is opgelost met een lange Gamma nagel. De complicatie betrof 45 maal een fractuur distaal van de standaard Gamma nagel, vier maal een implantaat dat was uitgebroken uit het trochantermassief. drie maal een malunion en eenmaal een gebroken standaard Gamma nagel. Van de 53 patiënten werden er 51 gecontroleerd met een gemiddelde follow-up van 27 ( 1 - 77) maanden. Eén patiënt overleed in het ziekenhuis, een ander verdween uit controle. Er waren twee trombo-embolische complicaties, geen aanwijzigingen voor vetembolieën. Bij één patiënt leidde een ernstige decubitus van de hiel tot een onderbeensamputatie. Drie peroperatieve fracturen distaal van de lange Gamma nagel werden conservatief behandeld. $\mathrm{Na}$ een adequate val fractureerde één femur distaal van de pen. Eenmaal werden de distale grendels naast de pen geplaatst. Eén collumschoef migreerde uit de pen. Eenmaal werd een femurkopnecrose gezien. Twee diepe infecties werden met antibiotica behandeld, bij één low grade infect werd de pen na consolidatie verwijderd. Drie standsafwijkingen werden gezien. De gemiddelde consolidatieduur was 4.6 maanden, eenmaal was dynamisatie van de pen nodig.

Veertig patiënten (76\%) werden volledig mobiel, 10 (19\%) gedeeltelijk mobiel en één bleef bedlegerig. Negenenveertig ( $96 \%)$ patiënten hadden geen pijn, bij twee was de pijn met pijnstillers goed verdraagbaar.

Hoofdstuk 9 beschrijft 5 patiènten waarbij een derotatie en verlengingsosteotomie noodzakelijk was na een eerder operatief behandelde femurfractuur. Een gemiddelde verlenging van $3 \mathrm{~cm}$ en een derotatie van $30^{\circ}$ was nodig. De follow up bedroeg 43 maanden (range 30 - 57). Er waren geen infecties of trombo-embolische complicaties. Eenmaal ontstond een letsel van een tak van de a. femoralis profunda hetgeen reoperatie noodzakelijk maakte. Eén patiēnt toonde een passagere peroneus neuropraxie. Bij twee patiēnten was dynamisatie en een spongiosa plastiek nodig om de fractuur te laten consolideren. Dit resulteerde in een verkorting van I en $1,5 \mathrm{~cm}$. De rotatie afwijkingen waren opgelost. Aanbevolen wordt om bij een verlengings en rotatie osteotomie primaire spongiosa aan te brengen. 
We kunnen samenvatten dat de lange Gamma nagel wordt ingezet bij de behandeling van ernstige problemen in het proximale femur, zoals uitgebreide fracturen, pathologische fracturen en revisiechirurgie. De ziekenhuis mortaliteit ligt tussen de $0 \%$ en $14 \%$, afhankelijk van de behandelde groep patiênten. Tromboembolische complicaties komen minder dan $3 \%$ voor. Vetembolieēn zijn mogelijk geconstateerd bij patiënten behandeld wegens een pathologische fractuur. Bij twee van deze drie patiênten is het overigens niet geheel zeker dat het vetembolieln betrof. De klinische relevatie wordt mogelijk overschat. Bij $5 \%$ van de patiënten treden er serieuze technische complicaties op. Deze zijn veelal gerelateerd aan een verkeerde operatie techniek. Opleiding en coaching zijn derhalve belangrijk. Diepe infecties treden bij $1 \%$ van primair geopereerden op. stijgend naar $6 \%$ bij secundaire interventies. Bij $2 \%$ van de patiënten zijn extra maatregelen nodig om tot consolidatie te komen. De functionele resultaten zijn erg goed, waarbij meer dan $90 \%$ van de patiënten mobiel wordt met geringe of afwezige pijnklachten. De osteosynthese is bij $70 \%$ van de patiënten direct volledig belastbaar. Dit blijkt met name af te hangen van de zienswijze van de operateur, er waren ziekenhuizen waar de osteosynthese in minder dan $50 \%$ als volledig belastbaar werd afgegeven, maar ook waar de lange Gamma nagel in meer dan $90 \%$ direct mocht worden belast. 


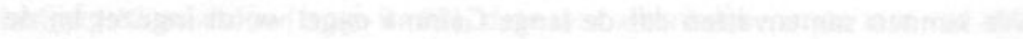

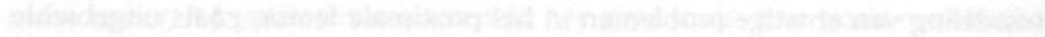

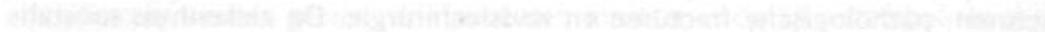

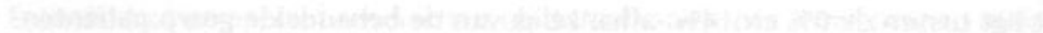

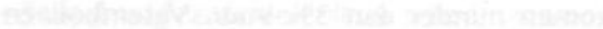

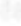


Enquiry form 
Enquiry use of the long Gamma nail

Name

Hospital

City

Speciality

orthopaedic surgeon / surgeon *

How long are you working in the field of trauma?

year

How many orthopaedic surgeons and / or surgeons treat femoral fractures in your hospital?

How many femoral fractures (femoral head to femoral condyl fractures)

do you treat annually?

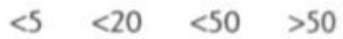

Do you use a fracture classification?

If yes which one?

For which indication can a long Gamma nail be used? *

stable pertrochanteric fracture

yes I no

unstable pertrochanteric fracture

yes / no

'normal' subtrochanteric fracture

yes / no

'reversed' subtrochanteric fracture

yes I no

ipsilateral femoral neck and shaft fracture

yes / no

high femoral shaft fracture

yes I no

mid-shaft fracture

yes / no

low femoral shaft fracture

yes / no

pathological femoral fracture

yes / no

osteotomy

yes / no

pseudo-arthrosis

yes / no

Are there better treatment modalities of trauma victims due to the introduction

of the long Gamma nail? *

yes / no

Remarks 
Next table is to see how often the long Gamma nail is used for the different indications stated in relation to other implants. If you use an other implant please remark it.

The first surgeon is a consultant Medial femoral neck fracture

(hemi)Arthroplasty

Screws / DHS

Conservative

Other

$\begin{array}{cccccc}\text { nr. per year } & \text { never } & 2 & 3 & 4 & \text { always } \\ & \square & \square & \square & \square & \square\end{array}$

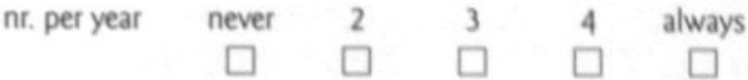

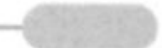

$\begin{array}{lllll}\square & \square & \square & \square & \square \\ \square & \square & \square & \square & \square \\ \square & \square & \square & \square & \square \\ \square & \square & \square & \square & \square\end{array}$

Lateral femoral neck fracture

\section{DHS}

Other

Pertrochanteric femoral fracture

DHS

DCS

Gamma nail

Other

Subtrochanteric fracture

\section{DHS \\ Angled blade plate \\ DCS \\ Gamma nail \\ Long Gamma nail \\ Other}

High femoral shaft fracture

Angled blade plate

DCS

Long Gamma nail

Intramedullary nail

Plate

External fixator

Other

Mid-shaft fracture

Intramedullary nail

Plate

External fixator

Other

Supracondylar femoral fracture

Plate

DCS

Intramedullary nail

Other

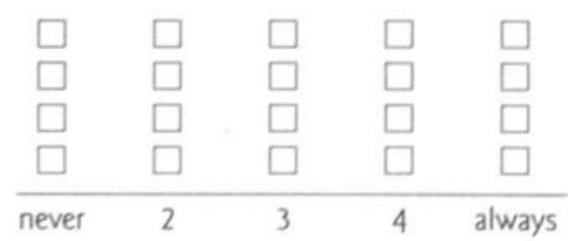


Dankwoord 
Een dankwoord. Waar moet je beginnen. Een ieder om je heen, in verleden en heden, draagt bij tot je vorming. Een van de resultanten van mijn vorming is dit proefschrift. Dan maar met het begin beginnen.

Lieve pa $\varepsilon \mathrm{ma}$, de basis van dit boekje ligt uiteraard bij jullie. Alle plezierige en iets minder plezierige momenten tijdens het opgroeien resulteerden in een medicijnenstudie, een opleiding tot chirurg en een wetenschappelijke verhandeling. Zie dat, naast de geboorte van de kleinkinderen, toch als een bekroning op jullie inspanningen. Bedankt voor het veilige nest.

Lieve Lena en Katja, wat hebben jullie altijd genoten van je broer.... Een boel scherpe kantjes hebben we van elkaar afgeslepen, dat is ware liefde. Bedankt voor jullie steun.

Lieve Christine, al 17 jaar een trouwe bakermat. Schaven gaat steeds moeilijker, maar het resultaat wordt steeds mooier. Woorden schieten tekort.

Lieve Tobias en Lukas, wonderbaar, ik hoop dat jullie net zo blij zijn met mij als ik met juilie. voor juilie leer IK mezeil'steeas deter kennen. bedankt voor juilie ifeicee.

Onderwijzers, leraren en docenten, vooral de taalkundigen onder u moeten het zwaar hebben gehad. Bedankt voor uw inspanningen.

Dr NF Bosma, misschien weet $u$ het niet, maar u bent mijn voorbeeld van een kundig chirurg in zowel technisch als menselijk opzicht. Bedankt voor de goede basis.

Prof. Dr G Kootstra en Dr JJ Jakimowicz u had het vertrouwen mij als chirurg te kunnen opleiden. Alle specialisten, assistenten, verpleegkundigen, dokters-assistenten, secretaressen en andere medewerkers hebben de opleiding tot een goede en plezierige gemaakt. Bedankt voor de vorming.

Professor Stapert, beste Jouwert, als je eersteling heeft het lang geduurd, maar met het behalen van een voldoende resultaat is de weg daar naar toe minder belangrijk geworden. Bedankt voor alle geduld en correcties.

Alle chirurgen en orthopeden die de enquête hebben ingevuld. Al degene die een bijdrage hebben geleverd aan de inclusie van patiënten: PAM Vierhout. ADP van Walsum: HJThM Haarman, P Patka, FC Bakker; AB van Vugt: AJH Kerver; BJ Dwars: PB Dunki Jacobs. JH Pot: C van der Werken. LS de Vries, ER Hammacher: PVM Pahlplatz: JM Ultee: JWJL Stapert. FAJM van den Wildenberg: JSK Luitse: G] Clevers: DJ Swank: R Leemans: VA de Ridder; HW Bolhuis: PCM de Jong: FG] Laudy: GJ Heijmans; $\mathrm{H}$ den Hollander: JA Charbon. ThJ van Straaten; AGA Spelde: KJ Oosterhuis: A Verburg. Bedankt voor uw inzet. 
Alle patiēnten die vrijwillig de resultaten van hun operaties wilden vertellen. Bedankt voor het vertrouwen.

Bart de Graaf en Marianne Berlot hebben vanuit de firma Howmedica contact gehouden en op weer eens een verzoek adequat gereageerd. Bedankt voor de soepele medewerking.

Ms. Evans corrected the English. Thank you for the effort.

De beoordelingscommissie onder leiding van Prof. Dr RGT Geesink, Prof. Dr PL Broos, Prof. Dr. AB van Vugt. Prof. Dr JMA van Engelshoven. Prof. Dr j Troost, u zette een latste stempel. Bedankt voor de beoordeling en de opbouwende kritiek.

Barend Schaart, samen met Mireille heb je alle belangrijke gebeurtenissen meegemaakt en het grafische werk verzorgd. Ook nu is het resultaat weer fantastisch. Bedankt voor jullie aanwezigheid.

Jacob de Baan, niet direct betrokken bij dit werk, maar altijd aanwezig. Bedankt voor je licht.

Stefan Brenninkmeijer. Pieter Gerritsen, Fred Jacobs, Bertus de Keizer en Steef Kranendonk: 'Het proefschrift is bijna af' beloofde ik bij de sollicitatie in december 1999. nu is het zover. Bedankt voor de samenwerking.

Een ieder in het TweeSteden. Bedankt voor de toekomst.

De paranimfen.

Jako Burgers, huisarts, de belangrijkste uitkomst van de eerste proef tijdens onze propodeuse was ons verschil van aard. Desondanks zijn we vrienden geworden en gebleven. Succes met je eigen boekje. Bedankt voor de vriendschap.

Rene van der Hulst, plastisch chirurg. wat heb ik veel van je geleerd. Je bent een klasse apart, ik hoop bij je inauguratie te worden uitgenodigd... Bedankt voor de samen doorgebrachte tijd.

Dankbaarheid kent geen tijd.

Ron. 


\section{CURRICULUM VITAE}

Ron van Doorn werd geboren op 12 mei 1962 te Losser. Twente.

De lagere school, de HAVO en het VWO werden doorlopen in Purmerend.

In 1988 ronde hij zijn artsenopleiding af aan de Vrije Universiteit.

Daarna werkte hij het eerste half jaar als operatie-assistent in Veenendaal, na een korte aanstelling als assistent Interne Geneeskunde in Sliedrecht startte hij de opleiding tot tropenarts in het Slotervaart Ziekenhuis te Amsterdam, chirurgie bij NF Bosma. gynaecologie E obstetrie bij A van Enk.

$\mathrm{Na}$ uitzending door Artsen zonder Grenzen naar Somalië werd hij assistent chirurgie in Maastricht en Veldhoven (Dr CMA Bruijninckx).

Zijn opleiding tot chirurg volgde hij in Maastricht onder leiding van Prof. Dr G Kootstra en in het Catharina Ziekenhuis te Eindhoven onder leiding van Dr IJ Jackimowicz. In het laatste jaar liep hij stage in het Level I Traumacentrum van het Johannesburg General Hospital onder leiding van Prof. KB Boffard, en bekwaamde hij zich in de arthroscopische chirurgie onder ausiciën van de Nederlandse Vereniging van Traumatologie (Prof. Dr PAM Vierhout. ThPH van Tiel en CR van den Hoogenband).

Sinds mei 2000 werkt hij samen met SJ Brenninkmeijer, GP Gerritsen, F Jacobs, Dr G de Keizer en Dr SE Kranendonk als chirurg met als aandachtsgebied de traumatologie en minimaal invasieve chirurgie in het TweeSteden ziekenhuis te Tilburg. 



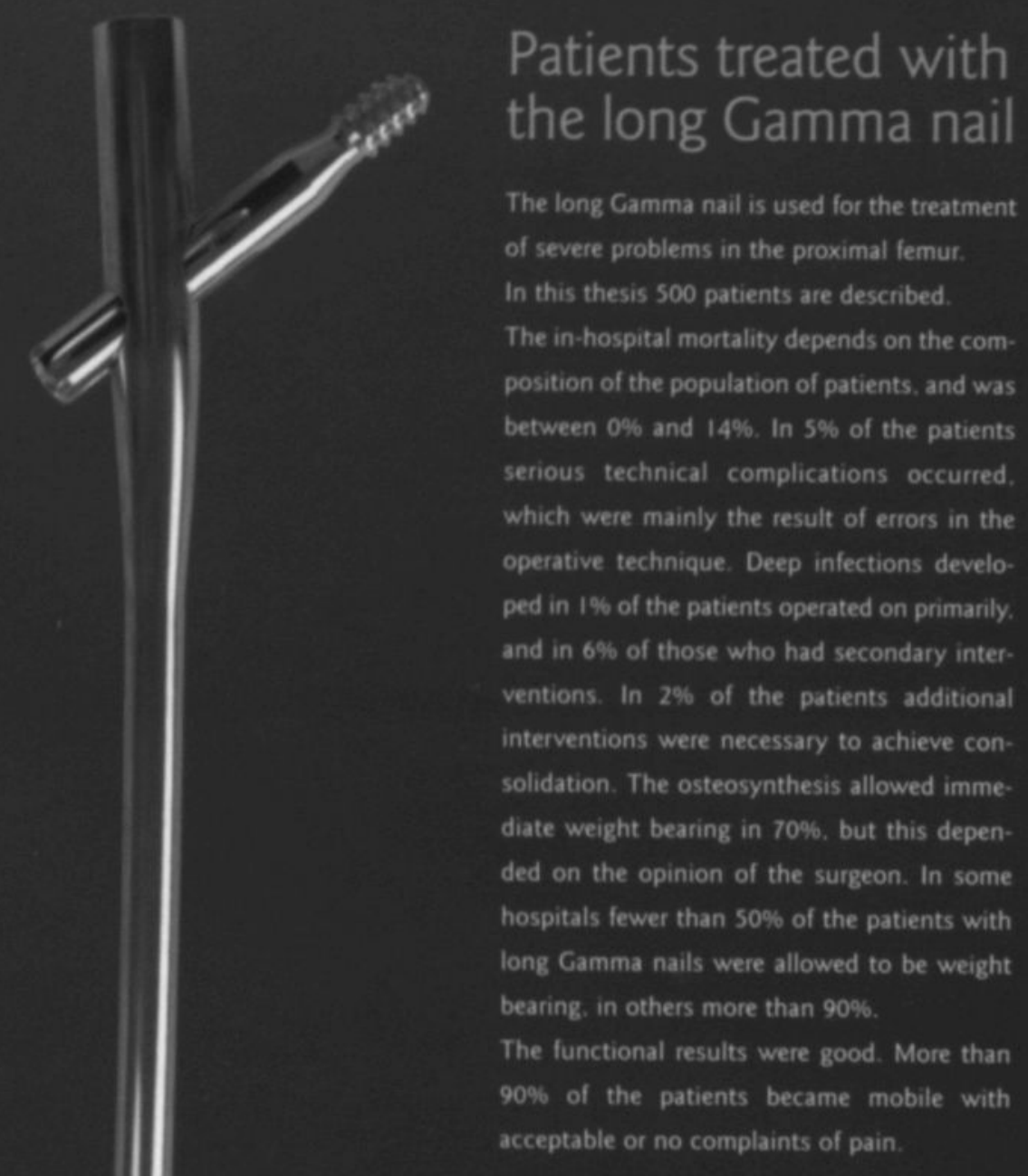

